\title{
RNA binding is essential for NONO condensates to modulate pre-mRNA processing of super enhancer-associated genes in neuroblastoma
}

Song Zhang ${ }^{1}$, Jack Cooper ${ }^{1}$, Yee Seng Chong ${ }^{2}$, Alina Naveed ${ }^{1}$, Chelsea Mayoh ${ }^{3,4,5}$, Nisitha Jayatilleke $^{3,4}$, Tao Liu ${ }^{3,4}$, Sebastian Amos ${ }^{1}$, Simon Kobelke ${ }^{1}$, Andrew C Marshall ${ }^{2}$, Oliver Meers ${ }^{1}$, Yu Suk Choi ${ }^{1}$, Charles S Bond ${ }^{2}$, Archa H Fox ${ }^{1,2, *}$

${ }^{1}$ School of Human Sciences, The University of Western Australia, Crawley, WA, 6009, Australia

${ }^{2}$ School of Molecular Sciences, The University of Western Australia, Crawley, WA, 6009, Australia

${ }^{3}$ Children's Cancer Institute Australia, Randwick, NSW, 2031, Australia.

${ }^{4}$ Centre for Childhood Cancer Research, UNSW Sydney, Kensington, NSW, 2052, Australia

${ }^{5}$ School of Women's and Children's Health, UNSW Sydney, Kensington, NSW, 2052, Australia

* To whom correspondence should be addressed. Tel: +61 86488 3297; Fax: +61 86488 1051; Email: archa.fox@uwa.edu.au

Keywords: DBHS, neuroblastoma, phase separation, RNA binding, super enhancer 


\begin{abstract}
High-risk neuroblastoma patients have poor survival rates and require better therapeutic options. High expression of a multifunctional DNA and RNA binding protein, NONO, in neuroblastoma is associated with poor patient outcome, however there is little understanding of the mechanism of NONO-dependent oncogenic gene regulatory activity in neuroblastoma. Here, we used cell imaging, biophysical and molecular analysis to reveal complex NONOdependent regulation of gene expression, finding that NONO forms RNA- and DNA-tethered phase-separated condensates throughout the nucleus. CLIP analyses show that NONO mainly binds to the 5' end of pre-mRNAs and modulates pre-mRNA processing, dependent on its RNA binding activity. NONO preferentially regulates super enhancer-associated genes, including HAND2 and GATA2. In the absence of functional NONO-RNA condensates, inefficient pre-mRNA processing at these loci leads to decreased expression of HAND2 and GATA2. Thus, future development of agents that target RNA binding activity of NONO may have therapeutic potential in this cancer context.
\end{abstract}




\section{Introduction}

Neuroblastoma is derived from neural crest cells in the sympathetic nervous system and is the most common extracranial solid cancer in children (Janoueix-Lerosey, Schleiermacher et al., 2010, Munzer, Menegaux et al., 2008). Whilst suitable treatments for low-risk patients exist, high-risk neuroblastoma patients have poor survival rates and a paucity of therapeutic options. High expression of the gene regulatory protein NONO (Non-POU Domain Containing Octamer Binding) in neuroblastoma is associated with poor patient survival, suggesting this could be a potential therapeutic target (Liu, Erriquez et al., 2014). However, beyond knowledge of NONO binding to one long non-coding RNA (lncRNA) in neuroblastoma, LncMycnUS, there is no further insight into NONO mechanistic activity in this cancer. NONO is a multifunctional protein with various roles in genome maintenance and gene regulation at the transcriptional and post-transcriptional levels, including transcription initiation, elongation and termination, pre-mRNA processing and splicing, and nuclear retention of RNA (Feng, Li et al., 2020, Hennig, Kong et al., 2015, Hentze, Castello et al., 2018, Knott, Bond et al., 2016). NONO is a member of the highly conserved Drosophila behaviour/human splicing (DBHS) protein family, which also includes the splicing factor proline/glutamine rich (SFPQ) and paraspeckle protein component 1 (PSPC1) proteins. DBHS proteins have two N-terminal RNA recognition motifs (RRM), a NonA/paraspeckle domain (NOPS), a coiled-coil at the C-terminus and $\mathrm{N}$ - and C-terminal intrinsically disordered regions (IDRs). DBHS proteins form obligate dimers that can bind DNA, RNA, undergo oligomerisation, mediate additional protein-protein interactions and also undergo liquid-liquid phase separation. Combined, these different interactions suggest DBHS proteins act as 'molecular scaffolds' to carry out their multipurpose activities in many facets of gene regulation.

Several studies have profiled the genome, and transcriptome wide DNA and RNA substrates bound by NONO in different biological contexts (Benegiamo, Mure et al., 2018, Ma, Karwacki-Neisius et al., 2016, Van Nostrand, Freese et al., 2020, Xiao, Chen et al., 2019). Broadly these studies have revealed widespread binding to diverse gene regulatory elements in chromatin as well as binding to mainly intronic elements of pre-mRNAs. In some instances this binding is linked to specific co-regulatory networks such as NONO binding to ERK promoter targets in stem cells (Ma et al., 2016), or binding to pre-mRNA of transcripts coding metabolic genes in liver hepatocytes (Benegiamo et al., 2018). Whilst NONO/ERK 
association at chromatin is required for mouse embryonic stem cell (mESC) pluripotency, there is little mechanistic insight explaining the consequences of NONO binding to RNA in different contexts. Other DBHS proteins have also been analysed by CLIP and ChIP (Hosokawa, Takeuchi et al., 2019, Iida, Hagiwara et al., 2020, Stagsted, O'Leary et al., 2021, Takeuchi, Iida et al., 2018); for instance, SFPQ binds to and enables processing of long introns in neurons, and prevents intron retention in ALS motor neurons (Luisier, Tyzack et al., 2018).

Given their extensive and diverse DNA and RNA targets, DBHS proteins are found throughout the nucleus as well as in specific sub-nuclear sites, such as paraspeckles - where they bind and play an essential role stabilising the lncRNA NEAT1_2 scaffold (Knott et al., 2016) - and to sites of DNA damage (Krietsch, Caron et al., 2012, Li, Li et al., 2014). Both paraspeckles and DNA damage foci are now classed as condensates built by the liquid-liquid phase separation properties of various component proteins (Fox, Nakagawa et al., 2018, Spegg \& Altmeyer, 2021). Liquid-liquid phase separation is an emerging phenomenon explaining the dynamic association of molecules, including RNA binding proteins, into membrane-less organelles, or condensates (Alberti \& Dormann, 2019, Sabari, Dall'Agnese et al., 2018, Zbinden, Pérez-Berlanga et al., 2020). Recently it was demonstrated that NONO undergoes phase separation at DNA damage foci (Fan, Wang et al., 2021), however how phase separation by NONO plays a role in gene regulation is unknown.

Super-enhancer (SE) regulated gene networks are defined by ChIP signatures and establish distinct cell lineage programs. Recently it was revealed that super enhancers are controlled by the formation of phase separated condensates composed of transcription factors and transcriptional cofactors (Boija, Klein et al., 2018, Guo, Manteiga et al., 2019). This regulation may be critical for neuroblastoma, as two main SE-associated transcriptional networks control lineage identity, intra-tumoral heterogeneity and cell-type specific gene expression, including a mesenchymal cell state and a noradrenergic cell state (Boeva, LouisBrennetot et al., 2017, van Groningen, Koster et al., 2017). The noradrenergic cells are further subdivided into three major SE-driven epigenetic subtypes and their underlying master regulatory networks recapitulating three clinical groups in neuroblastoma tumours and cell lines (Gartlgruber, Sharma et al., 2021). A small number of key transcription factors associated with SE were identified as members of the transcriptional core regulatory circuitry (CRC) that determine noradrenergic cell fate and growth, such as MYCN, PHOX2B, 
HAND2, GATA2 and GATA3 (Durbin, Zimmerman et al., 2018, Gartlgruber et al., 2021, van Groningen et al., 2017).

In this study, we take a holistic look at NONO in neuroblastoma to determine the mechanisms linking NONO to poor outcome in this context. We combine cell imaging, biophysical analysis, and various RNA-seq analyses to reveal a complex picture of NONOdependent regulation of gene expression. We find NONO in numerous small non-paraspeckle condensates throughout the nucleus, tethered to these by RNA and DNA. Accordingly, NONO mutants that cannot bind RNA mis-localise in larger spherical non-functional puncta that more readily phase separate, confirming the critical role of NONO RNA binding in its function. Using PAR-CLIP we show NONO binds to the 5' ends of pre-mRNA and influences pre-mRNA processing. Notably, NONO-bound transcripts are also more likely to be SE-regulated, including HAND2 and GATA2. We find that the decreased expression of HAND2 and GATA2 after NONO depletion is likely mediated by inefficient pre-mRNA processing at these loci. Thus overall, NONO requires the coordinated integration of multilevel components of mechanistic processes and signals to enact its oncogenic program.

\section{Results}

\section{NONO puncta are condensates dependent on RNA and DNA}

Given that high levels of NONO are correlated with poor patient outcome in neuroblastoma (Fig 1A and (Liu et al., 2014)), we set out to investigate the role of NONO in this biological context, to inform future rational design of therapeutics. At the cellular level, we have previously demonstrated that paraspeckles - as illustrated by Fluorescence In Situ Hybridisation (FISH) against NEAT1_2 - are co-localized with a subset of NONO immunofluorescence signal (Naveed, Cooper et al., 2021, Yamazaki, Souquere et al., 2018). When comparing the distribution of NONO puncta between high-risk neuroblastoma (KELLY and BE(2)-C) and HeLa cell lines, we observed fewer paraspeckles in neuroblastoma cells (Fig 1B), as shown previously (Naveed et al., 2021). Instead of within paraspeckles, NONO is localized in numerous small puncta throughout the nucleus, in both neuroblastoma cell lines.

To address the nature of the small non-paraspeckle NONO puncta, we incubated cells with 1,6-hexanediol (a compound that disrupts liquid-liquid phase separated condensates) and 
observed dramatically reduced NONO signal intensity in KELLY (Fig 1C-1D) and HeLa (Fig S1A-S1B) cells. Supporting a role for phase separation in the formation of NONO puncta, we also observed that recombinant full-length GFP tagged NONO could form droplets in vitro, regulated by varying concentrations of either NONO protein or $\mathrm{KCl}$ (Fig 1E). In addition, nuclease digestion using either RNase A or DNase I completely eradicated the nuclear NONO puncta signal in KELLY (Fig 1F-1G) and HeLa (Fig S1C-S1D) cells. Together, these in vitro and in vivo observations suggest that the numerous non-paraspeckle NONO puncta may be phase-separated condensates that are dependent on both RNA (distinct from NEAT1_2) and DNA for their structural integrity.

\section{RNA recognition motif 1 (RRM1) is essential for NONO to bind RNA targets}

Given the importance of RNA in NONO condensate formation, we next addressed NONO RNA binding ability for its localisation and function. The canonical RRM1 is structurally characterized in NONO, and is required for NONO binding RNA in vitro, however its role in RNA binding has not been fully evaluated in different biological settings (Fox, Bond et al., 2005, Knott et al., 2016, Knott, Chong et al., 2021, Kuwahara, Ikei et al., 2006, Passon, Lee et al., 2012). Thus, we compared the localisation of overexpressed YFP fused wild-type NONO (YFP-NONO_WT) with NONO lacking the RRM1 (YFP-NONO_ARRM1). We observed that, compared to YFP-NONO_WT, YFP-NONO_ARRM1 no longer co-localized with paraspeckles in KELLY (Fig 2A-2B) and HeLa (Fig S2A-S2E) cells suggesting the loss of RRM1 abrogated the ability to bind NEAT1_2. The YFP-NONO_ARRM1 puncta were also more spherical, fewer in number, and larger, compared to YFP-NONO_WT (Fig 2C-2E). Functionally, intact RRM1 in NONO was linked to KELLY cell proliferation, as measured by the percentage of BrdU positive cells increasing when exogenous YFP-NONO_WT was overexpressed, but not YFP-NONO_ARRM1 (Fig 2F). We also mutated some additional residues in the NONO NOPS domain that may mediate RNA association, as identified in RBDMap RNA crosslinking studies (Castello, Fischer et al., 2016). However, whilst these point mutants displayed a similar localisation to YFP-NONO_ARRM1, this is more likely the result of failure to dimerize than bind RNA, as, unlike YFP-NONO_WT, or YFPNONO_ $\triangle R R M 1$, the YFP-NONO point mutants no-longer co-immunoprecipitated endogenous SFPQ (Fig S2F).

In vitro, recombinant GFP-NONO__RRM1 could form droplets, with an increased propensity for droplet formation compared to GFP-NONO_WT (Fig 2G). Moreover, adding 
2'-O-methyl phosphorothioate antisense oligonucleotides (PS-ASO) against NEAT1 (a known RNA substrate for NONO (Vickers, Rahdar et al., 2019)) into GFP-NONO_WT solution caused NONO droplets to become small fibrils (Fig 2H, top). In contrast, adding PS-

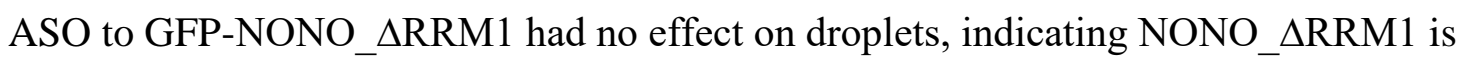
impervious to the addition of nucleic acid NONO substrate (Fig 2H, bottom). Taken together, these results suggest RNA binding through RRM1 modulates the propensity for NONO to phase separate, altering sub-nuclear distribution.

\section{NONO binds predominantly within introns}

We next assessed the transcriptome-wide binding of NONO in KELLY and BE(2)-C neuroblastoma cells. We performed PAR-CLIP and found, similar to other DBHS protein CLIP experiments, the majority of NONO binding occurs within introns, even when normalizing for the percentage of the transcriptome made up of introns (Fig 3A). NONO binding was biased towards the 5' end of transcripts (Fig 3B), a pattern also previously observed in CLIP against NONO and other DBHS family proteins in other biological settings (Benegiamo et al., 2018, Jiang, Shao et al., 2017, Takayama, Suzuki et al., 2017). To further define NONO targets, we summed aligned reads containing T-to-C transitions across genes (Hafner, Landthaler et al., 2010). Using TPM (transcripts-per-million (Wagner, Kin et al., 2012)) and normalizing for gene length, NONO targets (the top 20 percentile by TPM of all genes containing T-to-C read alignments, 1831 genes) were enriched in several ontologies, including 'mRNA binding' and 'post-transcriptional gene silencing' in KELLY and BE(2)-C cells (Fig 3C-3D).

Despite NEAT1 being less abundant in KELLY cells than other cell types, it was nevertheless the top NONO target RNA (Fig 3E), with by far the largest percentage of PARCLIP reads of any RNA, reflecting the high affinity of NONO for NEAT1 (Naveed et al., 2021). Amongst the rest of the top 10 transcripts, HAND2 and GATA2 were notable as they encode super-enhancer (SE) regulated transcription factors essential to mediate lineage control in neuroblastoma (Boeva et al., 2017, van Groningen et al., 2017). To determine if other SE-regulated genes were also highly bound by NONO, we analyzed publicly available H3K27 acetylation ChIP-seq data from Chipumuro et al. (Chipumuro, Marco et al., 2014) to identify the SE profile in KELLY cells, examining the overlap of NONO RNA binding for a subset of genes within SE regions from the H3K27ac ChIP-seq analysis. We found that transcripts from genes within SE regions had substantially greater NONO RNA binding when 
compared with expression-matched controls, suggesting a preferential RNA binding of NONO to SE-regulated target gene transcripts (Fig 3F).

To validate our PAR-CLIP findings, we conducted RNA immunoprecipitation (RIP) against NONO followed by RNA quantification of mRNAs and pre-mRNAs for MYCN, DAZAP1, GATA2 and HAND2, observing greater NONO binding to pre-mRNAs (Fig 4A). We then used siRNA to knock down endogenous NONO and rescued with siRNA-resistant YFPNONO_WT, or YFP-NONO_ARRM1 plasmids. When compared to controls, various target transcripts including total_NEAT1, DAZAP1, pre_HAND2 and pre_KCNQ2 were enriched with exogenous YFP-NONO_WT, but not with YFP-NONO_ $\triangle R R M 1$, confirming that binding to pre-mRNA targets is lost in the mutant NONO (Fig 4B). The pre-HAND2 and pre_KCNQ2 transcripts were also significantly different between the cells with YFPNONO_WT and YFP-NONO__RRM1. To determine if any NONO condensates corresponded to these target transcripts we used RNA FISH probes against NEAT1, or premRNAs of GATA2 and HAND2, in conjunction with immunofluorescence against NONO. Whilst each target transcript only had 1-2 foci per cell, likely representing nascent transcripts forming near gene loci, nevertheless, these foci were highly enriched in NONO (Fig 4C-4D). Thus, nuclear NONO condensates represent sites of NONO binding to a variety of lncRNA and pre-mRNA targets, particularly within the 5' part of pre-mRNAs regulated by super enhancers.

\section{NONO maintains proper RNA processing and splicing at the 5' end of transcripts}

To address the consequence of NONO knockdown (KD) on target gene expression, we used two siRNAs against NONO followed by RNA-seq in KELLY cells. We first confirmed a significant reduction in NONO mRNA and protein levels after KD (Fig 5A) and then compared four controls with eight NONO KD samples (4 for each NONO siRNA) using RNA-seq. In total, 3594 genes were differentially expressed (DESeq2 $p_{\text {adj }}<0.1$ ), with no bias for up- or down-regulation (Fig 5B) and no obvious difference according to gene length (Fig $\mathrm{S} 3 \mathrm{~A})$. Genes upregulated following NONO KD were enriched for ontologies relating broadly to the negative control of transcription, whereas genes downregulated were enriched in pathways relating to cholesterol synthesis and metabolism (Fig S3B-S3C). Gene Set Enrichment Analysis (GSEA) also found the most highly enriched pathways among NONO KD samples (containing genes that increased in activity) were GO:0006342 'chromatin 
silencing' (GSEA p $<10^{-3}$, FDR $<10^{-3}$ ) and GO:0045814 'negative regulation of gene expression (epigenetic)' (GSEA p $<10^{-3}, \mathrm{FDR}<10^{-3}$ ).

Given NONO's significant RNA binding activity, we next assessed the role of NONO in alternative splicing. To identify any overall changes we used IsoformSwitchAnalyzR, which showed that NONO disruption induced a significant bias in the use of upstream 'alternative transcription start sites' (ATSS) and downstream 'alternative 3' end acceptor sites' (A3) (Fig S3D). To further focus on these splicing changes, we used DESeq2 to test changes in the absolute expression of each intron and exon between control and KD samples. In addition, we used DEXSeq to test changes in the expression of each intron and exon relative to the overall expression of the parent gene: 'differential usage'. Thus, DEXSeq tests for changes that occur within a gene, controlling for expression changes of the gene as a whole. To look for a pattern of regulatory change with NONO KD, we divided each gene into 100 bins and looked at the position of each differentially expressed and differentially used exon/intron. We tested whether the proportion of significant upregulation events was significantly greater than the median, finding that exons within the first 13 bins had a significantly greater proportion of upregulated usage events (Fig 5C, top) and exons within the first 7 bins had a greater proportion of significantly upregulated expression changes (Fig 5C, bottom).

Examining the full transcripts (exons and introns) of the 2237 genes which had significant expression and/or usage events identified in Fig 5C, there is a significant bias for 5' upregulated usage and expression (Fig 5D, red). However, despite this 5' difference, there is no consistent change in the overall transcript expression for these genes (Fig 5B, yellow, Fig 5D row-side colours), even when overlapping with top NONO hits (Fig 5B, green). Thus, we observed that NONO KD induces upregulated usage and expression at the 5'-most extent of genes, which is independent of overall expression changes. This suggests a deficiency in processing at the 5 ' end of transcripts in the absence of NONO.

Combining the NONO KD RNA-seq with NONO PAR-CLIP, NONO-bound RNAs were significantly more likely to be differentially expressed $\left(\chi^{2}=76.9, p<10^{-15}\right.$, Fig S3E). To test whether NONO RNA binding is implicated in the observed 5' usage and expression changes, we looked at the average NONO PAR-CLIP coverage across these genes. The selected genes displayed a pronounced binding bias at the 5' end compared to genes which were 
differentially expressed overall, yet showed approximately equivalent binding at the 3' end (Fig 5E). Based on survival analysis, we also found that the upregulated genes at the 5 ' end are more likely to be prognostic in neuroblastoma, including GATA2 and HAND2, compared with other expressed genes (Fig 5F). These results suggest that NONO RNA binding at the 5' end may be required for successful pre-mRNA processing of transcripts with important roles in neuroblastoma.

\section{Delayed RNA processing of GATA2 and HAND2 results in decreased expression}

Given that GATA2 and HAND2 have been demonstrated to modulate differentiation and migration in neuroblastoma (Voth, Oberthuer et al., 2009, Willett \& Greene, 2011), we examined if their expression levels were regulated by NONO in KELLY cells. Indeed, GATA2 and HAND2 mRNA and protein levels were decreased after NONO KD (Fig 6A$6 \mathrm{C})$.

We next determined the possible mechanisms underlying the decreased expression of GATA2 and HAND2. Although we could detect NONO binding to the GATA2 gene by ChIP-qPCR , this chromatin binding did not alter when GATA2 transcription was reduced (Fig S4A-S4C), suggesting the binding of NONO to DNA and nascent RNA were not linked. We also tested any NONO-dependency for transcriptional elongation of GATA2 and HAND2, by ChIP-qPCR of phosphorylated Serine 2 of RNA polymerase II, yet found no difference in signal with NONO KD (Fig S4D), and no co-localisation of NONO condensates with PolII-phospho-Ser2 condensates by immunofluorescence (Fig S4E-S4F). In contrast, we found that NONO KD induced a higher relative expression of GATA2 and HAND2 premRNAs at the 5' end when compared to their mature transcripts (Fig 6D). Furthermore, overexpression of $\mathrm{NONO}_{-} \mathrm{WT}$, rather than $\mathrm{NONO}_{-} \Delta \mathrm{RRM} 1$ led to increased GATA2 and HAND2 protein levels (Fig 6E-6F), indicating that NONO has an effect on target gene expression through adequate RNA binding activity. Taken together, these data indicate that NONO binds pre-mRNAs and enhances RNA processing and splicing close to the 5 ' end of transcripts, driving optimal oncogenic expression levels.

\section{Discussion}

NONO acts as a molecular scaffold in gene regulation in many contexts. In this study, we identified NONO-mediated enhancement of RNA processing at the 5' end of important 
transcripts as a key molecular mechanism in neuroblastoma. This 5' associated RNA processing activity is linked to NONO nuclear condensates that form at individual gene loci, including those of the super-enhancer regulated genes GATA2 and HAND2. In the absence of functional NONO-RNA condensates, GATA2 and HAND2 protein levels decrease, with evidence for stalled 5' RNA processing. Therefore, we propose a model whereby NONO binds to, and coats the 5' ends of nascent transcripts, forming gene-body splicing-associated condensates to enhance gene expression and support an oncogenic program.

Here we show NONO forms numerous non-paraspeckle phase separated condensates in the nucleus, and that NONO readily forms droplets in vitro. NONO contains IDRs at the N-and C- termini, with a central globular domain for RNA binding, dimerization and coiled-coil oligomerisation; however, it is not known which of the IDRs, if any, drive condensate formation (Knott et al., 2016, Knott, Lee et al., 2015, Passon et al., 2012). Recently it was shown that the DBHS protein PSPC1 requires the C-terminal IDR to undergo phase separation (Li, Cui et al., 2021), and the analogous IDR exists in NONO, therefore this would be a good candidate region to test. We also showed that RNA binding, via RRM1, attenuates NONO phase separation, such that mutants with impaired RNA binding ability more readily phase separate in vitro and form large spherical droplets in the nuclei of cells. In contrast, wildtype NONO binds RNA and forms small fibrils in vitro and much smaller, finer, irregular condensates inside the nucleus. The propensity of RNA to prevent aberrant, gross phase separation by NONO is similar to what is observed for FUS, where mutants lacking RNA binding capacity excessively phase separate, while the wild-type protein is mostly diffuse (Maharana, Wang et al., 2018). However, NONO is different to FUS in that wildtype NONO is not diffuse, but instead forms many hundreds of smaller condensates, each likely representing a site of nascent transcription. For FUS, addition of small amounts of RNA promotes phase separation into droplets in vitro, whereas high RNA levels prevent droplet formation (Maharana et al., 2018). In contrast, addition of increasing concentration of RNA in vitro causes NONO droplets to convert into small fibrils, a behaviour also observed for PSPC1 (Shao, Bi et al., 2022). Thus, distinct families of RNA binding proteins use their suite of multivalent interactions to respond differently to the presence of RNA in vitro and in vivo. Our work adds to the growing appreciation of how RNA binding domains influence the final material state and modulate the dynamics of condensates in general (Gotor, Armaos et al., 2020, Wiedner \& Giudice, 2021). 
Paraspeckles are well-known protein-RNA condensates that form through microphase separation and are also not typically spherical. In the two main steps of paraspeckle formation, first, DBHS proteins, including NONO, bind and stabilise NEAT1 lncRNA. Secondly, FUS binds and carries out phase separation dependent on its prion-like domain (Yamazaki, Yamamoto et al., 2021). Whilst a role for NONO-driven phase separation in paraspeckle formation is yet to be established, NONO phase separation is required for radiation-induced DNA damage repair (Fan et al., 2021). In addition, NONO also promotes phase separation and activation of TAZ, the hippo pathway effector, to drive oncogenic transcription and tumorigenesis in glioblastoma, although a direct role for phase separation of NONO itself was not addressed in that study (Wei, Luo et al., 2021). Thus, NONO phase separation may be important for many of its regulatory activities in different contexts.

As well as binding to RNA, there is evidence from us and others, that NONO is bound to chromatin, albeit not through direct binding in many cases (Knott et al., 2016, Yang, Yang et al., 1997). In development, NONO and SPFQ are enriched at bivalent genes with high levels of poised RNA PolII, influencing lineage commitment (Ma et al., 2016, Van Nostrand et al., 2020, Xiao et al., 2019, Yadav, Hao et al., 2014). NONO is also responsible for recruitment of the 5-hydroxymethylcytosine enzyme TET1 to chromatin in mESCs (Li, Karwacki-Neisius et al., 2020). NONO RRM1 deletion did not abrogate its interaction with TET1, nor prevent NONO-dependent recruitment of TET1 to chromatin in mESCs, therefore NONO RNA binding appears to be less important in regulation of pluripotency. This is in contrast to PSPC1, which recruits TET2 to chromatin, dependent on its RNA binding activity (Guallar, Bi et al., 2018). However, for neuroblastoma our data argue that chromatin associated NONO is not the main driver of the gene regulatory role in this context, but instead might have a permissive role, preparing and facilitating a rapid transcriptional response when stimulators are present. This interpretation is partly due to our ChIP evidence that NONO recruitment to the GATA2 promoter is insensitive to transcription inhibition. Further, NONO mutants lacking RNA binding were no longer recruited to normal NONO condensates, instead appearing in fewer, larger, rounder nuclear droplets that are non-functional as they do not support enhanced cell proliferation in a similar manner to wildtype NONO.

Our sequencing and CLIP data suggest many genes display NONO-dependent expression. These genes normally have high levels of NONO bound at the 5' ends of their transcripts, principally in the introns. In the absence of NONO there is an increase in reads corresponding 
to the first $\sim 13 \%$ of transcript length, however this does not always correlate with overall differential expression. In the case of GATA2 and HAND2 we showed NONO loss leads to decreased protein production, with an increase in 5' end of transcripts corresponding to the pre-mRNA, implicating improper RNA processing in this downregulation. Thus, we propose a model in which a gene regulatory role for NONO in neuroblastoma hinges on binding to the pre-mRNA of nascent SE-regulated genes, promoting the formation of RNA-processing condensates, allowing efficient splicing. Extensive prior literature supports a role for NONO in pre-mRNA processing and splicing in different cell types and clinical samples (Feng et al., 2020, Yamamoto, Osawa et al., 2018). Although NONO is not a crucial component in spliceosome assembly, it interacts with critical spliceosomal proteins (Kameoka, Duque et al., 2004, Zhang \& Wu, 1996).

The primary mechanism of RNA processing enhanced by NONO condensates is still uncertain. Preventing intron retention is one explanation. However, using established bioinformatic pipelines we did not observe intron retention to be significantly altered with NONO KD. Given the 5' usage bias, this may be due to an inability to differentiate first intron retention, from all-intron retention. Others have shown NONO KD resulted in aberrant splicing, including intron retention, and altered gene expression in mouse developing retina (Yadav et al., 2014). Moreover, SFPQ, but not NONO, prevents intron retention in early neural differentiation (Luisier et al., 2018, Stagsted et al., 2021). Another factor to consider is the importance of NONO condensates for intron removal in co-transcriptional splicing, as opposed to post-transcriptional splicing. Whilst earlier findings support a role for NONO in co-transcriptional splicing (through association both with nascent RNA and PolII CTD) (Emili, Shales et al., 2002, Kameoka et al., 2004), new evidence of the importance of 'nuclear anchoring' of partially processed, but fully transcribed, pre-mRNA transcripts at the gene locus is emerging (Girard, Will et al., 2012, Popp \& Maquat, 2013, Quinn \& Chang, 2016). In this context, a chromatin-anchored nuclear pool of partially spliced, but polyadenylated RNA, may act in a regulatory manner as a reservoir for mature mRNA, upon splicing. Intriguingly, such a mechanism seems to be important in the neuronal gene regulation context (Yeom, Pan et al., 2021). Important future experiments would therefore include testing if NONO condensates act at the co- or post-transcriptional level, by repeating NONO KD RNA-seq, but with a polyA-restricted library. If the 5' usage bias is still apparent it suggests that pre-mRNAs, already decorated with polyA tails, depend on NONO for proper splicing, supporting post-transcriptional splicing. 
How the formation of NONO RNA processing condensates impacts transcription initiation and elongation condensates remains open to debate. One possibility is that NONO condensates help release paused PolII (Adelman \& Lis, 2012, Core, Waterfall et al., 2008, Lee, Li et al., 2008), or prevent promoter-proximal premature transcriptional termination (Ehrensberger, Kelly et al., 2013, Kamieniarz-Gdula \& Proudfoot, 2019). Indeed, NONO copurifies with some subunits of the mediator complex (required for release of paused PolII) (Huang, Li et al., 2012). A signature of paused PolII is abundant 20-60nt nascent RNA at the TSS (Rasmussen \& Lis, 1993, Rougvie \& Lis, 1988). Whilst we do see some genes with increased 5' usage after NONO KD exhibiting such 20-60nt fragments, we also observe more extensive 5 ' transcript increases (over the first $13 \%$ of transcript length). Increased abundance of reads at the TSS may also be an increase in nascent transcription of NONOdependent genes to compensate for lower target protein levels. Additionally, NONO condensates may enhance PolII elongation, as SE's generally regulate transcriptional elongation (Henriques, Scruggs et al., 2018, Tang, Yang et al., 2020) and SFPQ influences elongation (Hosokawa et al., 2019, Iida et al., 2020, Stagsted et al., 2021, Takeuchi et al., 2018). However, NONO KD leads to a significant upregulation only over the first $13 \%$ of the transcript, rather than a gradual decrease of transcript abundance across the entire gene. Further, PolII-Ser2 ChIP at the GATA2 locus is not altered by NONO KD. Thus whilst NONO condensates may influence PolII release and elongation to some extent, these are not the only mechanisms at play here.

NONO disruption leads to decreased expression of HAND2 and GATA2, transcription factors that are amongst a small group that maintain noradrenergic cell fate and survival in neuroblastoma (Boeva et al., 2017, Chipumuro et al., 2014, Durbin et al., 2018, Gartlgruber et al., 2021, Oldridge, Wood et al., 2015, van Groningen et al., 2017). High expression levels of these and other transcription factors work cooperatively in a defined core regulatory circuit creating a feed-forward loop to mediate sympathetic neuron specification, proliferation and differentiation (Rohrer, 2011, Voth et al., 2009, Willett \& Greene, 2011). Enhancing expression of such targets suggests NONO may be part of a master transcriptional and posttranscriptional nexus that concertedly assemble a high density of transcription factors and coactivators to drive robust expression in neuroblastoma, which is in agreement with cancer cells that acquire SEs to drive expression of prominent oncogenes (Chapuy, McKeown et al., 2013, Hnisz, Shrinivas et al., 2017, Lovén, Hoke et al., 2013a). Thus NONO joins the ranks 
of oncogenic neuroblastoma coactivators such as BRD4, which forms nuclear phaseseparated condensates at sites of SE-driven transcription (Sabari et al., 2018). Interestingly, BRD4/bromodomain inhibitors impair growth and induce apoptosis in neuroblastoma, hinting that potentially targeting NONO activity may also have therapeutic potential in this context (Puissant, Frumm et al., 2013). Furthermore, small molecules that interfere with RNA binding activity of NONO may serve as novel inhibitors of NONO biological functions and impede tumour cell growth. More broadly, this study may provide a new avenue for developing pharmaceutical drugs to manipulate RNA binding capacity of key regulators in combating cancer and other diseases.

\section{Materials and methods}

\section{Cell culture and transfections}

Two neuroblastoma cell lines including KELLY and BE(2)-C as well as HeLa cell line were used in this study. KELLY cells were grown in Gibco RPMI 1640 (ThermoFisher, 11835055) with 10\% Serana foetal bovine serum (FBS) (Fisher Biotec, FBS-AU-015) and 100U/mL penicillin-streptomycin (PenStrep) (ThermoFisher, 15140122), whereas BE(2)-C and HeLa cell lines were grown in Gibco DMEM medium (ThermoFisher, 11995073) with 10\% FBS and $100 \mathrm{U} / \mathrm{mL}$ PenStrep. All cells were cultured in a $37^{\circ} \mathrm{C}$ incubator supplied with $5 \% \mathrm{CO}_{2}$. These adherent cells were trypsinised using Gibco Tryple Express (ThermoFisher, 12604021) for routine passaging.

All transfections were performed in a forward transfection manner, with KELLY cells grown in RPMI (4\% FBS) and HeLa cells grown in DMEM (10\% FBS) during transfection. Lipofectamine 3000 (ThermoFisher, L3000015) and Lipofectamine RNAiMAX (ThermoFisher, 13778150) were the transfection reagents used in this study. All transfection mixtures were made up in serum-reduced Gibco Optimem (ThermoFisher, 11058021), as per the manufacturer's instructions. The cells were collected 2 days after the final transfection unless otherwise stated. The siRNAs used in the study were silencer select negative control No. 1 siRNA (Thermofisher 4390844), Silencer Select siRNA NONO s9612 (Thermofisher 4392422) and Silencer Select siRNA NONO s9613 (Thermofisher, 4392420). Plasmid pEYFP-NONO containing siRNA resistance site corresponding to siRNA NONO s9612 was made by QuikChange site-directed mutagenesis kit (Stratagene, 200518) with base-pair 
substitutions and the template plasmid pEYFP-C1-NONO (human). Using siRNA resistant pEYFP-NONO plasmid as a template, plasmids pEYFP-NONO_ARRM1 (67-141 deletion), R256I and F257I were made by Q5 site-directed mutagenesis kit (New England BioLabs, E0554S) with base-pair substitutions according to the manufacturer's instructions.

For siRNA-only transfections, $25 \mathrm{nM}$ of siRNAs and Lipofectamine RNAiMAX were used. For pEYFP-control and pEYFP-NONO plasmids-only transfections, Lipofectamine 3000 was used, with 1.25 ug transfected into 6-wells for Western blots and $200 \mathrm{ng}$ (HeLa cells) or 400 ng (KELLY cells) transfected into 12-wells for microscopic analysis. Sequential transfections for NONO RIP experiments were performed in 6-well plates using $10 \mathrm{nM}$ of siRNAs and Lipofectamine RNAiMAX to reduce the endogenous NONO followed by 1.25 ug of plasmid DNA and Lipofectamine 3000 on the next day. Co-transfections of siRNAs and plasmids for BrdU assays were conducted in 12-well plates using Lipofectamine RNAiMAX with $25 \mathrm{nM}$ of siRNAs and 1 ug of plasmid DNAs.

\section{RNA extraction and real time RT-qPCR}

Cells were lysed with Nucleozol (Macherey-Nagel, 740404) and RNA extractions were conducted according to the manufacturer's instructions. Lysed samples were heated at $55^{\circ} \mathrm{C}$ and vortexed at 1,000 rpm for $10 \mathrm{~min}$. GlycoBlue coprecipitant (ThermoFisher, AM9516) was added prior to isopropanol precipitation to aid pellet visualisation.

RNA samples were reverse transcribed to cDNA using the QuantiTect reverse transcription kit (Qiagen, 205314). Real time qPCRs were performed in the Rotor-Gene Q real-time PCR cycler (Qiagen). A PCR reaction consisted of SensiMix SYBR No-ROX (Bioline, QT65020), 250nM of forward and reverse primers (Integrated DNA Technologies, Table S1), molecular-grade $\mathrm{H}_{2} \mathrm{O}$, and cDNA. Ribosomal protein P0 (RPLP0) and U6 spliceosomal RNA (U6) were used as reference genes and mRNA expression level relative to U6 was presented using 2- $\Delta \Delta \mathrm{Ct}$ method. To assess differential processing at the 5' end of the transcripts, primer pairs over adjacent exon-intron junction (HAND2_2 and GATA2_2) were used to measure levels of pre-mRNAs, and primers pairs across exon-exon junction (HAND2_3) or located only in the exons (GATA2_3) were used to analyse the mature spliced transcripts. The level of pre-mRNA processing was then normalized over the expression of each mature spliced transcript. In ChIP-qPCR experiments, primer pairs of HAND2 and GATA2_4 were used to analyse the enrichment of chromatin fragments against RNA polymerase II 
phosphorated at Serine 2 with RPLP2 and CEP55 as positive and negative controls respectively. Primer pairs of GATA2_S, GATA2_M and GATA2_L were used to analyse the enrichment of chromatin fragments against NONO with GATA2_intron (equivalent to pre_GATA2) as a negative control.

\section{Protein extraction and Western blot}

Cells were lysed with RIPA lysis buffer $(150 \mathrm{mM} \mathrm{NaCl}, 25 \mathrm{mM}$ Tris $\mathrm{pH} 7.5,1 \%$ sodium deoxycholate, $0.1 \%$ SDS, $1 \%$ IGEPAL CA-630). Protein samples were mixed with SDS gelloading buffer and heated to $95^{\circ} \mathrm{C}$ for $10 \mathrm{~min}$. Samples and Precision Plus Protein ${ }^{\mathrm{TM}}$ All Blue Prestained Protein Standards (Bio-Rad, 1610373) were loaded onto Mini-PROTEAN TGX Pre-Cast Gels (Bio-Rad, 4561086). Gels were run in Tris/Glycine Buffer (Bio-Rad, 1610771) at 200V. Trans-Blot Turbo Mini Nitrocellulose Transfer packs (Bio-Rad, 1704158) were used for membrane transfer. Primary antibodies used were NONO (mouse monoclonal, in-house made), GATA2 (CG2-96) (mouse monoclonal, Santa Cruz, sc-267), HAND2 (A-12) (mouse monoclonal, Santa Cruz, sc-398167) and SFPQ (mouse monoclonal, Merck, P2860). Primary antibodies of NONO and SFPQ were diluted 1:1,000 in 5\% milk PBST, while GATA2 and HAND2 were used at 1:500 dilution in PBST. The secondary (horseradish-peroxidase conjugated) antibodies including goat anti-mouse IgG H\&L HRP (Abcam, ab97023) and goat anti-rabbit IgG H\&L HRP (Abcam, ab97051) were diluted 1:10,000 in 5\% milk PBST for NONO and SFPQ and 1:5,000 for GATA2 and HAND2. Luminata Crescedo Western HRP substrate (Merck, WBLUR0100) was added and blot images were acquired by Bio-Rad Chemidoc. Bio-Rad Imagelab Version 5.2 was used to quantify total protein levels and the intensity of the protein chemiluminescent bands. The relative intensity of chemiluminescent bands were normalized to the amount of total protein in each sample lane, and the sizes of chemiluminescent bands determined in relation to the standards ladder bands.

\section{GFP-trap}

Cells $\left(2.5 \times 10^{6}\right)$ were rinsed twice with ice-cold PBS and lysed in 150 uL RIPA buffer (25 $\mathrm{mM}$ Tris $\mathrm{pH} 7.5,150 \mathrm{mM} \mathrm{NaCl}, 1 \%$ IGEPAL CA-630, $1 \%$ Sodium deoxycholate, $0.1 \%$ SDS) with $1 \times$ protease inhibitor cocktail (Merck, 04693132001). The cell lysates were centrifuged at $20,000 \mathrm{~g}$ for $15 \mathrm{~min}$ at $4^{\circ} \mathrm{C}$ and resuspended in $\mathrm{TN}$ buffer $(25 \mathrm{mM}$ Tris $\mathrm{pH} 7.5$, $150 \mathrm{mM} \mathrm{NaCl}, 0.5 \%$ IGEPAL CA-630). After taking pre-GFP-trap aliquots, the lysates were incubated with $10 \mu \mathrm{L}$ GFP-Trap Magnetic Agarose beads (ChromoTek, gtma-20) for $3 \mathrm{~h}$ at 
$4^{\circ} \mathrm{C}$, followed by washing three times with $\mathrm{TN}$ buffer. The samples were mixed with SDS buffer for Western blot.

\section{Immunofluorescence and RNA fluorescence in situ hybridization}

Cells were grown on and fixed onto coverslips (Schott, G405-15) using 4\% paraformaldehyde in PBS. Immunofluorescence started with permeabilisation in freshly made $1 \%$ Triton X-100 diluted in PBS for 10 min. Epitope detection was conducted with a primary monoclonal mouse antibody against NONO at 1:500 dilution in PBST and a polyclonal rabbit antibody against RNA Pol II phosphorated at Serine 2 (Abcam, ab5095) at 1:500 dilution. After three times of PBST washes, coverslips were incubated with secondary FITC antimouse antibody for NONO (Jackson Laboratories, 115-095-072) and TRITC anti-rabbit antibody for Pol II pSer2 (Jackson Laboratories, 711-026-152) at 1:500 dilution in PBST. Coverslips were then counter stained with DAPI and images acquired. For dual immunofluorescence, the cells were incubated with primary antibodies raised in different species together.

For dual immunofluorescence and RNA FISH, after immunofluorescence with NONO, coverslips were then hybridised overnight with $\mathrm{FISH}$ probes at $37^{\circ} \mathrm{C}$ according to the manufacturer's instructions. The RNA FISH probes used in this study included human NEAT1 middle segment with Quasar R 570 Dye (Stellaris, SMF-2037-1) and custom-made human GATA2 and HAND2 segments with Quasar R 570 Dye (Stellaris).

For the treatment with 1,6-hexanediol, 1,6-hexanediol (Merck, 240117-50G) dissolved in the culture medium was added to cells at room temperature for $5 \mathrm{~min}$. Then, the cells were fixed with $4 \%$ paraformaldehyde in PBS, followed by immunofluorescence procedure. The cells with low levels of overexpression were imaged.

Coverslips with cells grown on were rinsed in PBS and reaction buffer (20mM Tris pH 7.5, $5 \mathrm{mM} \mathrm{MgCl} 2,0.5 \mathrm{mM}$ EGTA, $1 \times$ protease inhibitor cocktail). Cells were permeabilised with $0.1 \%$ Triton X-100 diluted in reaction buffer for $5 \mathrm{~min}$ at room temperature, followed by rinsing subsequently in reaction buffer and PBS. Coverslips were then incubated with RNase A (Merck, R4642) or DNase I (Worthington, LS006333) to achieve a final concentration of $100 \mu \mathrm{g} / \mathrm{mL}$ in nuclease buffer ( $5 \mathrm{mM} \mathrm{MgCl}_{2}$ in PBS) for $20 \mathrm{~min}$ at room temperature. After 
nuclease digestion, cells were fixed with $4 \%$ paraformaldehyde in PBS and continued with immunofluorescence procedure.

\section{BrdU cell replication assay}

KELLY cells were plated onto coverslips in 12-well plates and transfected with plasmids for 4 days. 2 hours prior to fixation, medium was replaced with the culture medium containing $10 \mathrm{nM}$ 5-Bromo-2'-deoxyuridine (BrdU) (Merck, B5002-100MG). Coverslips were then fixed, and cells were permeabilised in 1\% Triton X-100 diluted in PBS for $10 \mathrm{~min}$ at room temperature. After washing in PBS, coverslips were incubated in $1 \mathrm{M} \mathrm{HCl}$ for $30 \mathrm{~min}$, rinsed twice in PBS and then incubated in $0.1 \mathrm{M}$ sodium borate for $30 \mathrm{~min}$, followed by blocking in 5\% goat serum in PBST. Immunofluorescent staining was carried out using Anti-BrdU antibody (Abcam, ab8955) at 1:500 dilution in PBST and then anti-mouse Cy5-conjugated secondary antibody (Jackson Laboratories, 115-175-072) at 1:300 dilution in PBST.

\section{Expression and purification of recombinant proteins in vitro}

The pEGFP-NONO_WT or pEGFP-NONO_ARRM1 plasmid was transformed into competent Rosetta 2(DE3)pLysS Escherichia coli cells (Novagen, 71400) and plated on LB agar plates with selection for kanamycin and chloramphenicol. When the optical density of the culture reaches $0.6-0.8$, the flasks were cooled on ice for 15 minutes before expression was induced with $0.5 \mathrm{mM}$ isopropyl $\beta$-D-1-thiogalactopyranoside. After incubation for 16 hours, the cells were harvested by centrifugation at $4000 \mathrm{~g}$. A single pellet from $500 \mathrm{~mL}$ of expression culture was gently resuspended on ice in $50 \mathrm{~mL}$ binding buffer $(50 \mathrm{mM}$ Tris, $\mathrm{pH}$ 7.5, $1 \mathrm{M} \mathrm{KCl}, 300 \mathrm{mM}$ L-arginine, $25 \mathrm{mM}$ imidazole, 5\% glycerol) supplemented with $5 \mu \mathrm{L}$ Benzonase nuclease (Sigma, E1014-25KU), $1 \mathrm{mM}$ phenylmethanesulfonyl fluoride, 1X cOmplete $^{\mathrm{TM}}$ protease inhibitor cocktail (Roche, 11873580001) and $1 \mathrm{mM} \mathrm{MgCl} 2$. The cells were lysed with an Emulsiflex C5 high-pressure homogeniser (Avestin). The lysate was clarified by centrifugation at $24,000 \mathrm{~g}$ and then filtered through a $0.22 \mu \mathrm{M}$ syringe filter. The supernatant was applied to a 5-ml His-Trap HF column charged with $\mathrm{NiCl}_{2}$ (GE Healthcare, 17-5248-02). GFP-NONO_WT or GFP-NONO_ARRM1 was eluted at room temperature with an imidazole gradient $(25-500 \mathrm{mM})$ using the binding buffer and elution buffer $(50 \mathrm{mM}$ Tris, pH 7.5, $1 \mathrm{M} \mathrm{KCl,} 300 \mathrm{mM}$ L-arginine, $500 \mathrm{mM}$ imidazole, 5\% glycerol) over ten column volumes. The peak fractions were pooled and loaded onto a Superdex 200 HiLoad 16/60 preparative-grade column (GE Healthcare, 17-1069-01) in $5 \mathrm{~mL}$ injections and developed at room temperature with the size exclusion buffer $(20 \mathrm{mM}$ Tris, $\mathrm{pH} 7.5,1 \mathrm{M} \mathrm{KCl}$, 
$50 \mathrm{mM}$ L-Proline, $300 \mathrm{mM}$ L-arginine, $0.5 \mathrm{mM}$ EDTA, 5\% glycerol). Relevant peak fractions were pooled and concentrated with Amicon Ultra Centrifugal Filter Units $30 \mathrm{kDa}$ MWCO (Merck Millipore, UFC903024) to the required concentration.

\section{In vitro phase separation assay}

Exogenously expressed NONO_WT and NONO__RRM1, both tagged at the N-terminus with monomeric eGFP, were concentrated to $250 \mu \mathrm{M}$ in storage buffer (20 mM Tris, $\mathrm{pH} 7.5$, $500 \mathrm{mM} \mathrm{KCl}, 50 \mathrm{mM}$ L-proline, $300 \mathrm{mM}$ L-arginine, $0.5 \mathrm{mM}$ EDTA, 5\% glycerol). Four two-fold serial dilutions of the proteins were made in storage buffer to obtain proteins with concentration, 125, 62.5, 31.3 and $15.6 \mu \mathrm{M}$. Proteins at these five concentrations were diluted 1 in 10 in appropriate dilution buffers to $25,12.5,6.25,3.13$ and $1.56 \mu \mathrm{M}$. The composition of the dilution buffer was $20 \mathrm{mM}$ Tris, $\mathrm{pH} 7.5,50 \mathrm{mM}$ L-proline, $0.5 \mathrm{mM}$ EDTA, 5\% glycerol and with the $\mathrm{KCl}$ concentration adjusted so that the final $\mathrm{KCl}$ concentrations after dilution were $50,100,150,300$ and $500 \mathrm{mM}$ as required. Twenty $\mu \mathrm{L}$ of each of the diluted proteins were pipetted into wells of a 384-well flat-bottomed non-protein binding microplate (Grenier, \#781906). The wells were sealed with clear film and incubated at room temperature for about $30 \mathrm{~min}$. After incubation, DIC and FITC images of the wells were acquired with the Nikon Eclipse Ti2-E inverted microscope. To observe the effect of 2'-O-methyl phosphorothioate antisense oligonucleotides (PS-ASO) against NEAT1 on the phase separation of GFP-NONO_WT and GFP-NONO_ARRM1, the phase separation assays were repeated by diluting 1 in 10 the protein at $250 \mu \mathrm{M}$ in appropriate dilution buffers to reach a final concentration of $100 \mathrm{mM} \mathrm{KCL}, 30 \mathrm{mM} \mathrm{L}-A r g$ and 0, 2, 4, 6, 8 and $10 \mu \mathrm{M}$ PS-ASO after dilution, keeping other buffer component concentrations the same as the storage buffer.

\section{Microscopy and image analysis}

All images were acquired on a Deltavision Elite microscope (GE) using a 60X for BrdU assays or $100 \mathrm{X}$ objectives for others. For subsequent counting and quantitative analysis of fluorescent intensities, the Nikon NiS Elements software (Version 4.3, Nikon, Tokyo, Japan) was used. Acquisition parameters were kept consistent and intensity thresholds were set the same for samples within each experiment. Cells that had incorporated BrdU into their DNA during replication (labelled by $\mathrm{Cy} 5$ ) were measured and expressed relative to the total number of nuclei, as measured by DAPI staining. MeanGreen of NONO within each RNA FISH foci or each immunofluorescent foci of other proteins was calculated as a ratio relative to nuclear MeanGreen of NONO, and then averaged for each cell. The ratio close to 1 
indicates that NONO MeanGreen within specific foci is similar to nuclear NONO MeanGreen, implying no NONO enrichment and thus no co-localization between NONO signal and other molecules. Sphericity analysis was performed in ImageJ/Fiji with additional plugins (Haase, Jain et al., 2020, Haase, Royer et al., 2020, Legland, Arganda-Carreras et al., 2016, Ollion, Cochennec et al., 2013). Briefly, images were processed with CLIJ2 and the CLIJX-Assistant, NONO puncta were segmented using MorpholibJ's Marker-controlled Watershed, and sphericity was calculated from the resulting objects in the 3D ImageJ Suite. All image processing and segmentation parameters were standardised between experimental groups.

\section{RNA immunoprecipitation (RIP)}

KELLY cells $\left(2.5 \times 10^{6}\right)$ were rinsed twice with ice-cold PBS, UV crosslinked at $400 \mathrm{~mJ} / \mathrm{cm}^{2}$ on ice for $10 \mathrm{~min}$ in PBS, and then resuspended in $100 \mathrm{uL}$ RIPA buffer (25 mM Tris pH 7.5, $150 \mathrm{mM} \mathrm{NaCl}, 1 \%$ IGEPAL CA-630, 1\% Sodium deoxycholate, 0.1\% SDS, $1 \times$ protease inhibitor cocktail (Merck, 04693132001) and 2 U SUPERase-In RNase inhibitor (Thermofisher, AM2696)). Cells were sonicated using S220 Focused-ultrasonicator (Covaris, MA, USA) and cell lysates were centrifuged at $14,000 \mathrm{rpm}$ for $15 \mathrm{~min}$ at $4{ }^{\circ} \mathrm{C}$. The supernatants were diluted in $300 \mathrm{uL}$ TN buffer with RNase inhibitor (25 mM Tris pH 7.5, 150 $\mathrm{mM} \mathrm{NaCl}, 0.5 \%$ IGEPAL CA-630) and pre-cleared with $15 \mu \mathrm{L}$ Dynabeads Protein G (Thermofisher, 10004D) for $3 \mathrm{~h}$ at $4^{\circ} \mathrm{C}$. After taking pre-RIP aliquots, the pre-cleared supernatants were divided into two parts equally and incubated with $15 \mu \mathrm{L}$ Dynabeads prebound with antibodies for $1.5 \mu \mathrm{g}$ NONO or normal mouse IgG (Santa Cruz, sc-2025) overnight at $4{ }^{\circ} \mathrm{C}$. The bead complexes were washed twice with RIPA buffer and twice with TN buffer. Then, the samples were incubated with TN buffer with $0.5 \%$ SDS and proteinase $\mathrm{K}$ (ThermoFisher, EO0491) at $55^{\circ} \mathrm{C}$ for $30 \mathrm{~min}$, followed by RNA extraction. After reverse transcription, qPCR was used to amplify immunoprecipitated transcripts and data were presented as fold change relative to the input.

\section{Chromatin immunoprecipitation}

KELLY cells $\left(2 \times 10^{7}\right)$ were fixed in $10 \mathrm{~mL}$ PBS with $1 \%$ formaldehyde for 20 min at room temperature. Crosslinking was quenched by the addition of glycine to a final concentration of $0.125 \mathrm{M}$ for $5 \mathrm{~min}$. Cells were centrifuged at 3,000 rpm for $5 \mathrm{~min}$ and resuspended in lysis buffer (50 mM Hepes pH 7.5, $140 \mathrm{mM} \mathrm{NaCl}, 1 \mathrm{mM}$ EDTA pH 8.0, $10 \%$ glycerol, 0.5\% IGEPAL CA-630, $0.25 \%$ Triton X-100) with $1 \times$ protease inhibitor cocktail, followed by 
rinsing twice in wash buffer $(10 \mathrm{mM}$ Tris $\mathrm{pH} 8.0,200 \mathrm{mM} \mathrm{NaCl}, 1 \mathrm{mM}$ EDTA pH 8.0, 0.5 mM EGTA). The cell pellets were resuspended in nuclei lysis buffer (50 mM Tris pH 8.0, 10 mM EDTA pH 8.0, $1 \%$ SDS) with $1 \times$ protease inhibitor cocktail and sonicated with S220 Focused-ultrasonicator to achieve 200-500 bp DNA fragments. After centrifuging at 10,000 g for $10 \mathrm{~min}$ at $4{ }^{\circ} \mathrm{C}$, the supernatants were mixed with ChIP dilution buffer (50 mM Tris pH 8.0, $167 \mathrm{mM} \mathrm{NaCl}, 1.1 \%$ Triton X-100, 0.11\% sodium deoxycholate) and RIPA-150 buffer (50 mM Tris $\mathrm{pH} 8.0,150 \mathrm{mM} \mathrm{NaCl}, 1 \mathrm{mM}$ EDTA pH 8.0, 0.1\% SDS, $1 \%$ Triton X-100, $0.1 \%$ sodium deoxycholate). The samples were pre-cleared with $20 \mu \mathrm{L}$ Dynabeads and preChIP aliquots taken. The pre-cleared supernatants were divided into two parts and incubated with $40 \mu \mathrm{L}$ Dynabeads pre-bound with antibodies for $3.5 \mu \mathrm{g}$ NONO or RNA polymerase II phosphorated at Serine 2 (Abcam, ab5095) and normal mouse IgG overnight at $4{ }^{\circ} \mathrm{C}$. The bead complexes were sequentially washed twice each with RIPA-150 buffer, RIPA-500 buffer (50 mM Tris pH 8.0, $500 \mathrm{mM} \mathrm{NaCl}, 1 \mathrm{mM}$ EDTA pH 8.0, 0.1\% SDS, $1 \%$ Triton X$100,0.1 \%$ sodium deoxycholate), RIPA-LiCl buffer (50 mM Tris pH 8.0, 1 mM EDTA pH 8.0, $1 \%$ IGEPAL CA-630, 0.1\% sodium deoxycholate, $500 \mathrm{mM} \mathrm{LiCl})$ and TE/10 buffer (10 $\mathrm{mM}$ Tris $\mathrm{pH}$ 8.0, $0.1 \mathrm{mM}$ EDTA $\mathrm{pH}$ 8.0). The complexes were eluted by proteinase $\mathrm{K}$ in proteinase $\mathrm{K}$ digestion buffer (20 mM Hepes pH 7.5, $1 \mathrm{mM}$ EDTA pH 8.0, 0.5\% SDS) for 15 min at $50^{\circ} \mathrm{C}$, followed by adding $3 \mu \mathrm{L} 5 \mathrm{M} \mathrm{NaCl}$ and $1 \mu \mathrm{L} 30 \mathrm{mg} / \mathrm{mL}$ RNase A for reverse crosslinking overnight at $65^{\circ} \mathrm{C}$. The samples were further digested by proteinase $\mathrm{K}$ for $1 \mathrm{~h}$ at $50^{\circ} \mathrm{C}$. The DNAs were then purified by SparQ Pure Mag beads (Quantabio, 95196-005) according to the manufacturer's instructions and diluted in TE/10 buffer. qPCR was used to amplify immunoprecipitated chromatin fragments and data were presented as the percent input.

KELLY cells were treated with $100 \mu \mathrm{M}$ 5,6-Dichlorobenzimidazole 1- $\beta$-D-ribofuranoside (DRB, Merck, D1916-10MG) for $3 \mathrm{~h}$ at $37^{\circ} \mathrm{C}$. Cells in washout group were treated with DRB for $3 \mathrm{~h}$ at $37^{\circ} \mathrm{C}$, followed by replacing with the normal culture medium for $2 \mathrm{~h}$ at $37^{\circ} \mathrm{C}$. Cells from control, DRB and washout groups were harvested for ChIP-qPCR.

\section{RNA sequencing}

KELLY cells were plated in 6-well plates and transfected with control siRNA and NONO KD siRNAs at a final concentration of $10 \mathrm{nM}$ using Lipofectamine RNAiMAX for 72 hours. Cells $\left(2.5 \times 10^{6}\right)$ were extracted for RNA samples as outlined above. RNA samples were sent to the Australian Genome Research Facility (AGRF) for sequencing. RNA quality was 
confirmed using a Bioanalyser (Perkin Elmar, MA, USA) prior to RNA-seq. Whole transcriptome libraries were prepared with the TruSeq stranded total RNA library prep kit (Illumina, CA, USA) and ribosomal RNA depleted with the Ribo-Zero-Gold kit (Illumina, CA, USA). Sequencing was performed using a HiSeq 2000 (Illumina, CA, USA) to generate 50 bp single end reads, resulting in an average 17-19 million reads per lane per sample. Reads from two lanes were pooled for each sample to generate 34-38 million reads for each sample.

\section{Phosphoactivatable ribonucleoside-enhanced crosslinking and immunoprecipitation}

KELLY cells were grown on $20 \times 14 \mathrm{~cm}$ dishes and treated for 14-16 hours with $100 \mu \mathrm{M}$ of 4-Thiouridine (Merck, T4509). Cells $\left(1.6 \times 10^{8}\right)$ were rinsed with ice-cold PBS, irradiated at $0.15 \mathrm{~J} / \mathrm{cm}^{2}$ with $365 \mathrm{~nm}$ UV light, scraped and resuspended in NP40 lysis buffer $(50 \mathrm{mM}$ Hepes pH7.5, 1.5M KCl, 2mM EDTA, 0.5\% NP-40, 0.5mM DTT, $1 \times$ protease inhibitor cocktail). Then, cells were lysed and treated with $1 \mathrm{U} / \mu \mathrm{L}$ RNase T1 (Thermo Fisher Scientific, EN0541) for 5 min at room temperature to ensure that only RNA molecules bound by proteins were left. The lysates were pre-cleared with $20 \mu \mathrm{L}$ Dynabeads for $30 \mathrm{~min}$ at $4^{\circ} \mathrm{C}$ and then incubated with $100 \mu \mathrm{L}$ Dynabeads conjugated with $50 \mu \mathrm{g}$ NONO antibody for $2 \mathrm{~h}$ at $4^{\circ} \mathrm{C}$. Samples were rinsed three times with NP40 lysis buffer and treated with $0.5 \mathrm{U} / \mu \mathrm{L}$ calf intestinal alkaline phosphatase (New England BioLabs, M0290) in dephosphorylation buffer (50 mM Tris pH 7.5, $100 \mathrm{mM} \mathrm{NaCl}, 10 \mathrm{mM} \mathrm{MgCl}_{2}, 1 \mathrm{mM} \mathrm{DTT}$ ) for $10 \mathrm{~min}$ at $37^{\circ} \mathrm{C}$. The bead complexes were rinsed twice in phosphatase wash buffer $(50 \mathrm{mM}$ Tris $\mathrm{pH} 7.5,20 \mathrm{mM}$ EGTA, 0.5\% NP40) and twice in polynucleotide kinase buffer (PNK, $50 \mathrm{mM}$ Tris pH 7.5, 50

$\mathrm{mM} \mathrm{NaCl}, 10 \mathrm{mM} \mathrm{MgCl}_{2}$ ). The samples were end-labelled with radioactive $\gamma-{ }^{32} \mathrm{P}$-ATP (Perkin Elmar, NEG002250UC) to a final concentration of $0.5 \mu \mathrm{Ci} / \mu \mathrm{L}$ and $0.8 \mathrm{U} / \mu \mathrm{L} \mathrm{T} 4$ polynucleotide kinase (New England BioLabs, M0201S) for $30 \mathrm{~min}$ at $37^{\circ} \mathrm{C}$. Then, the bead complexes were rinsed five times in PNK buffer and resuspended in $2 \times$ SDS buffer. After SDS-PAGE electrophoresis, gels were visualized on films and gel bands containing the target crosslinked protein-RNA complexes cut out. Gel bands were treated to electro-elution and the eluted complexes in SDS buffer were further incubated with $1 \%$ SDS and proteinase K for 30 min at $55^{\circ} \mathrm{C}$. RNA extraction was then carried out using the miRNeasy Micro Kit (Qiagen, 217084) and RNA samples were sequenced.

\section{Bioinformatics}

Raw sequencing files were quality checked using FastQC (version 0.11.5) with all files passing. All subsequent analysis was performed using the gencodev37lift37 transcript model. 


\section{PAR-CLIP}

PARpipe (https://github.com/ohlerlab/PARpipe) was used with the default parameters to process PAR-CLIP datasets. In brief, after pre-processing, the pipeline uses PARalyzer (version 1.5) to identify reads containing T-to-C transitions (which are indicative of successful RNA-protein crosslinking), and aggregates these reads into clusters to define RNA-protein binding sites. Alignment files from PARpipe were analysed using wavClusteR (version 2.24.0) to determine and annotate binding sites. TPM was calculated as described (Wagner et al., 2012) and used to define NONO-bound genes as those in the top $20^{\text {th }}$ percentile of genes featuring reads with T-to-C transitions. Gene ontology analysis was performed for NONO bound genes using Metascape (http://metascape.org, (Tripathi, Pohl et al., 2015)), with expressed genes as the background. PAR-CLIP coverage plots were generated using metagene2 (version 1.6.1).

\section{Gene-level RNA-seq}

Transcript quantification was performed using salmon (version 1.4.0), summarised to genelevel counts and imported into R using tximport (1.18.0). Differential expression analysis was performed using DESeq2 (1.30.1) and the default parameters (alpha $=0.1$ ). In the NONO KD siRNA experiment, four control samples were tested against eight NONO KD samples. Samples from the two NONO KD siRNAs were grouped in an attempt to correct for offtarget effects of the individual siRNAs. Gene ontology analysis was performed for differentially expressed genes using Metascape (http://metascape.org, (Tripathi et al., 2015)), separating genes by positive or negative log fold change (LFC). Gene Set Enrichment Analysis (GSEA, version 3.0) was also performed using the count data generated above and tested against the Biological Process gene sets maintained at MSigDB (https://software.broadinstitute.org/gsea/msigdb/).

\section{Splicing analysis}

IsoformSwitchAnalyzeR (version 1.12.0) was run using output from salmon to look for overall splicing changes. To extend this, DEXSeq (version 1.36.0) was used to extract all exons from the gencodev37lift37 gtf, and custom scripts were used to extract all introns. DESeq 2 and DEXSeq were then run to determine differential expression and differential usage respectively, at the level of exons and introns (separately). Then, for each gene, the maximum length transcript was divided into 100 bins. The position of each significant 
differentially expressed and differentially used exon and intron was then overlapped with these 100 bins. The number and direction of change of significant events within each bin was summed. Bins for which the proportion of positive fold change events was 2 standard deviations greater than the median proportion were deemed as significant. Heatmaps were created for all genes which showed significant events within the first 13 bins (as defined by significant difference in the proportion of positive and negative events). Heatmaps show the $\log 2$ fold change of significant events as a function of their relative position within the gene.

\section{Super enhancer detection from ChIP-seq}

Publicly available KELLY (Chipumuro et al., 2014) cell line ChIP-seq data for the H3K27ac histone mark (GSM1532401) and associated input (GSM1532403) were downloaded from GEO. ChIP-seq reads were aligned using Bowtie 2 (Langmead \& Salzberg, 2012) against the hg19 (GRCh37) reference genome with the parameters -k 2 -q. Aligned reads were filtered, sorted and indexed using SAMtools (Li, Handsaker et al., 2009) using a minimum mapping quality score of 30. ChIP-seq peak calling was performed using MACS2 (Zhang, Liu et al., 2008) with the parameters: --keep-dup auto -p 1e-9 -B. Super enhancer calling was performed using ROSE (Lovén, Hoke et al., 2013b, Whyte, Orlando et al., 2013) with the parameters: -s 12500 -t 1000. Promoter associated enhancer exclusion in ROSE was changed to a $1000 \mathrm{bp}$ window (+/- 500bp) to allow the detection of MYCN associated super enhancer regions. Annotation of associated gene TSS for super enhancer regions was done using the org.Hs.eg.db and TxDb.Hsapiens.UCSC.hg19.knownGene packages in R. All genes whose TSS fell within $600 \mathrm{kbp}$ flanking of detected super enhancer start and end sites were included as associated genes.

\section{Survival Analysis}

The Kaplain-Meier tool from R2 genomics (https://hgserver1.amc.nl/cgibin/r2/main.cgi?option=kaplan_main) was used to identify neuroblastoma datasets which showed MYCN as having a prognostic value for overall survival using the 'scan' method and default settings. Using these four datasets (Cangelossi, Maris, SEQC and Versteeg) the tool was then used to identify all genes which were of prognostic value, using the 'median' method and default settings. The median method here was used as a more conservative means of identifying prognostic genes of otherwise unproven clinical relevance. Any gene whose expression was significantly associated with prognosis in at least 3 of the 4 datasets was then taken as showing prognostic value in neuroblastoma. 


\section{Acknowledgements}

We thank other members of the Fox lab for helpful discussions about the manuscript. This work was supported by a research grant APP1147496 from the National Health and Medical Research Council of Australia to AF and CB and FT180100204 from the Australian Research Council to AF.

\section{Author contributions}

SZ performed experiments and analysed data. JC analysed RNA sequencing data. YSC, AN, TL, SA, SK, OM and YSC performed experiments. SZ, JC and AF wrote the manuscript and prepared the figures. All authors read and approved the manuscript.

\section{Conflict of interest}

The authors declare that they have no conflict of interest.

\section{References}

Adelman K, Lis JT (2012) Promoter-proximal pausing of RNA polymerase II: emerging roles in metazoans. Nat Rev Genet 13: 720-31

Alberti S, Dormann D (2019) Liquid-Liquid Phase Separation in Disease. Annu Rev Genet 53: $171-194$

Benegiamo G, Mure LS, Erikson G, Le HD, Moriggi E, Brown SA, Panda S (2018) The RNA-Binding Protein NONO Coordinates Hepatic Adaptation to Feeding. Cell Metab 27: 404-418 e7

Boeva V, Louis-Brennetot C, Peltier A, Durand S, Pierre-Eugène C, Raynal V, Etchevers HC, Thomas S, Lermine A, Daudigeos-Dubus E, Geoerger B, Orth MF, Grünewald TGP, Diaz E, Ducos B, Surdez D, Carcaboso AM, Medvedeva I, Deller T, Combaret V et al. (2017) Heterogeneity of neuroblastoma cell identity defined by transcriptional circuitries. Nature Genetics 49: 1408-1413

Boija A, Klein IA, Sabari BR, Dall'Agnese A, Coffey EL, Zamudio AV, Li CH, Shrinivas K, Manteiga JC, Hannett NM, Abraham BJ, Afeyan LK, Guo YE, Rimel JK, Fant CB, Schuijers J, Lee TI, Taatjes DJ, Young RA (2018) Transcription Factors Activate Genes through the Phase-Separation Capacity of Their Activation Domains. Cell 175: 1842-1855.e16 
Castello A, Fischer B, Frese CK, Horos R, Alleaume AM, Foehr S, Curk T, Krijgsveld J, Hentze MW (2016) Comprehensive Identification of RNA-Binding Domains in Human Cells. Mol Cell 63: 696-710

Chapuy B, McKeown Michael R, Lin Charles Y, Monti S, Roemer Margaretha GM, Qi J, Rahl Peter B, Sun Heather H, Yeda Kelly T, Doench John G, Reichert E, Kung Andrew L, Rodig Scott J, Young Richard A, Shipp Margaret A, Bradner James E (2013) Discovery and Characterization of Super-Enhancer-Associated Dependencies in Diffuse Large B Cell Lymphoma. Cancer Cell 24: 777-790

Chipumuro E, Marco E, Christensen CL, Kwiatkowski N, Zhang T, Hatheway CM, Abraham BJ, Sharma B, Yeung C, Altabef A, Perez-Atayde A, Wong KK, Yuan GC, Gray NS, Young RA, George RE (2014) CDK7 inhibition suppresses super-enhancer-linked oncogenic transcription in MYCN-driven cancer. Cell 159: 1126-1139

Core LJ, Waterfall JJ, Lis JT (2008) Nascent RNA sequencing reveals widespread pausing and divergent initiation at human promoters. Science 322: 1845-8

Durbin AD, Zimmerman MW, Dharia NV, Abraham BJ, Iniguez AB, Weichert-Leahey N, He S, Krill-Burger JM, Root DE, Vazquez F, Tsherniak A, Hahn WC, Golub TR, Young RA, Look AT, Stegmaier K (2018) Selective gene dependencies in MYCN-amplified neuroblastoma include the core transcriptional regulatory circuitry. Nature Genetics 50: $1240-1246$

Ehrensberger Andreas H, Kelly Gavin P, Svejstrup Jesper Q (2013) Mechanistic Interpretation of Promoter-Proximal Peaks and RNAPII Density Maps. Cell 154: 713-715 Emili A, Shales M, McCracken S, Xie W, Tucker PW, Kobayashi R, Blencowe BJ, Ingles CJ (2002) Splicing and transcription-associated proteins PSF and p54nrb/nonO bind to the RNA polymerase II CTD. RNA 8: 1102-11

Fan XJ, Wang YL, Zhao WW, Bai SM, Ma Y, Yin XK, Feng LL, Feng WX, Wang YN, Liu Q, Hung MC, Wan XB (2021) NONO phase separation enhances DNA damage repair by accelerating nuclear EGFR-induced DNA-PK activation. Am J Cancer Res 11: 2838-2852 Feng P, Li L, Deng T, Liu Y, Ling N, Qiu S, Zhang L, Peng B, Xiong W, Cao L, Zhang L, Ye M (2020) NONO and tumorigenesis: More than splicing. Journal of cellular and molecular medicine 24: 4368-4376

Fox AH, Bond CS, Lamond AI (2005) P54nrb forms a heterodimer with PSP1 that localizes to paraspeckles in an RNA-dependent manner. Mol Biol Cell 16: 5304-15 Fox AH, Nakagawa S, Hirose T, Bond CS (2018) Paraspeckles: Where Long Noncoding RNA Meets Phase Separation. Trends Biochem Sci 43: 124-135 
Gartlgruber M, Sharma AK, Quintero A, Dreidax D, Jansky S, Park Y-G, Kreth S, Meder J, Doncevic D, Saary P, Toprak UH, Ishaque N, Afanasyeva E, Wecht E, Koster J, Versteeg R, Grünewald TGP, Jones DTW, Pfister SM, Henrich K-O et al. (2021) Super enhancers define regulatory subtypes and cell identity in neuroblastoma. Nature Cancer 2: 114-128

Girard C, Will CL, Peng J, Makarov EM, Kastner B, Lemm I, Urlaub H, Hartmuth K, Lührmann R (2012) Post-transcriptional spliceosomes are retained in nuclear speckles until splicing completion. Nature Communications 3: 994

Gotor NL, Armaos A, Calloni G, Torrent Burgas M, Vabulas RM, De Groot NS, Tartaglia GG (2020) RNA-binding and prion domains: the Yin and Yang of phase separation. Nucleic Acids Res 48: 9491-9504

Guallar D, Bi X, Pardavila JA, Huang X, Saenz C, Shi X, Zhou H, Faiola F, Ding J, Haruehanroengra P, Yang F, Li D, Sanchez-Priego C, Saunders A, Pan F, Valdes VJ, Kelley K, Blanco MG, Chen L, Wang H et al. (2018) RNA-dependent chromatin targeting of TET2 for endogenous retrovirus control in pluripotent stem cells. Nature genetics 50: 443-451 Guo YE, Manteiga JC, Henninger JE, Sabari BR, Dall'Agnese A, Hannett NM, Spille J-H, Afeyan LK, Zamudio AV, Shrinivas K, Abraham BJ, Boija A, Decker T-M, Rimel JK, Fant CB, Lee TI, Cisse II, Sharp PA, Taatjes DJ, Young RA (2019) Pol II phosphorylation regulates a switch between transcriptional and splicing condensates. Nature 572: 543-548 Haase R, Jain A, Rigaud S, Vorkel D, Rajasekhar P, Suckert T, Lambert TJ, Nunez-Iglesias J, Poole DP, Tomancak P, Myers EW (2020) Interactive design of GPU-accelerated Image Data Flow Graphs and cross-platform deployment using multi-lingual code generation. bioRxiv: 2020.11.19.386565

Haase R, Royer LA, Steinbach P, Schmidt D, Dibrov A, Schmidt U, Weigert M, Maghelli N, Tomancak P, Jug F, Myers EW (2020) CLIJ: GPU-accelerated image processing for everyone. Nature Methods 17: 5-6

Hafner M, Landthaler M, Burger L, Khorshid M, Hausser J, Berninger P, Rothballer A, Ascano M, Jungkamp AC, Munschauer M, Ulrich A, Wardle GS, Dewell S, Zavolan M, Tuschl T (2010) PAR-CliP--a method to identify transcriptome-wide the binding sites of RNA binding proteins. Journal of visualized experiments : JoVE: 10.3791/2034

Hennig S, Kong G, Mannen T, Sadowska A, Kobelke S, Blythe A, Knott GJ, Iyer KS, Ho D, Newcombe EA, Hosoki K, Goshima N, Kawaguchi T, Hatters D, Trinkle-Mulcahy L, Hirose T, Bond CS, Fox AH (2015) Prion-like domains in RNA binding proteins are essential for building subnuclear paraspeckles. The Journal of cell biology 210: 529-539 
Henriques T, Scruggs BS, Inouye MO, Muse GW, Williams LH, Burkholder AB, Lavender CA, Fargo DC, Adelman K (2018) Widespread transcriptional pausing and elongation control at enhancers. Genes Dev 32: 26-41

Hentze MW, Castello A, Schwarzl T, Preiss T (2018) A brave new world of RNA-binding proteins. Nature Reviews Molecular Cell Biology 19: 327-341

Hnisz D, Shrinivas K, Young RA, Chakraborty AK, Sharp PA (2017) A Phase Separation Model for Transcriptional Control. Cell 169: 13-23

Hosokawa M, Takeuchi A, Tanihata J, Iida K, Takeda S, Hagiwara M (2019) Loss of RNABinding Protein Sfpq Causes Long-Gene Transcriptopathy in Skeletal Muscle and Severe Muscle Mass Reduction with Metabolic Myopathy. iScience 13: 229-242

Huang Y, Li W, Yao X, Lin Q-J, Yin J-W, Liang Y, Heiner M, Tian B, Hui J, Wang G (2012) Mediator complex regulates alternative mRNA processing via the MED23 subunit. Molecular cell 45: 459-469

Iida K, Hagiwara M, Takeuchi A (2020) Multilateral Bioinformatics Analyses Reveal the Function-Oriented Target Specificities and Recognition of the RNA-Binding Protein SFPQ. iScience 23: 101325

Janoueix-Lerosey I, Schleiermacher G, Delattre O (2010) Molecular pathogenesis of peripheral neuroblastic tumors. Oncogene 29: 1566-1579

Jiang L, Shao C, Wu Q-J, Chen G, Zhou J, Yang B, Li H, Gou L-T, Zhang Y, Wang Y, Yeo G, Zhou Y, Fu X-D (2017) NEAT1 scaffolds RNA-binding proteins and the Microprocessor to globally enhance pri-miRNA processing. Nature Structural \& Molecular Biology 24: 816824

Kameoka S, Duque P, Konarska MM (2004) p54(nrb) associates with the 5' splice site within large transcription/splicing complexes. The EMBO journal 23: 1782-1791

Kamieniarz-Gdula K, Proudfoot NJ (2019) Transcriptional Control by Premature Termination: A Forgotten Mechanism. Trends Genet 35: 553-564

Knott GJ, Bond CS, Fox AH (2016) The DBHS proteins SFPQ, NONO and PSPC1: a multipurpose molecular scaffold. Nucleic Acids Res 44: 3989-4004

Knott GJ, Chong YS, Passon DM, Liang XH, Deplazes E, Conte MR, Marshall AC, Lee M, Fox AH, Bond CS (2021) Structural basis of dimerization and nucleic acid binding of human DBHS proteins NONO and PSPC1. Nucleic Acids Res

Knott GJ, Lee M, Passon DM, Fox AH, Bond CS (2015) Caenorhabditis elegans NONO-1: Insights into DBHS protein structure, architecture, and function. Protein Sci 24: 2033-43 
Krietsch J, Caron M-C, Gagné J-P, Ethier C, Vignard J, Vincent M, Rouleau M, Hendzel MJ, Poirier GG, Masson J-Y (2012) PARP activation regulates the RNA-binding protein NONO in the DNA damage response to DNA double-strand breaks. Nucleic acids research 40 : 10287-10301

Kuwahara S, Ikei A, Taguchi Y, Tabuchi Y, Fujimoto N, Obinata M, Uesugi S, Kurihara Y (2006) PSPC1, NONO, and SFPQ Are Expressed in Mouse Sertoli Cells and May Function as Coregulators of Androgen Receptor-Mediated Transcription1. Biology of Reproduction 75: 352-359

Langmead B, Salzberg SL (2012) Fast gapped-read alignment with Bowtie 2. Nature Methods 9: 357-359

Lee C, Li X, Hechmer A, Eisen M, Biggin M, Venters BJ, Jiang C, Li J, Pugh B, Gilmour D (2008) NELF and GAGA Factor Are Linked to Promoter-Proximal Pausing at Many Genes in Drosophila. Molecular and Cellular Biology 28: 3290 - 3300

Legland D, Arganda-Carreras I, Andrey P (2016) MorphoLibJ: integrated library and plugins for mathematical morphology with ImageJ. Bioinformatics 32: 3532-3534

Li H, Handsaker B, Wysoker A, Fennell T, Ruan J, Homer N, Marth G, Abecasis G, Durbin R (2009) The Sequence Alignment/Map format and SAMtools. Bioinformatics 25: 2078-9 Li J, Cui P, Sun Q, Du Z, Chen Z, Li Z, Liu C, Cao Y, Yang Z, Liu R, Luo M (2021) PSPC1 regulates $\mathrm{CHK} 1$ phosphorylation through phase separation and participates in mouse oocyte maturation. Acta Biochimica et Biophysica Sinica 53: 1527-1537

Li S, Li Z, Shu FJ, Xiong H, Phillips AC, Dynan WS (2014) Double-strand break repair deficiency in NONO knockout murine embryonic fibroblasts and compensation by spontaneous upregulation of the PSPC1 paralog. Nucleic Acids Res 42: 9771-80 Li W, Karwacki-Neisius V, Ma C, Tan L, Shi Y, Wu F, Shi YG (2020) Nono deficiency compromises TET1 chromatin association and impedes neuronal differentiation of mouse embryonic stem cells. Nucleic Acids Research 48: 4827-4838

Liu PY, Erriquez D, Marshall GM, Tee AE, Polly P, Wong M, Liu B, Bell JL, Zhang XD, Milazzo G, Cheung BB, Fox A, Swarbrick A, Hüttelmaier S, Kavallaris M, Perini G, Mattick JS, Dinger ME, Liu T (2014) Effects of a Novel Long Noncoding RNA, IncUSMycN, on NMyc Expression and Neuroblastoma Progression. Journal of the National Cancer Institute 106: 10.1093/jnci/dju113

Lovén J, Hoke Heather A, Lin Charles Y, Lau A, Orlando David A, Vakoc Christopher R, Bradner James E, Lee Tong I, Young Richard A (2013a) Selective Inhibition of Tumor Oncogenes by Disruption of Super-Enhancers. Cell 153: 320-334 
Lovén J, Hoke HA, Lin CY, Lau A, Orlando DA, Vakoc CR, Bradner JE, Lee TI, Young RA (2013b) Selective inhibition of tumor oncogenes by disruption of super-enhancers. Cell 153: 320-34

Luisier R, Tyzack GE, Hall CE, Mitchell JS, Devine H, Taha DM, Malik B, Meyer I, Greensmith L, Newcombe J, Ule J, Luscombe NM, Patani R (2018) Intron retention and nuclear loss of SFPQ are molecular hallmarks of ALS. Nature Communications 9: 2010 Ma C, Karwacki-Neisius V, Tang H, Li W, Shi Z, Hu H, Xu W, Wang Z, Kong L, Lv R, Fan Z, Zhou W, Yang P, Wu F, Diao J, Tan L, Shi YG, Lan F, Shi Y (2016) Nono, a Bivalent Domain Factor, Regulates Erk Signaling and Mouse Embryonic Stem Cell Pluripotency. Cell Rep 17: 997-1007

Maharana S, Wang J, Papadopoulos DK, Richter D, Pozniakovsky A, Poser I, Bickle M, Rizk S, Guillén-Boixet J, Franzmann TM, Jahnel M, Marrone L, Chang YT, Sterneckert J, Tomancak P, Hyman AA, Alberti S (2018) RNA buffers the phase separation behavior of prion-like RNA binding proteins. Science 360: 918-921

Munzer C, Menegaux F, Lacour B, Valteau-Couanet D, Michon J, Coze C, Bergeron C, Auvrignon A, Bernard F, Thomas C, Vannier J-P, Kanold J, Rubie H, Hémon D, Clavel J (2008) Birth-related characteristics, congenital malformation, maternal reproductive history and neuroblastoma: the ESCALE study (SFCE). Int J Cancer 122: 2315-2321

Naveed A, Cooper JA, Li R, Hubbard A, Chen J, Liu T, Wilton SD, Fletcher S, Fox AH (2021) NEAT1 polyA-modulating antisense oligonucleotides reveal opposing functions for both long non-coding RNA isoforms in neuroblastoma. Cellular and Molecular Life Sciences 78: $2213-2230$

Oldridge DA, Wood AC, Weichert-Leahey N, Crimmins I, Sussman R, Winter C, McDaniel LD, Diamond M, Hart LS, Zhu S, Durbin AD, Abraham BJ, Anders L, Tian L, Zhang S, Wei JS, Khan J, Bramlett K, Rahman N, Capasso M et al. (2015) Genetic predisposition to neuroblastoma mediated by a LMO1 super-enhancer polymorphism. Nature 528: 418-421 Ollion J, Cochennec J, Loll F, Escudé C, Boudier T (2013) TANGO: a generic tool for highthroughput 3D image analysis for studying nuclear organization. Bioinformatics (Oxford, England) 29: 1840-1841

Passon DM, Lee M, Rackham O, Stanley WA, Sadowska A, Filipovska A, Fox AH, Bond CS (2012) Structure of the heterodimer of human NONO and paraspeckle protein component 1 and analysis of its role in subnuclear body formation. Proc Natl Acad Sci U S A 109: 4846-50 Popp MW-L, Maquat LE (2013) Organizing principles of mammalian nonsense-mediated mRNA decay. Annual review of genetics 47: 139-165 
Puissant A, Frumm SM, Alexe G, Bassil CF, Qi J, Chanthery YH, Nekritz EA, Zeid R, Gustafson WC, Greninger P, Garnett MJ, McDermott U, Benes CH, Kung AL, Weiss WA, Bradner JE, Stegmaier K (2013) Targeting MYCN in neuroblastoma by BET bromodomain inhibition. Cancer discovery 3: 308-323

Quinn JJ, Chang HY (2016) Unique features of long non-coding RNA biogenesis and function. Nature Reviews Genetics 17: 47-62

Rasmussen EB, Lis JT (1993) In vivo transcriptional pausing and cap formation on three Drosophila heat shock genes. Proc Natl Acad Sci U S A 90: 7923-7

Rohrer H (2011) Transcriptional control of differentiation and neurogenesis in autonomic ganglia. Eur J Neurosci 34: 1563-73

Rougvie AE, Lis JT (1988) The RNA polymerase II molecule at the 5' end of the uninduced hsp70 gene of D. melanogaster is transcriptionally engaged. Cell 54: 795-804

Sabari BR, Dall'Agnese A, Boija A, Klein IA, Coffey EL, Shrinivas K, Abraham BJ, Hannett NM, Zamudio AV, Manteiga JC, Li CH, Guo YE, Day DS, Schuijers J, Vasile E, Malik S, Hnisz D, Lee TI, Cisse, II, Roeder RG et al. (2018) Coactivator condensation at superenhancers links phase separation and gene control. Science 361 Shao W, Bi X, Pan Y, Gao B, Wu J, Yin Y, Liu Z, Peng M, Zhang W, Jiang X, Ren W, Xu Y, Wu Z, Wang K, Zhan G, Lu JY, Han X, Li T, Wang J, Li G et al. (2022) Phase separation of RNA-binding protein promotes polymerase binding and transcription. Nat Chem Biol 18: $70-80$

Spegg V, Altmeyer M (2021) Biomolecular condensates at sites of DNA damage: More than just a phase. DNA Repair 106: 103179

Stagsted LVW, O'Leary ET, Ebbesen KK, Hansen TB (2021) The RNA-binding protein SFPQ preserves long-intron splicing and regulates circRNA biogenesis in mammals. Elife 10 Takayama KI, Suzuki T, Fujimura T, Yamada Y, Takahashi S, Homma Y, Suzuki Y, Inoue S (2017) Dysregulation of spliceosome gene expression in advanced prostate cancer by RNAbinding protein PSF. Proc Natl Acad Sci U S A 114: 10461-10466

Takeuchi A, Iida K, Tsubota T, Hosokawa M, Denawa M, Brown JB, Ninomiya K, Ito M, Kimura H, Abe T, Kiyonari H, Ohno K, Hagiwara M (2018) Loss of Sfpq Causes Long-Gene Transcriptopathy in the Brain. Cell Rep 23: 1326-1341

Tang F, Yang Z, Tan Y, Li Y (2020) Super-enhancer function and its application in cancer targeted therapy. npj Precision Oncology 4: 2

Tripathi S, Pohl MO, Zhou Y, Rodriguez-Frandsen A, Wang G, Stein DA, Moulton HM, DeJesus P, Che J, Mulder LC, Yanguez E, Andenmatten D, Pache L, Manicassamy B, 
Albrecht RA, Gonzalez MG, Nguyen Q, Brass A, Elledge S, White M et al. (2015) Meta- and Orthogonal Integration of Influenza "OMICs" Data Defines a Role for UBR4 in Virus Budding. Cell Host Microbe 18: 723-35

van Groningen T, Koster J, Valentijn LJ, Zwijnenburg DA, Akogul N, Hasselt NE, Broekmans M, Haneveld F, Nowakowska NE, Bras J, van Noesel CJM, Jongejan A, van Kampen AH, Koster L, Baas F, van Dijk-Kerkhoven L, Huizer-Smit M, Lecca MC, Chan A, Lakeman A et al. (2017) Neuroblastoma is composed of two super-enhancer-associated differentiation states. Nature Genetics 49: 1261-1266

Van Nostrand EL, Freese P, Pratt GA, Wang X, Wei X, Xiao R, Blue SM, Chen J-Y, Cody NAL, Dominguez D, Olson S, Sundararaman B, Zhan L, Bazile C, Bouvrette LPB, Bergalet J, Duff MO, Garcia KE, Gelboin-Burkhart C, Hochman M et al. (2020) A large-scale binding and functional map of human RNA-binding proteins. Nature 583: 711-719

Vickers TA, Rahdar M, Prakash TP, Crooke ST (2019) Kinetic and subcellular analysis of PS-ASO/protein interactions with P54nrb and RNase H1. Nucleic Acids Res 47: 10865-10880 Voth H, Oberthuer A, Simon T, Kahlert Y, Berthold F, Fischer M (2009) Co-regulated expression of HAND2 and DEIN by a bidirectional promoter with asymmetrical activity in neuroblastoma. BMC Molecular Biology 10: 28

Wagner GP, Kin K, Lynch VJ (2012) Measurement of mRNA abundance using RNA-seq data: RPKM measure is inconsistent among samples. Theory Biosci 131: 281-5

Wei Y, Luo H, Yee PP, Zhang L, Liu Z, Zheng H, Zhang L, Anderson B, Tang M, Huang S, Li W (2021) Paraspeckle Protein NONO Promotes TAZ Phase Separation in the Nucleus to Drive the Oncogenic Transcriptional Program. Adv Sci (Weinh) 8: e2102653

Whyte WA, Orlando DA, Hnisz D, Abraham BJ, Lin CY, Kagey MH, Rahl PB, Lee TI, Young RA (2013) Master transcription factors and mediator establish super-enhancers at key cell identity genes. Cell 153: 307-19

Wiedner HJ, Giudice J (2021) It's not just a phase: function and characteristics of RNAbinding proteins in phase separation. Nature Structural \& Molecular Biology 28: 465-473 Willett RT, Greene LA (2011) Gata2 is required for migration and differentiation of retinorecipient neurons in the superior colliculus. J Neurosci 31: 4444-55

Xiao R, Chen JY, Liang Z, Luo D, Chen G, Lu ZJ, Chen Y, Zhou B, Li H, Du X, Yang Y, San M, Wei X, Liu W, Lécuyer E, Graveley BR, Yeo GW, Burge CB, Zhang MQ, Zhou Y et al. (2019) Pervasive Chromatin-RNA Binding Protein Interactions Enable RNA-Based Regulation of Transcription. Cell 178: 107-121 e18 
Yadav SP, Hao H, Yang HJ, Kautzmann MA, Brooks M, Nellissery J, Klocke B, Seifert M, Swaroop A (2014) The transcription-splicing protein NonO/p54nrb and three NonOinteracting proteins bind to distal enhancer region and augment rhodopsin expression. Hum Mol Genet 23: 2132-44

Yamamoto R, Osawa T, Sasaki Y, Yamamoto S, Anai M, Izumi K, Matsumura Y, Sakai J, Aburatani H, Mizokami A, Kodama T, Tanaka T (2018) Overexpression of p54(nrb)/NONO induces differential EPHA6 splicing and contributes to castration-resistant prostate cancer growth. Oncotarget 9: 10510-10524

Yamazaki T, Souquere S, Chujo T, Kobelke S, Chong YS, Fox AH, Bond CS, Nakagawa S, Pierron G, Hirose T (2018) Functional Domains of NEAT1 Architectural lncRNA Induce Paraspeckle Assembly through Phase Separation. Mol Cell 70: 1038-1053.e7

Yamazaki T, Yamamoto T, Yoshino H, Souquere S, Nakagawa S, Pierron G, Hirose T (2021) Paraspeckles are constructed as block copolymer micelles. EMBO J 40: e107270

Yang YS, Yang MC, Tucker PW, Capra JD (1997) NonO enhances the association of many DNA-binding proteins to their targets. Nucleic acids research 25: 2284-2292

Yeom KH, Pan Z, Lin CH, Lim HY, Xiao W, Xing Y, Black DL (2021) Tracking pre-mRNA maturation across subcellular compartments identifies developmental gene regulation through intron retention and nuclear anchoring. Genome Res 31: 1106-1119

Zbinden A, Pérez-Berlanga M, De Rossi P, Polymenidou M (2020) Phase Separation and Neurodegenerative Diseases: A Disturbance in the Force. Dev Cell 55: 45-68

Zhang WJ, Wu JY (1996) Functional properties of p54, a novel SR protein active in constitutive and alternative splicing. Molecular and cellular biology 16: 5400-5408

Zhang Y, Liu T, Meyer CA, Eeckhoute J, Johnson DS, Bernstein BE, Nusbaum C, Myers RM, Brown M, Li W, Liu XS (2008) Model-based Analysis of ChIP-Seq (MACS). Genome Biology 9: R137

\section{Figure legends}

Figure 1: Both RNA and DNA are essential for distinct distribution of NONO puncta in neuroblastoma cell lines

(A) The probability of overall survival is lower in neuroblastoma patients with high NONO expression based on Kaplan-Meier curve using the SEQC neuroblastoma dataset. (B) Fluorescence micrograph images of representative cells stained for NONO and NEAT1_2 in KELLY and BE(2)-C neuroblastoma and Hela cells showing clear paraspeckle (as marked by 
NEAT1_2), and non-paraspeckle NONO puncta. DAPI (blue) stain indicates cell nuclei, NONO immunofluorescence (green) and NEAT1_2 RNA FISH (red). Scale bar: $5 \mu \mathrm{m}$. (C) Fluorescence micrograph images of representative cells stained for NONO in KELLY cells treated with 2, 4, 6, 8 or 10\% 1,6 hexanediol showing dissolution of NONO puncta with increasing concentration. Scale bar: $5 \mu \mathrm{m}$. (D) Dot plot of summed green fluorescence per nucleus at different concentrations of 1,6 hexanediol as in (C). Bars are SD. (E) Recombinant GFP-NONO_WT can phase separate spontaneously. Its propensity to phase separate increases with increasing protein and decreasing $\mathrm{KCl}$ concentration. Scale bar: $20 \mu \mathrm{m}$. (F) Fluorescence micrograph images of representative cells stained for NONO in KELLY cells treated with PBS, RNase A or Dnase I, as indicated. Scale bar: $5 \mu \mathrm{m}$. (G) Dot plot of summed green fluorescence per nucleus in $(\mathrm{F})$. Bars are $\mathrm{SD} . * * * \mathrm{P}<0.001$.

\section{Figure 2: RRM1 is an important region for NONO to bind RNA targets in KELLY cells}

(A) Fluorescence micrograph images of representative cells stained for NONO and NEAT1_2 after transfection with plasmids expressing YFP fused NONO_WT and NONO_ARRM1 protein. DAPI (blue) stain indicates cell nuclei, YFP fused NONO (green) and NEAT1_2 RNA FISH (red). Scale bar: $5 \mu \mathrm{m}$. (B) The enrichment of mean NONO fluorescence detected within RNA FISH foci is quantitatively determined as a ratio relative to mean nuclear NONO fluorescence in (A). Bars are SD. ${ }^{*} \mathrm{p}<0.05$, ** $\mathrm{p}<0.01$, ***p<0.001. (C) Sphericity per NONO segment, (D) NONO foci number per nucleus and (E) NONO foci size between YFP fused NONO_WT and NONO_ARRM1 plasmids were measured. Bars are SD. (F) Percentage of BrdU incorporation between control cells (YFP only transfection), cells with YFP fused NONO_WT and YFP-NONO_ARRM1 plasmids transfected. Bars are SEM. $\mathrm{n} \geq 3$. (G) Recombinant GFP-NONO_ARRM1 has a higher propensity to phase separate than GFP-NONO_WT at the same $\mathrm{KCl}$ concentration. Blue and red colours denote GFPNONO_WT and GFP-NONO- $\triangle \mathrm{RRM} 1$ respectively. Filled circles, open circles and crosses indicate distinct phase separation, minor phase separation and no phase separation respectively. Dotted lines denote putative binodal line separating single and two phase states. Scale bar: $20 \mu \mathrm{m}$. (H) PS-ASO against NEAT1 disrupts the phase separation of GFPNONO_WT but not GFP-NONO__RRM1 in a PS-ASO concentration-dependent manner. Scale bar: $20 \mu \mathrm{m}$.

\section{Figure 3: NONO preferentially binds 5' introns and SE regulated target genes have} more NONO binding 
(A) NONO RNA binding sites are strongly biased towards introns, as determined by PARCLIP and wavClusteR. Sense: percentage of annotated binding sites on sense strand.

Antisense: percentage of annotated binding sites on antisense strand. Transcriptome: relative length of each annotation category within the transcriptome. Normalized: percentage of annotated binding sites corrected by total length of each annotation category in transcriptome. (B) NONO binding sites within introns show preference for the 5' end of genes as determined by PAR-CLIP and PARpipe. (C) Metascape gene ontology analysis of NONO-bound target transcripts. (D) Metascape gene ontology analysis of NONO-bound target transcripts in BE(2)-C cells. (E) Summary of most highly NONO-bound RNA targets by NONO TPM and $\%$ of all T-to-C reads. (F) NONO PAR-CLIP coverage profiles (metagene2) across SEregulated genes compared to expression and length-matched controls. NONO binds to SE regulated target genes with greater coverage compared to matched controls.

\section{Figure 4: NONO binds more abundantly on pre-mRNAs than mature counterparts in}

\section{KELLY cells}

(A) Relative pre-mRNA levels and their mature counterparts were measured by NONO RNA RIP followed by RT-qPCR. RIP data with normal mouse serum IgG as controls are not displayed because all values are $<0.01$. Bars are SEM. $\mathrm{n} \geq 3 .{ }^{*} \mathrm{p}<0.05,{ }^{* *} \mathrm{p}<0.01,{ }^{* * *} \mathrm{p}<0.001$. (B) Relative pre-mRNA levels and their mature counterparts were measured by NONO RNA RIP followed by RT-qPCR in cells transfected sequentially with NONO KD siRNA and then siRNA-resistant control (YFP only), YFP fused NONO_WT or NONO_ARRM1 plasmids. Bars are SEM. $n \geq 3$. (C) Fluorescence micrograph images of representative cells stained for NONO and NEAT1_2 (top), GATA2 (middle) and HAND2 (bottom). DAPI (blue) stain indicates cell nuclei, NONO immunofluorescence (green) and RNA FISH (red) for NEAT1_2, GATA2 and HAND2. Scale bar: $5 \mu \mathrm{m}$. (D) In micrograph image quantitation analysis, the enrichment of mean NONO fluorescence detected within RNA FISH foci is determined as a ratio relative to mean nuclear NONO fluorescence in (C). Bars are SD.

\section{Figure 5: NONO KD results in altered RNA processing and splicing in KELLY cells}

(A) Relative NONO mRNA and protein levels in KELLY cells treated with control or NONO KD siRNAs. Representative Western blot image for NONO protein. Bars are SEM. $\mathrm{n} \geq 3$. ** $\mathrm{p}<0.01, * * * \mathrm{p}<0.001$. (B) Differentially expressed genes do not demonstrate a length, or foldchange bias (red). The upregulated genes at the 5' end (orange), including those that are NONO bound (green), have a moderate bias towards longer genes. (C) Histogram of 
significant differential usage and differential expression events by gene position. The proportion of total significant events for each exon bin is compared to the median proportion. Bins whose proportion exceeds the median by twice the standard deviation are coloured red. (D) A subset of genes show 5' upregulation of both differential usage (left, DEXSeq) and differential expression (right, DESeq2). Each row represents a gene, split into 100 bins (exons and introns). Coloured bins represent significant events in differential usage and differential expression testing. The bar to the left of each row indicates whether the gene as a whole is differentially expressed. Red indicates increased expression, and blue indicates decreased expression. (E) NONO coverage across genes showing 5' upregulation has a distinct 5 ' bias when compared with genes which are differentially expressed, and compared to all expressed genes (metagene2). (F) There is a higher proportion of neuroblastomaprognostic genes in the upregulated genes at the 5' end compared with the other expressed genes based on the Kaplan-Meier tool using four neuroblastoma datasets (Cangelossi, Maris, SEQC and Versteeg).

\section{Figure 6: NONO KD reduces mRNA and protein expression of GATA2 and HAND2, which may result from inappropriate processing and splicing in KELLY cells}

(A) Relative GATA2 and HAND2 mRNA levels via RT-qPCR between control and NONO KD siRNAs. Bars are SEM. $\mathrm{n} \geq 3$. ${ }^{*} \mathrm{p}<0.05,{ }^{*} \mathrm{p}<0.01$. (B) Western blot quantitation analysis of GATA2 and HAND2 protein levels between control and NONO KD siRNAs. Bars are SEM. $\mathrm{n} \geq 3$. (C) Representative Western blot images for GATA2 and HAND2 proteins in (B). (D) The percentage of GATA2 and HAND2 pre-mRNAs at the 5' end was measured relative to their mature transcripts between control and NONO KD siRNAs. Bars are SEM. $n \geq 3$. (E) Western blot quantitation analysis of GATA2 and HAND2 protein levels in cells transfected sequentially with NONO KD siRNA and then siRNA-resistant control (YFP only), YFP fused NONO_WT or NONO_ARRM1 plasmids. Bars are SEM. $\mathrm{n} \geq 3$. (F) Representative Western blot images for GATA2 and HAND2 proteins in (E).

\section{Tables and their legends}

Table S1. A list of primers

\begin{tabular}{lll}
\hline Primer & Direction & $5^{\prime}-3^{\prime}$ \\
\hline U6 & Forward & CTCGCTTCGGCAGCACA \\
& Reverse & AACGCTTCACGAATTTGCGT
\end{tabular}




\begin{tabular}{|c|c|c|}
\hline \multirow[t]{2}{*}{ RPLP0 } & Forward & AGCCCAGAACACTGGTCTC \\
\hline & Reverse & ACTCAGGATTTCAATGGTGCC \\
\hline \multirow[t]{2}{*}{ Total NEAT1 } & Forward & GTGGCTGTTGGAGTCGGTAT \\
\hline & Reverse & TAACAAACCACGGTCCATGA \\
\hline \multirow[t]{2}{*}{ NEAT1_2 } & Forward & GTCTTTCCATCCACTCACGTCTATTT \\
\hline & Reverse & GTACTCTGTGATGGGGTAGTCAGTCAG \\
\hline \multirow[t]{2}{*}{ MYCN } & Forward & CGACCACAAGGCCCTCAGTA \\
\hline & Reverse & CAGCCTTGGTGTTGGAGGAG \\
\hline \multirow[t]{2}{*}{ pre_MYCN } & Forward & CTGCCTGGACAGAAACCTGTTAG \\
\hline & Reverse & TGCACAGCCCTTGAATCTTCTC \\
\hline \multirow[t]{2}{*}{ DAZAP1 } & Forward & CAGACCGCACACGCTAGATG \\
\hline & Reverse & GTTATCGCTCCTGGGTCCTTTC \\
\hline \multirow[t]{2}{*}{ pre_DAZAP1 } & Forward & TGGAACTGGAGAGAGAGGTTTATGG \\
\hline & Reverse & ССТСССТCTGTGACTTTCCTACAA \\
\hline \multirow[t]{2}{*}{ HAND2 } & Forward & AAACAGGGCCGCTAACATTTC \\
\hline & Reverse & TAGAGGACGGAAGTGCACAAA \\
\hline \multirow[t]{2}{*}{ pre_HAND2 } & Forward & AACTGGCTTCGGTAGGGTAGAG \\
\hline & Reverse & GGTCTGAGGGCTAATGGAGGTTA \\
\hline \multirow[t]{2}{*}{ GATA2 } & Forward & CTGACGACAACCACCACCTTAT \\
\hline & Reverse & CTTCATGGTCAGTGGCCTGTTA \\
\hline \multirow[t]{2}{*}{ pre_GATA2 } & Forward & AGCGCCAGCATTTCCAACTATAC \\
\hline & Reverse & AGGCCTGGTGAGAGCAGATTTA \\
\hline \multirow[t]{2}{*}{ MALAT1 } & Forward & GAC GGA GGT TGA GAT GAA GC \\
\hline & Reverse & ATT CGG GGC TCT GTA GTC CT \\
\hline \multirow[t]{2}{*}{ KCNQ2 } & Forward & СCCTCATCGGTGTCTCCTTCTT \\
\hline & Reverse & TTCTCAAAGTGCTTCTGCCTGTG \\
\hline \multirow[t]{2}{*}{ pre_KCNQ2 } & Forward & TCATCCACTGTTGCTCCTCTGT \\
\hline & Reverse & CAGGTCTGACGCCCTTCTAACT \\
\hline \multirow[t]{2}{*}{ RPLP2 } & Forward & ATGGATGCAGGAAGTGAGCC \\
\hline & Reverse & AAGCCTGAGGAGTGATTGCC \\
\hline \multirow[t]{2}{*}{ CEP55 } & Forward & ATTCGCTCAATCACTGTGGTTCT \\
\hline & Reverse & TGAGAGTGATTCTTTGGTTGGTATCT \\
\hline GATA2_2 & Forward & CTGCTCCCAGCTCTACTCCAG \\
\hline
\end{tabular}




$\begin{array}{lll}\text { GATA2_3 } & \text { Reverse } & \text { AGGGAAGGTGGAAGTGGAAGAA } \\ & \text { Forward } & \text { GAAGTGTCTCCTGACCCTAGCA } \\ \text { HAND2_2 } & \text { Reverse } & \text { GGGACTGCCACTTTCCATCTTC } \\ & \text { Forward } & \text { GAGGAAGAAGGAGCTGGTCAGTA } \\ \text { HAND2_3 } & \text { Feverse } & \text { CGCAGCCAAAGAACACGAGAT } \\ & \text { Reverse } & \text { TTTCTTGTCGTTGCTGCTCACT } \\ \text { GATA2_4 } & \text { Forward } & \text { AACGTGTCCCGAGCTTAGATTC } \\ & \text { Reverse } & \text { GGTCACTACATCAGCACAATCCT } \\ \text { GATA2_S } & \text { Forward } & \text { GGCTTACAGGGTAGGAGCTG } \\ & \text { Reverse } & \text { TTCATGTCTGTGCAGGAGTCG } \\ \text { GATA2_M } & \text { Forward } & \text { GAACAGCAGGAGCCGAGAG } \\ & \text { Reverse } & \text { TCCACTGGGTCAAGCACAG } \\ \text { GATA2_L } & \text { Forward } & \text { TGGAGTAGAGCTGGGAGCA } \\ & \text { Reverse } & \text { CCCACCAGGCGGACAAA }\end{array}$

Expanded View Figure legends

Supplementary figure 1: Both RNA and DNA are required for NONO distribution in Hela cells

(A) Fluorescence micrograph images of representative cells treated with 0, 5, 7.5 or 10\% 1,6 hexanediol. DAPI (blue) stain indicates cell nuclei and NONO immunofluorescence (green). (B) Dot plot of SumGreen per nucleus at different concentrations of 1,6 hexanediol in (A). Bars are SD. (C) Fluorescence micrograph images of representative cells treated with PBS, RNase A or DNase I and stained for NONO. (D) Dot plot of SumGreen per nucleus in (C). Bars are $\mathrm{SD} . * * * \mathrm{P}<0.001$.

\section{Supplementary figure 2: Two single mutants of NONO play roles in dimerization}

(A) Representative Western blot images of YFP fused NONO_WT and NONO_ $\triangle$ RRM1 proteins in KELLY cells. (B) Fluorescence micrograph images of representative KELLY cells stained for NONO and NEAT1_2 after transfection with YFP fused NONO_R256I and NONO_F257I exogenous protein plasmids. DAPI (blue) stain indicates cell nuclei, YFP fused NONO (green) and NEAT1_2 RNA FISH (red). Scale bar: $5 \mu \mathrm{m}$. (C) The enrichment of mean NONO fluorescence detected within RNA FISH foci is quantitatively determined as a 
ratio relative to mean nuclear NONO fluorescence in (B). Bars are SD. (D) Fluorescence micrograph images of representative HeLa cells stained for NONO and NEAT1_2 after transfection with YFP fused NONO_WT, NONO__RRM1, NONO_R256I and NONO_F257I exogenous protein plasmids. DAPI (blue) stain indicates cell nuclei, YFP fused NONO (green) and NEAT1_2 RNA FISH (red). Scale bar: $5 \mu \mathrm{m}$. (E) The enrichment of mean NONO fluorescence detected within RNA FISH foci is quantitatively determined as a ratio relative to mean nuclear NONO fluorescence in (D). Bars are SD. ***p<0.001. (F) Representative Western blot images of SFPQ protein in pre-GFP-trap lysate samples and GFP-trapped samples transfected with YFP fused NONO_WT, NONO_ARRM1, NONO_R256I, NONO_F257I and NONO_Y267A/W271A exogenous protein plasmids in KELLY and HeLa cells.

\section{Supplementary figure 3: NONO KD induces significant changes in ATSS and A3 in KELLY cells}

(A) Box plots showing log fold change for genes which were significantly differentially expressed (padj < 0.1), separated by gene length. (B) Summary of most highly enriched gene ontology categories produced by 'Metascape' analysis of significantly upregulated (LFC >0) and downregulated $(\mathrm{LFC}<0)$ genes following NONO KD. (C) Enrichment score profile plots produced by 'GSEA' for the 'sterol biosynthetic process' and 'chromatin silencing' gene sets respectively. (D) NONO KD results in significant splicing events including ATSS and A3.

(E) Proportions of differentially expressed genes between NONO bound and non-bound target genes.

\section{Supplementary figure 4: NONO function is dependent on DNA binding, which in turn is not sensitive to transcription levels}

(A) NONO ChIP-seq peaks for GATA2 in HepG2 and K562 cell lines shown as a Genome Browser image (Xiao et al., 2019). The primer pairs for GATA2 used in our ChIP-qPCR are indicated. (B) The enrichment of relative GATA2 chromatin fragments via ChIP-qPCR against NONO and normal mouse serum IgG in KELLY cells. Bars are SEM. $n \geq 3$. (C) NONO ChIP-qPCR indicates the enrichment of relative GATA2 chromatin fragments in KELLY cells treated with control, DRB and DRB followed by a washout period. Bars are SEM. $n \geq 3$. (D) The enrichment of relative GATA2 and HAND2 chromatin fragments after NONO KD via ChIP-qPCR against RNA PolII phosphorated at Serine 2 in KELLY cells. Bars are SEM. $n \geq 3$. (E) Fluorescence micrograph images of representative cells stained for 
NONO and RNA PolII phosphorated at Serine 2. DAPI (blue) stain indicates cell nuclei, NONO immunofluorescence (green) and immunofluorescence (red) for Pol II pSer2. Scale bar: $5 \mu \mathrm{m}$. (F) In micrograph image quantitation analysis, the enrichment of mean NONO fluorescence detected within immunofluorescence foci of Pol II pSer2 is determined as a ratio relative to mean nuclear NONO fluorescence in (E). Bars are SD. 
A

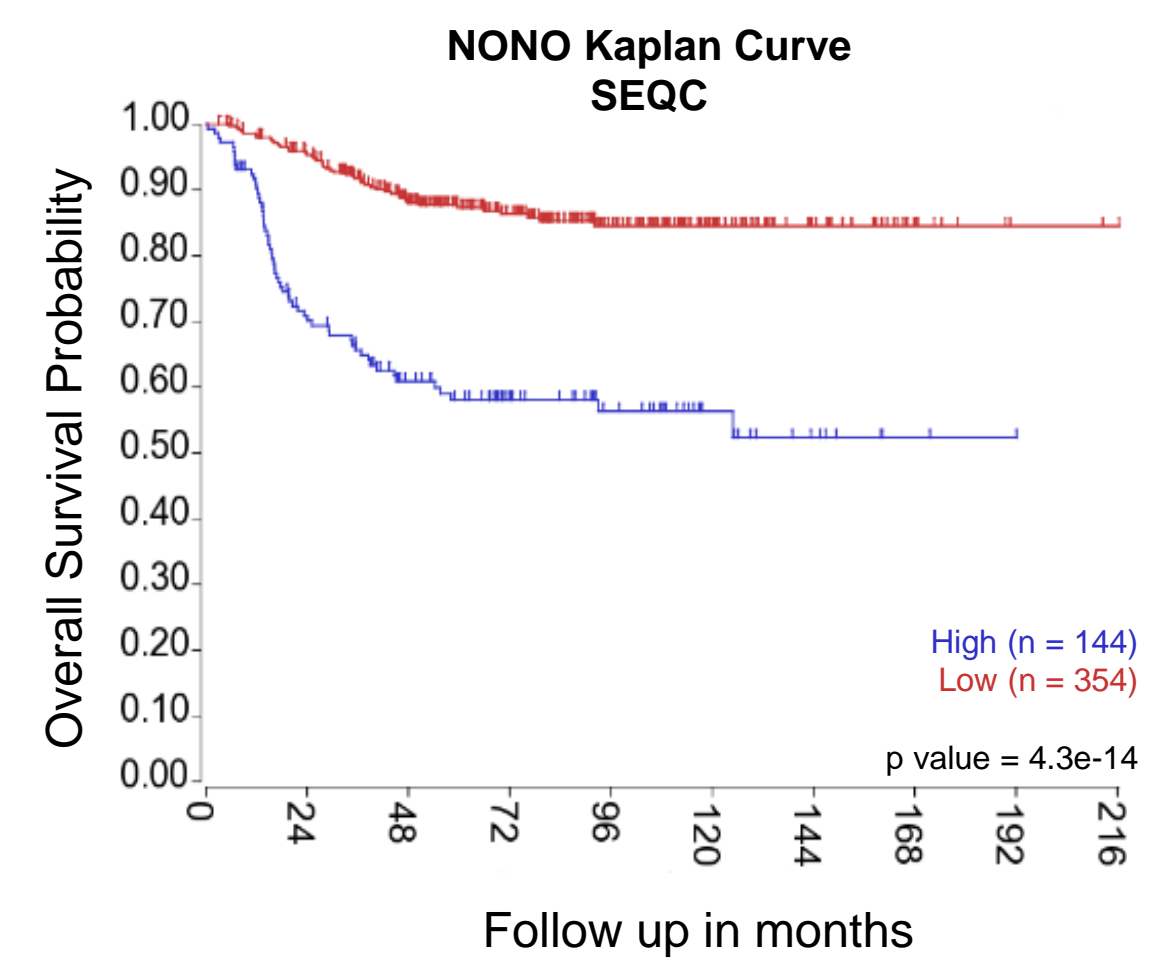

C

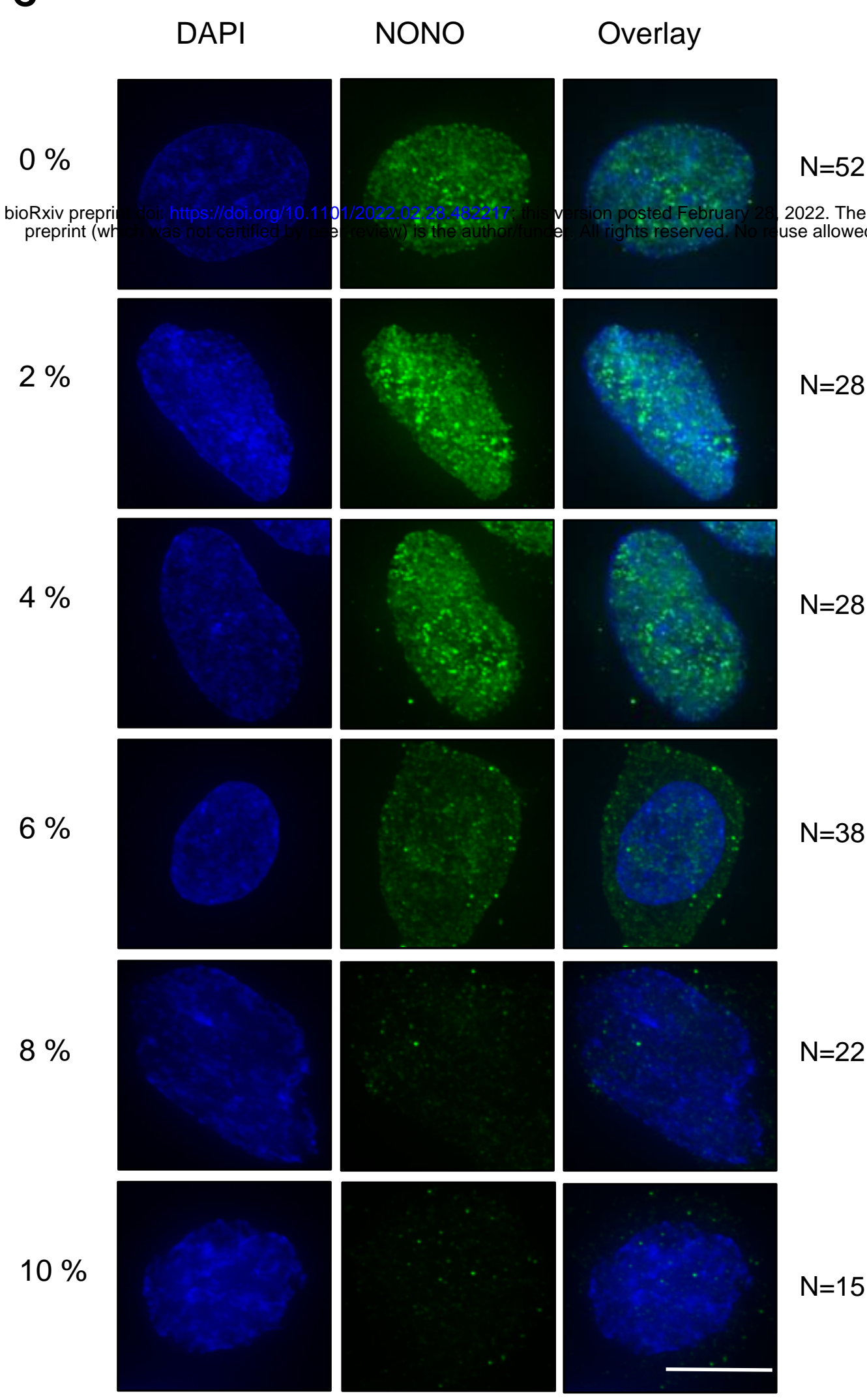

D

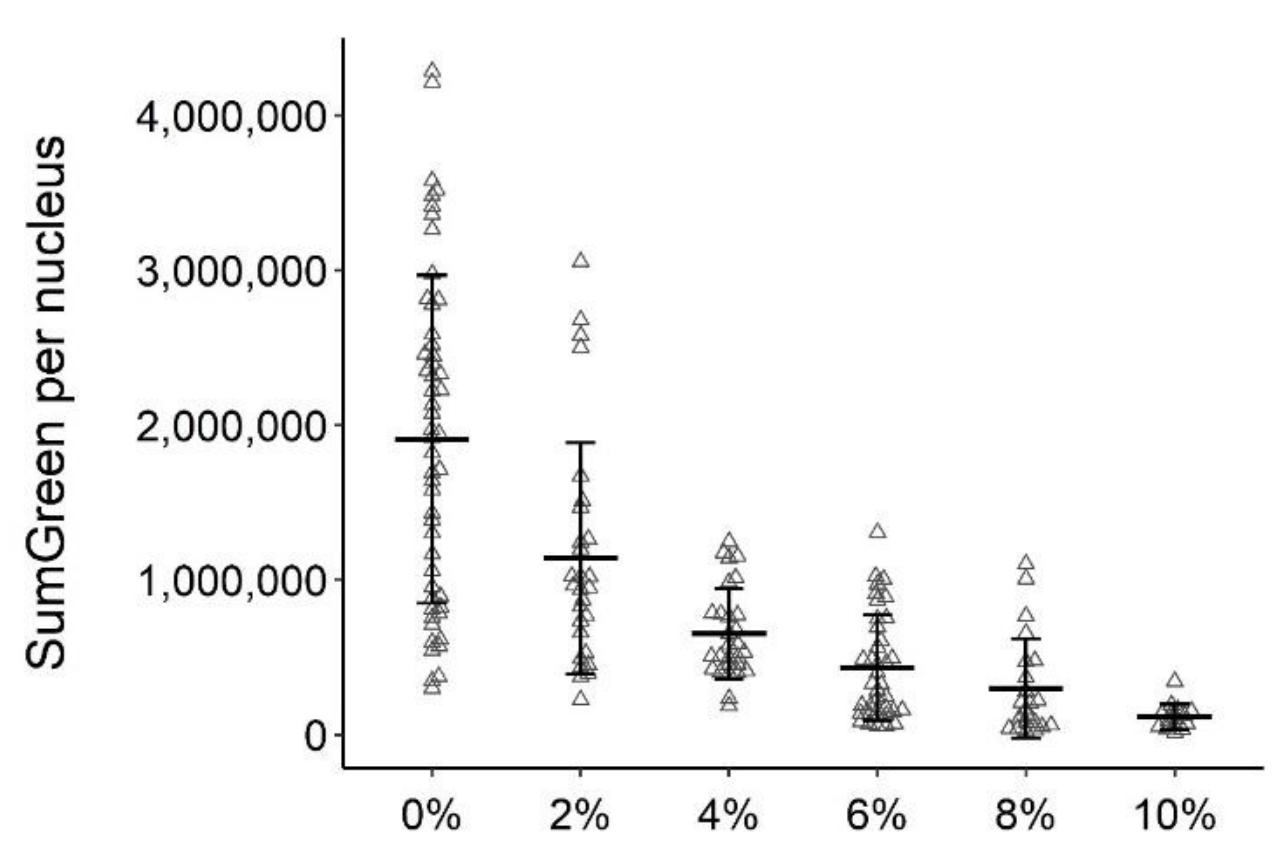

$N=28$

$=38$

$=22$

$N=15$
B

DAPI

NONO

NEAT1_2

Overlay

衣
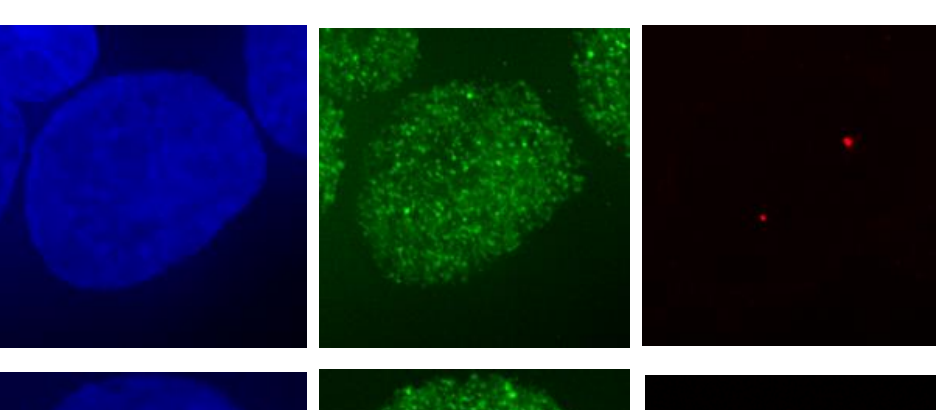

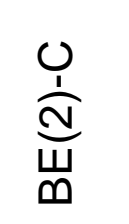
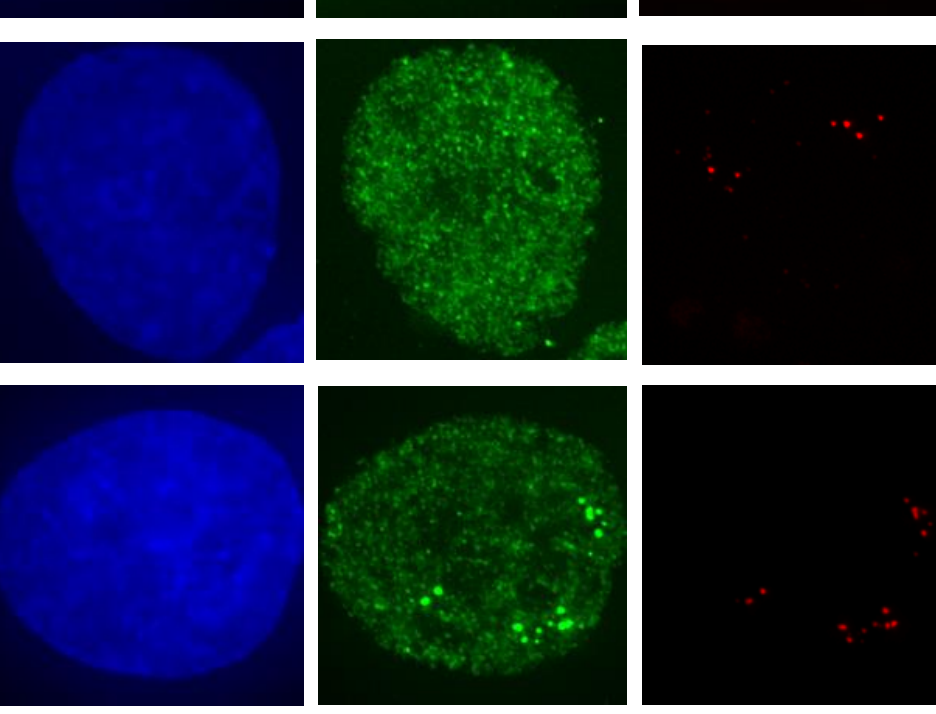

$\frac{\widetilde{J}}{1}$

E
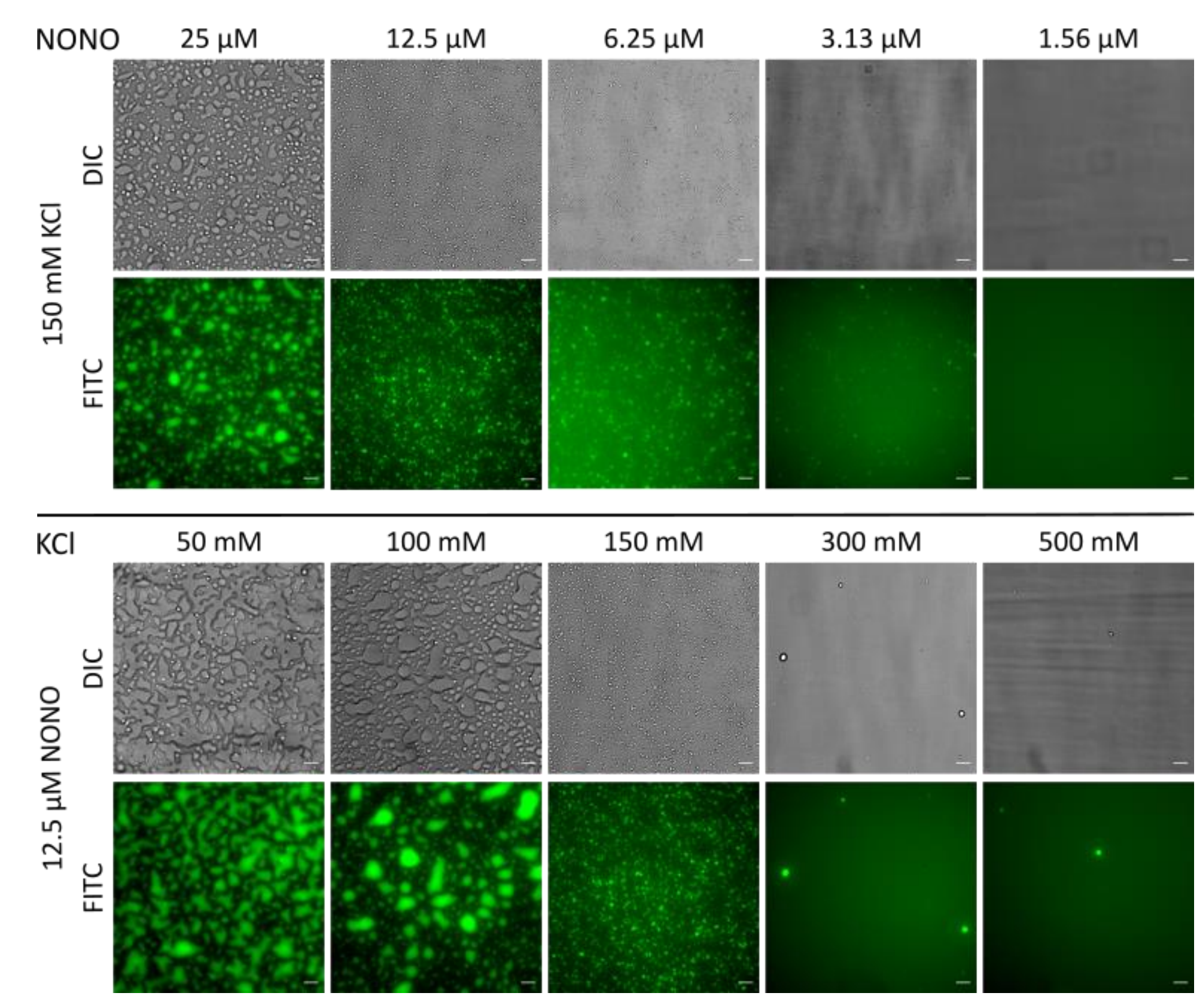

F

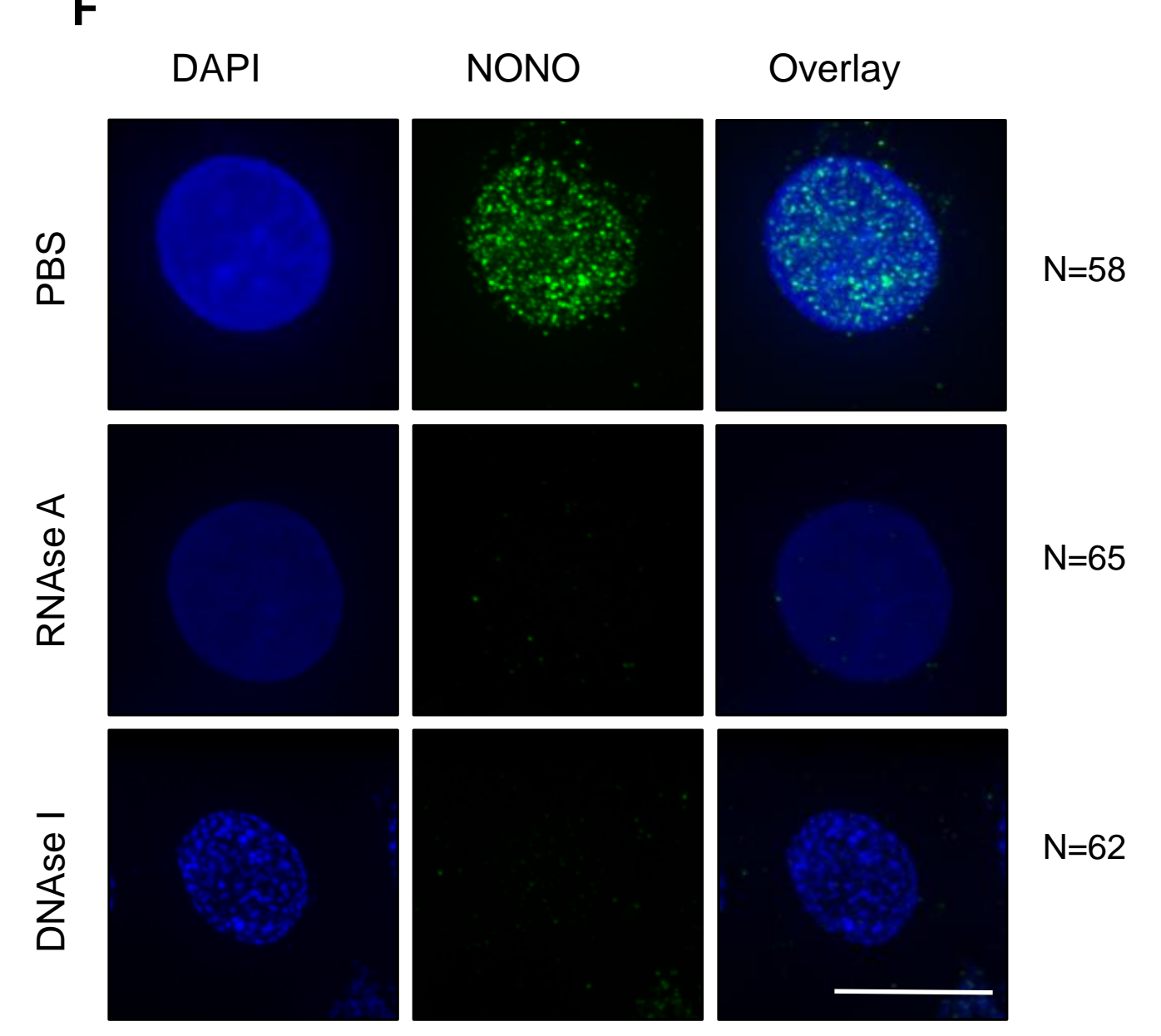

G

$=58$

$\mathrm{N}=62$
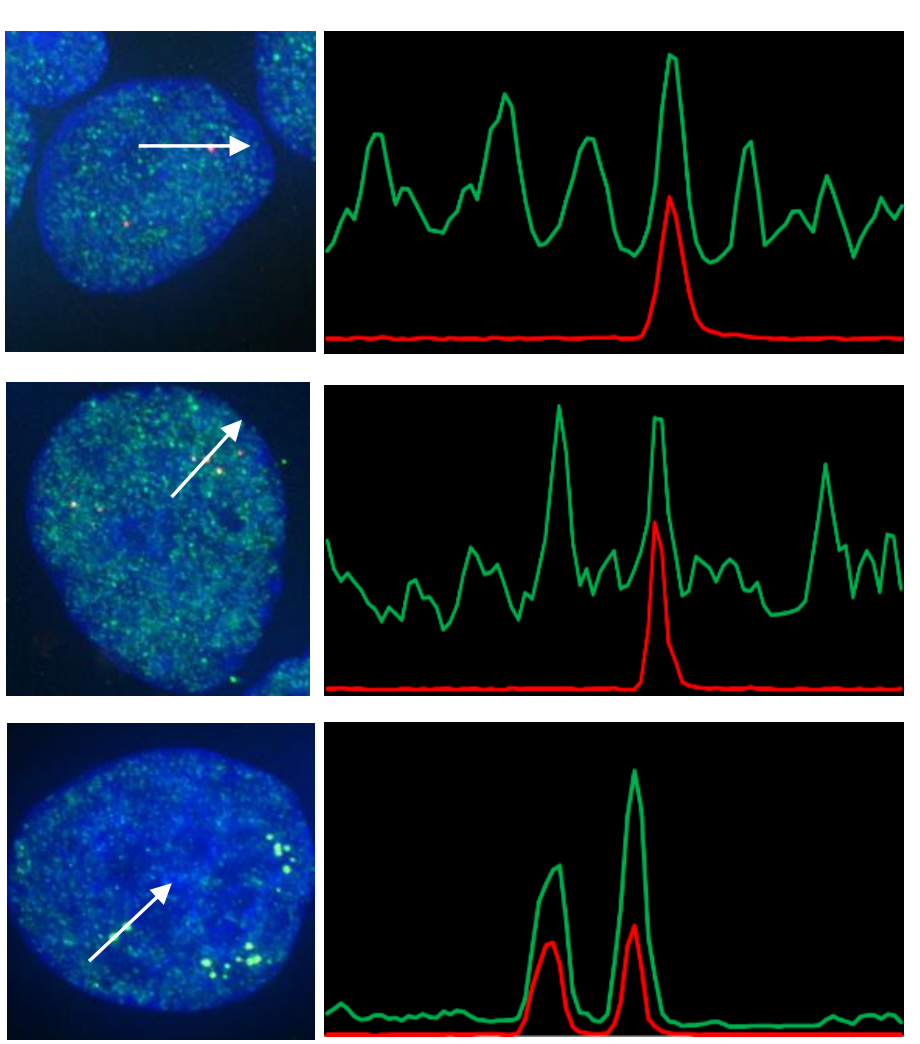

$\mathrm{N}=52$ 2022. The copyright holder for this
We allowed without permission.
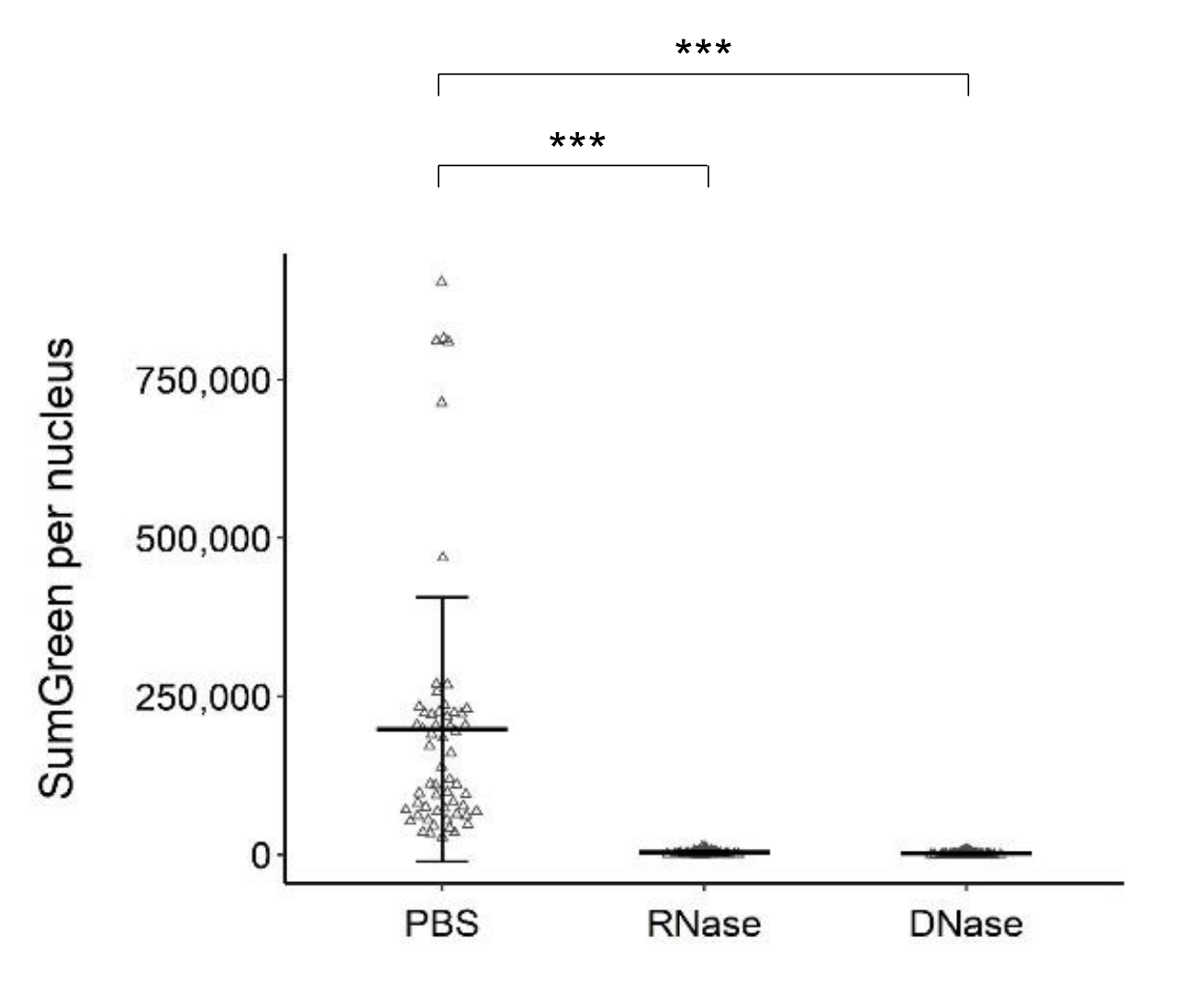

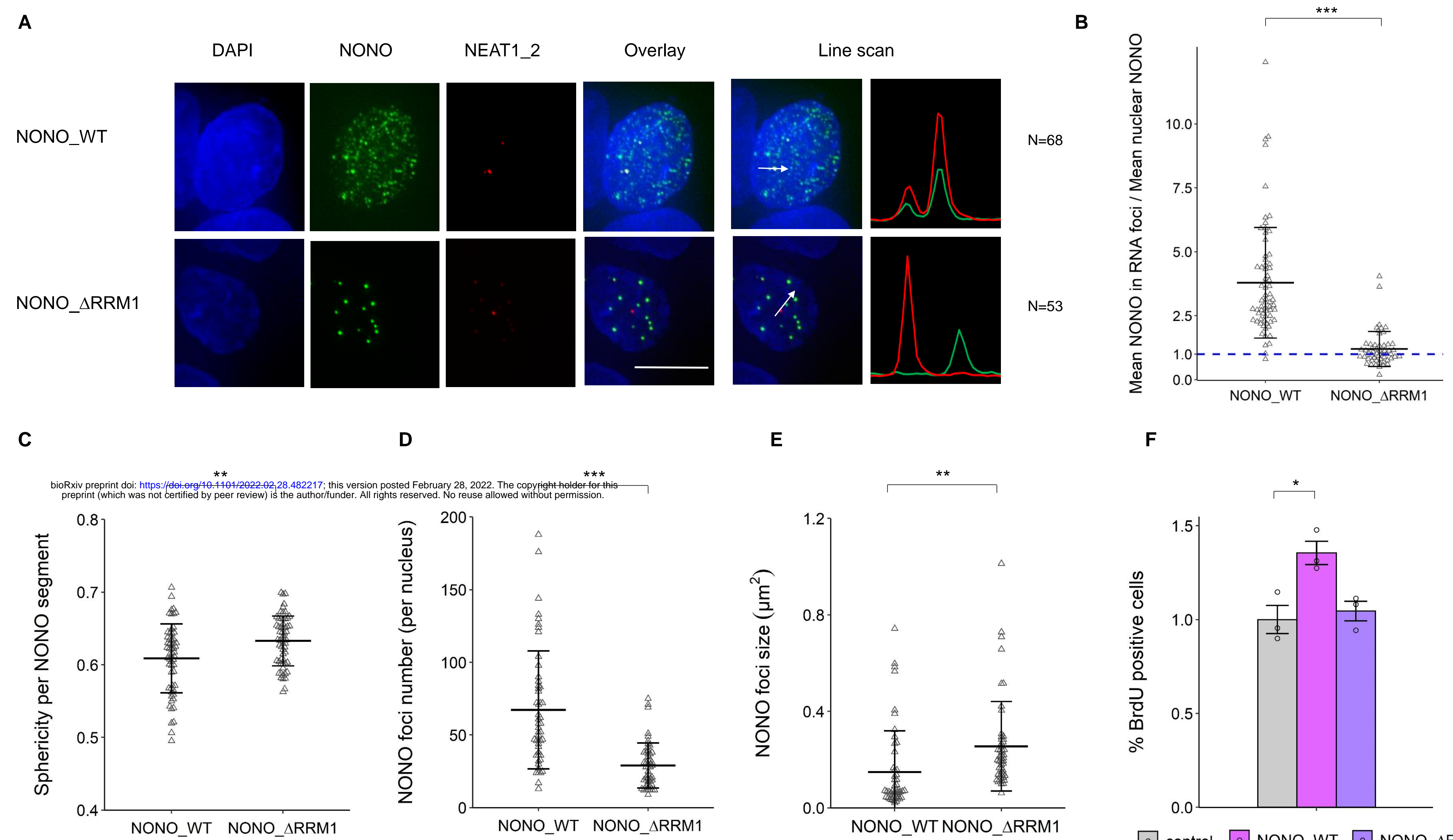

E

$\mathbf{F}$
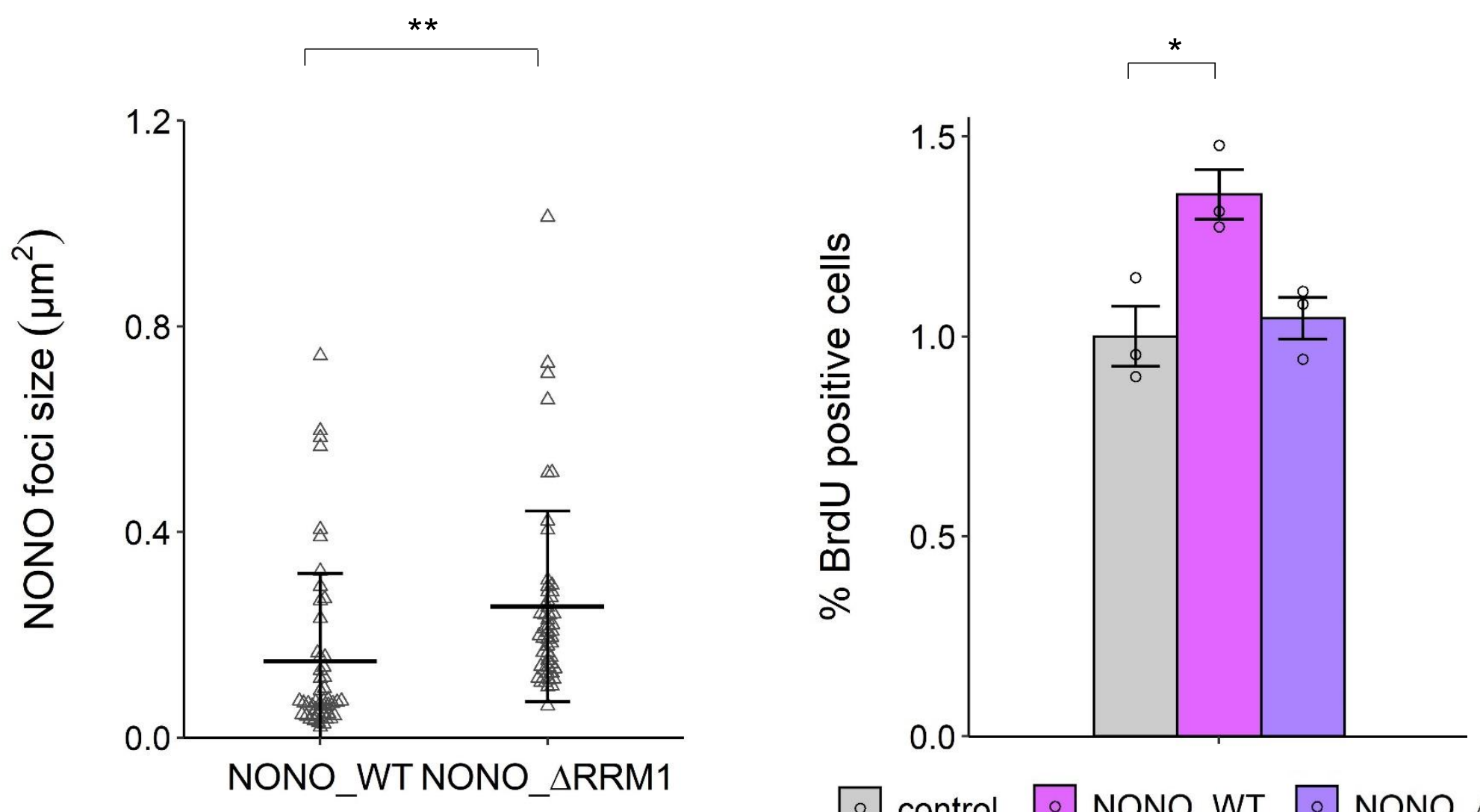

$\square$ control $\square$ NONO_WT $\square$ NONO_ARRM1

G

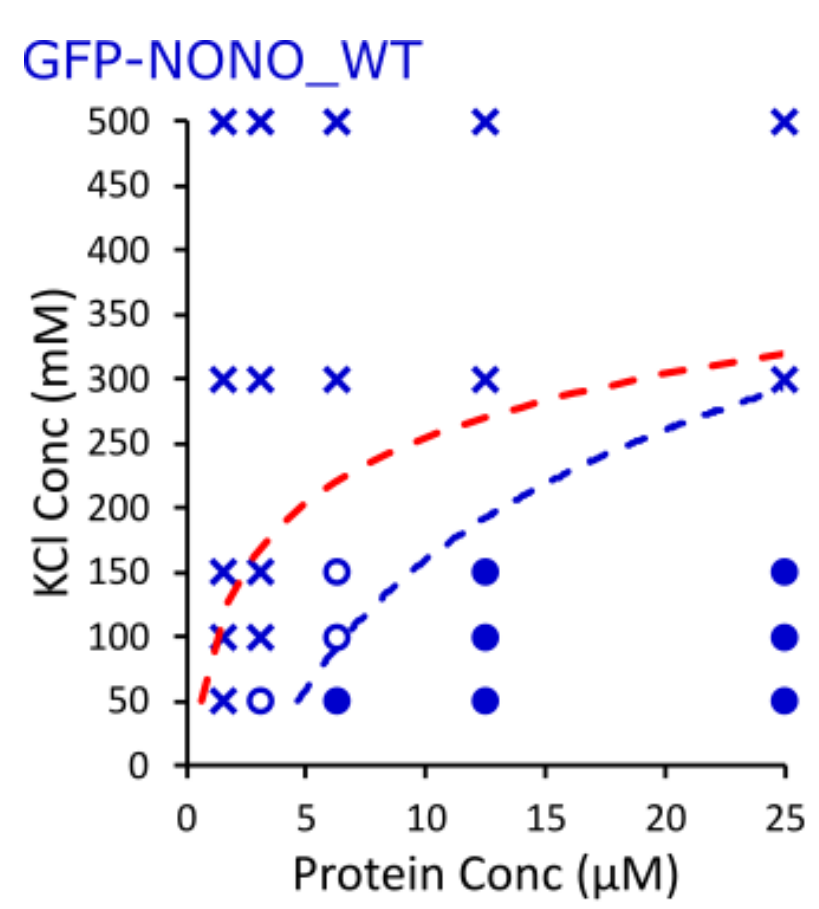

- phase

- separation
GFP-NONO_ARRM1

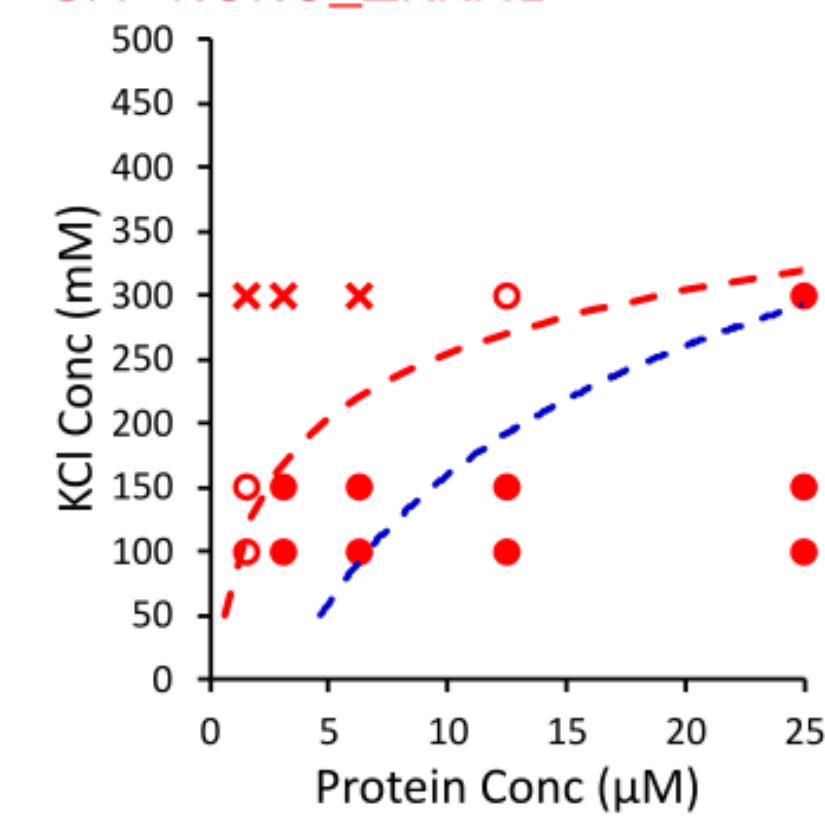

- minor phase

o separation

$x$ no phase

$x$ separation

- - - binodal for GFP-NONO_WT

- - - binodal for GFP-NONO_ARRM1

H
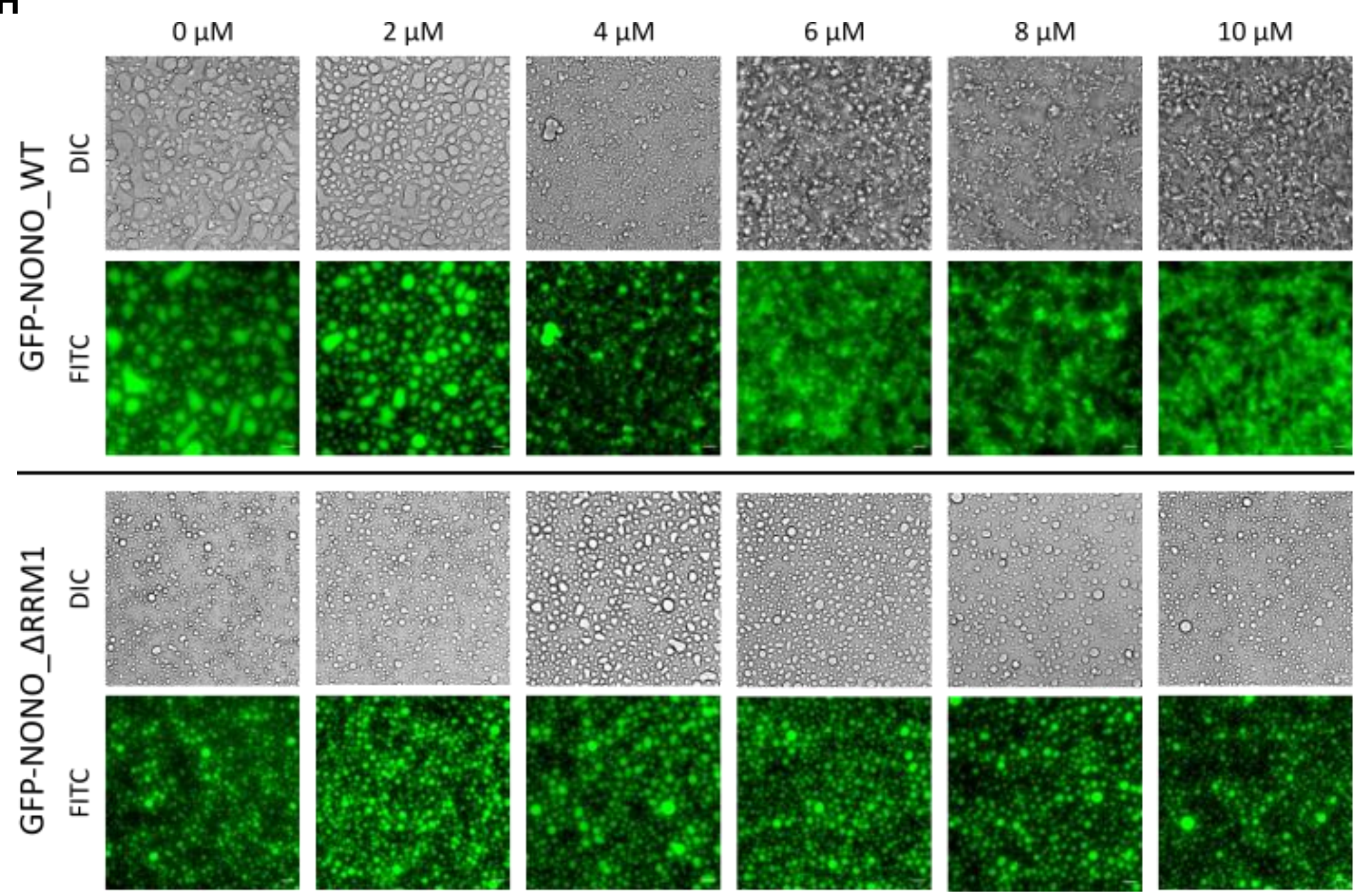
A

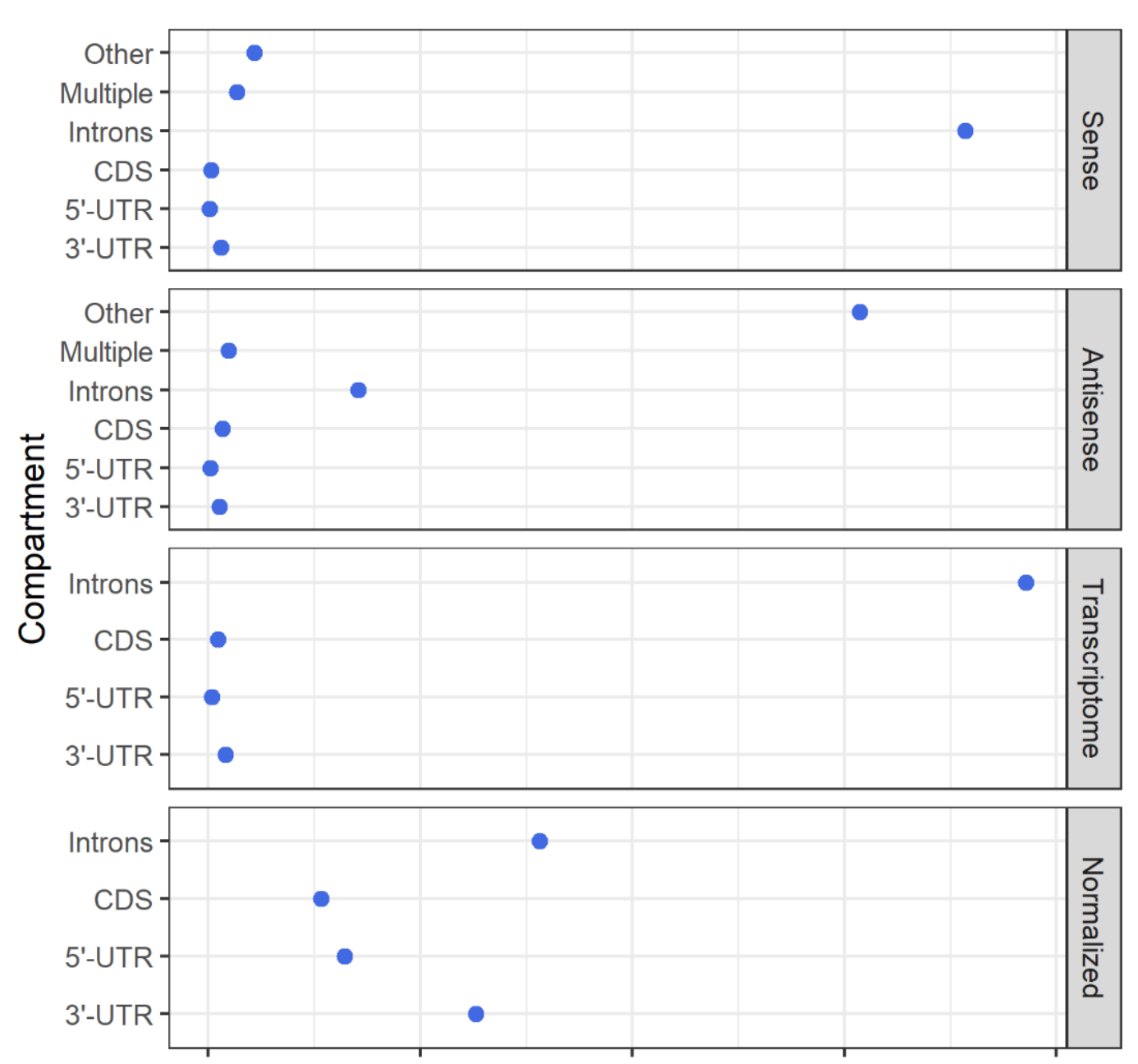

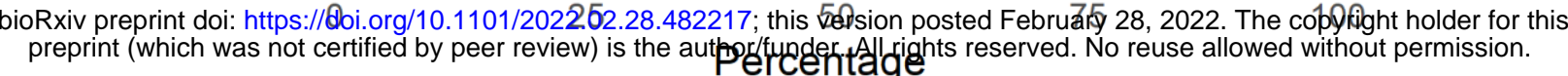

C

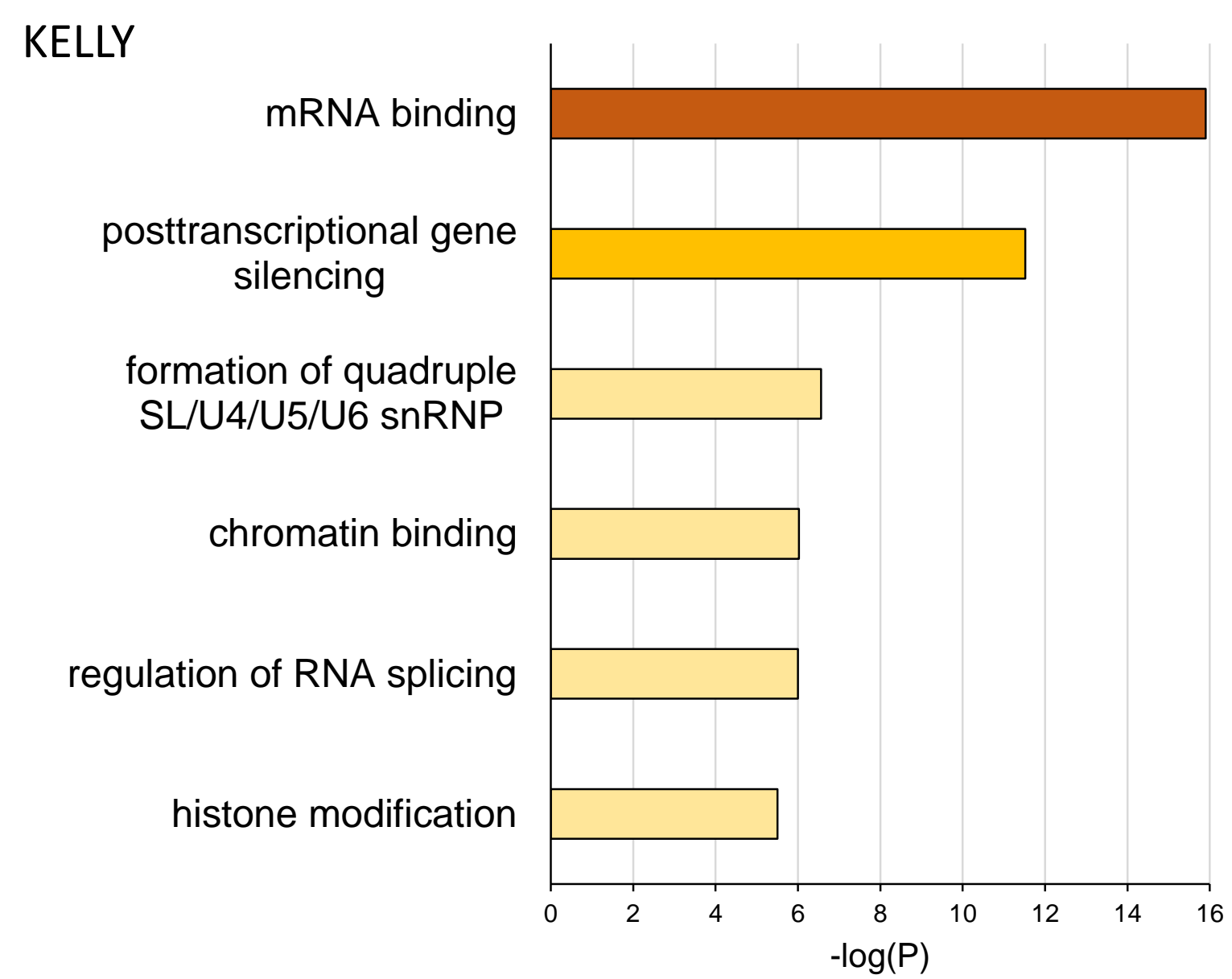

E

\begin{tabular}{llllll}
\hline Gene ID & Gene & TPM & $\%$ & Length (bp) & Gene Type \\
\hline ENSG00000245532 & NEAT1 & 8521 & 1.2 & 22767 & IncRNA \\
ENSG00000251562 & MALAT1 & 6053 & 0.33 & 8829 & IncRNA \\
ENSG00000164107 & HAND2 & 2671 & 0.09 & 5261 & mRNA \\
ENSG00000134323 & MYCN & 1956 & 0.08 & 6458 & mRNA \\
ENSG000000071626 & DAZAP1 & 1711 & 0.3 & 28119 & mRNA \\
ENSG00000133316 & WDR74 & 1416 & 0.08 & 9468 & mRNA \\
ENSG00000103326 & CAPN15 & 1278 & 0.21 & 26925 & mRNA \\
ENSG00000179348 & GATA2 & 1145 & 0.1 & 13775 & mRNA \\
ENSG00000167244 & IGF2 & 1113 & 0.08 & 12127 & mRNA \\
ENSG00000114554 & PLXNA1 & 1049 & 0.32 & 48799 & mRNA
\end{tabular}

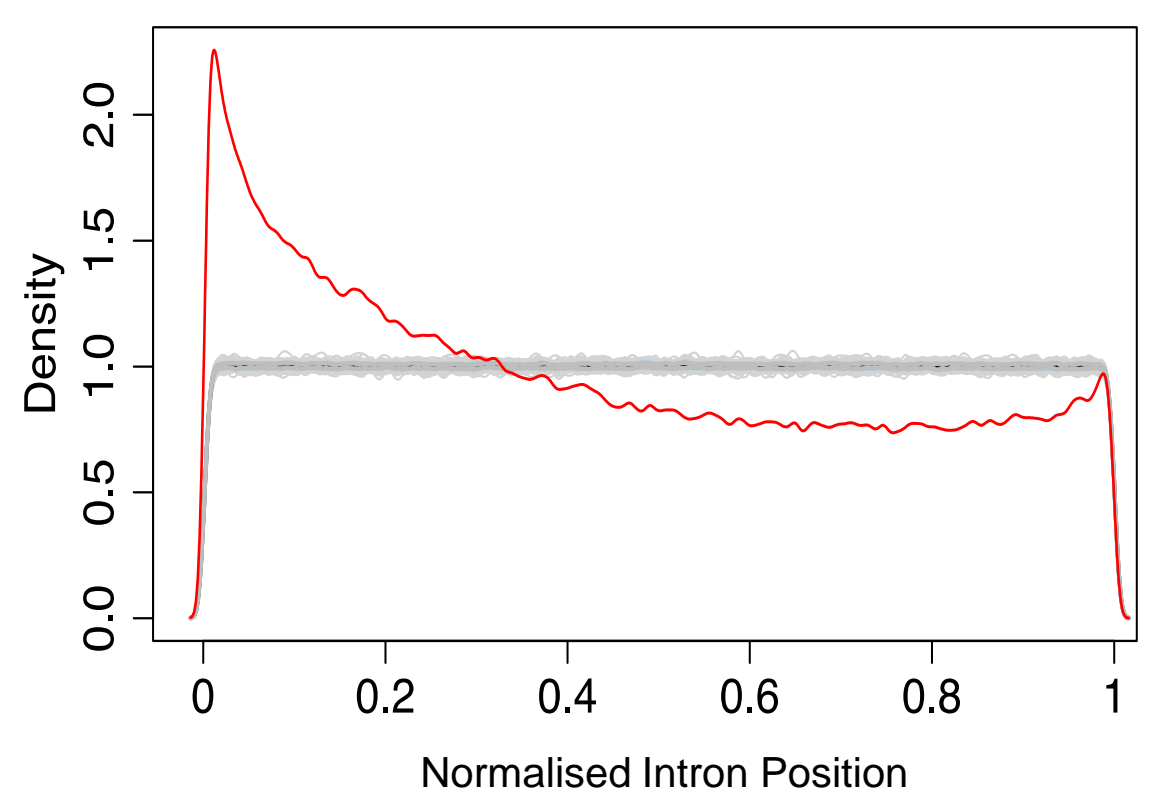

D

$B E(2)-C$

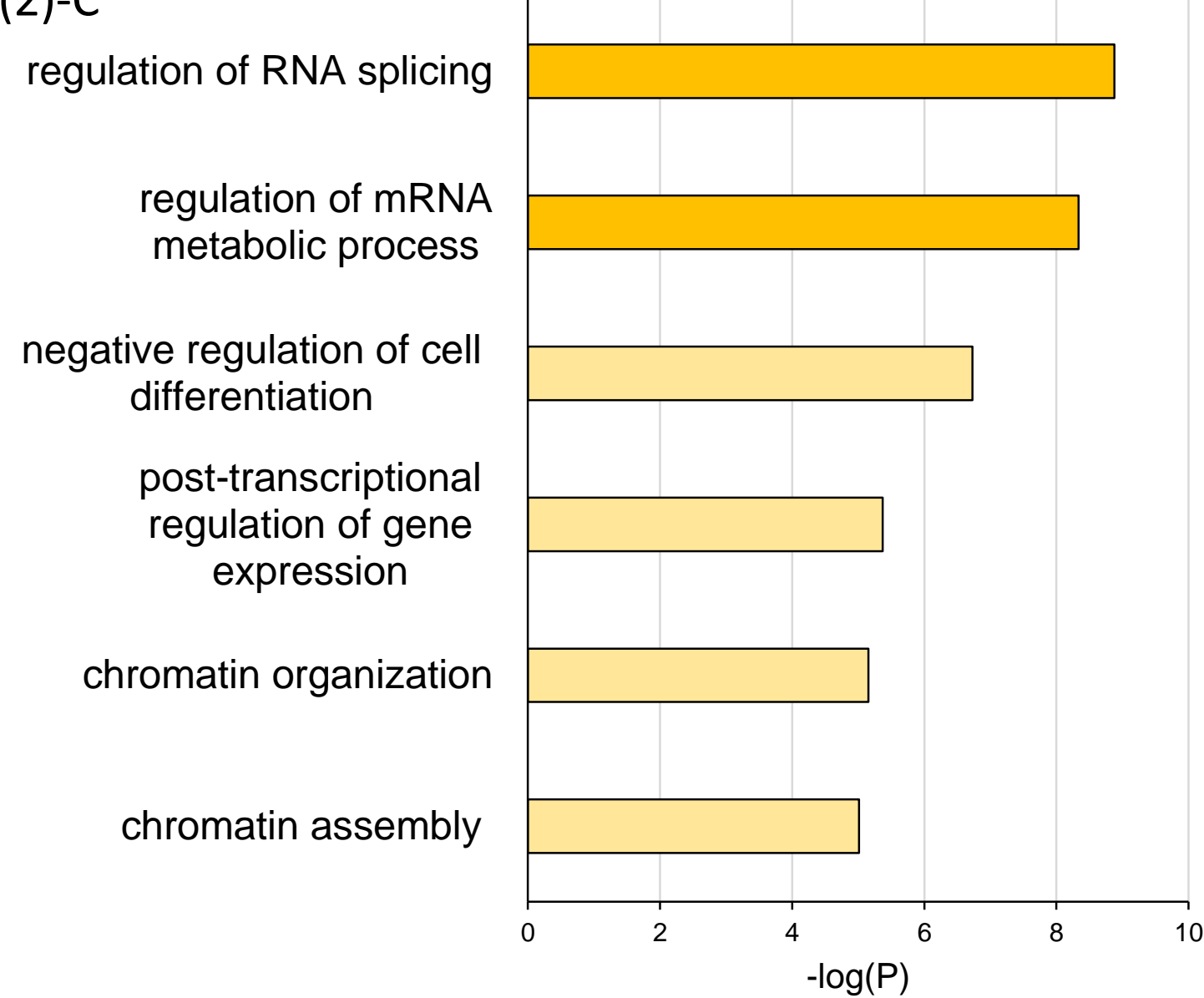

F

\section{NONO coverage}

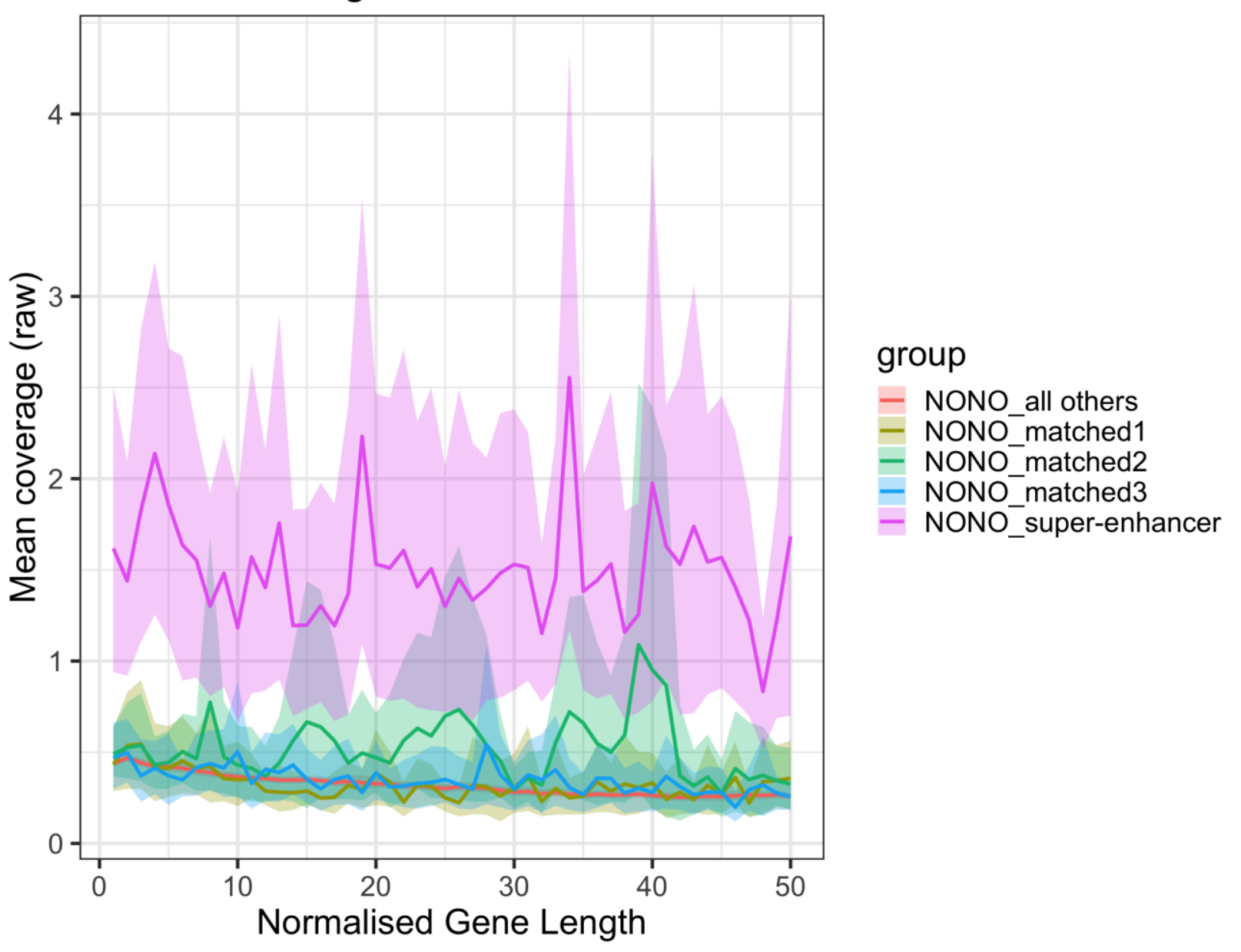


A

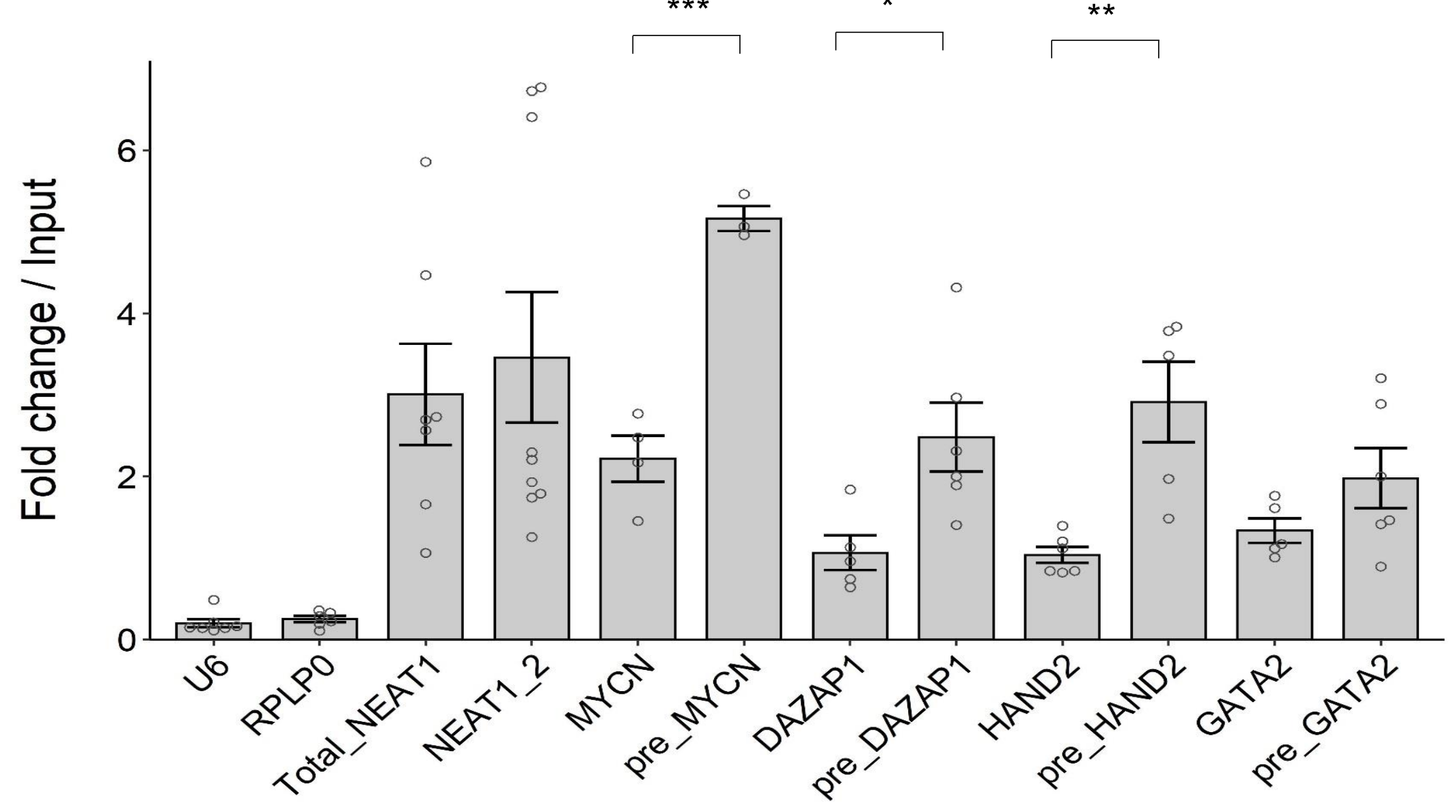

B

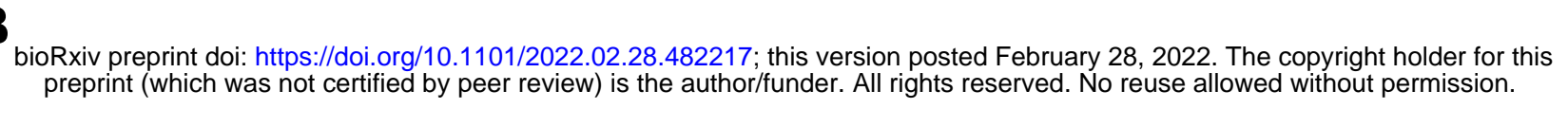

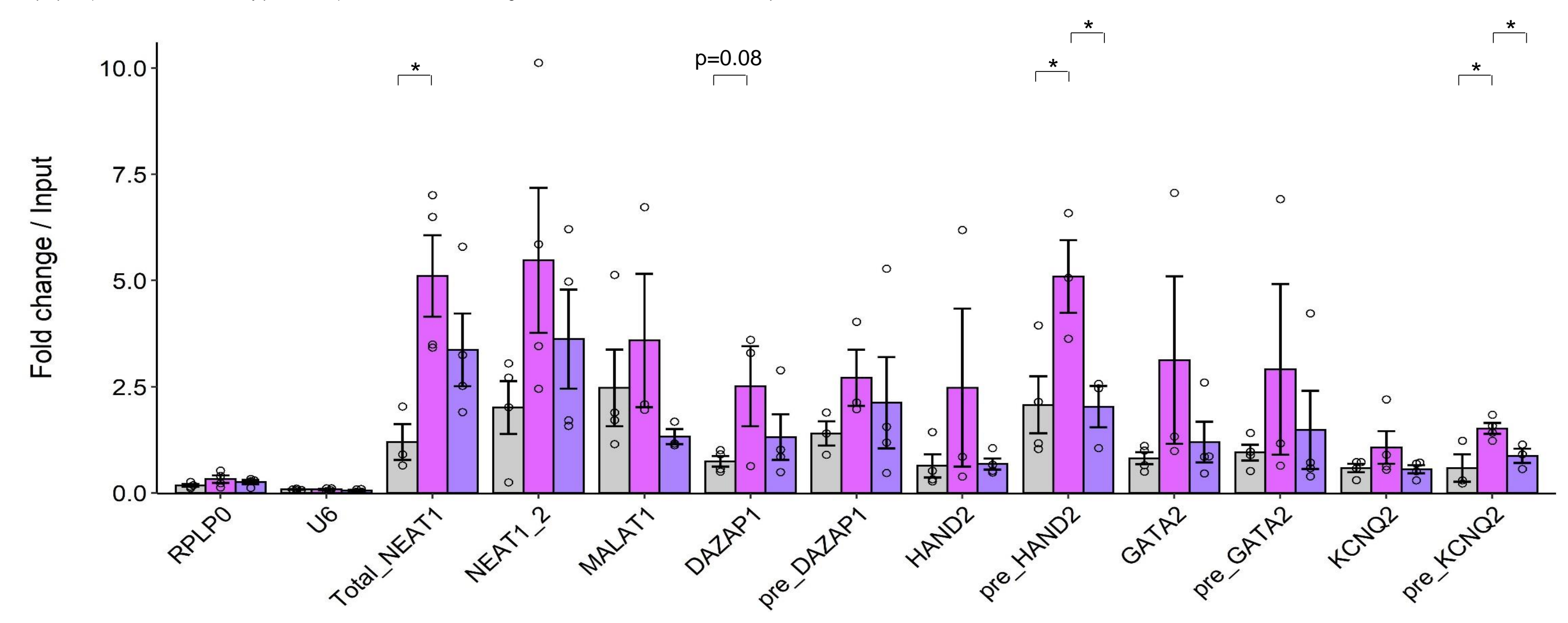

0 siRNA NONO_KD + control

siRNA NONO_KD + NONO_WT

SIRNA NONO_KD + NONO_ARRM1
C

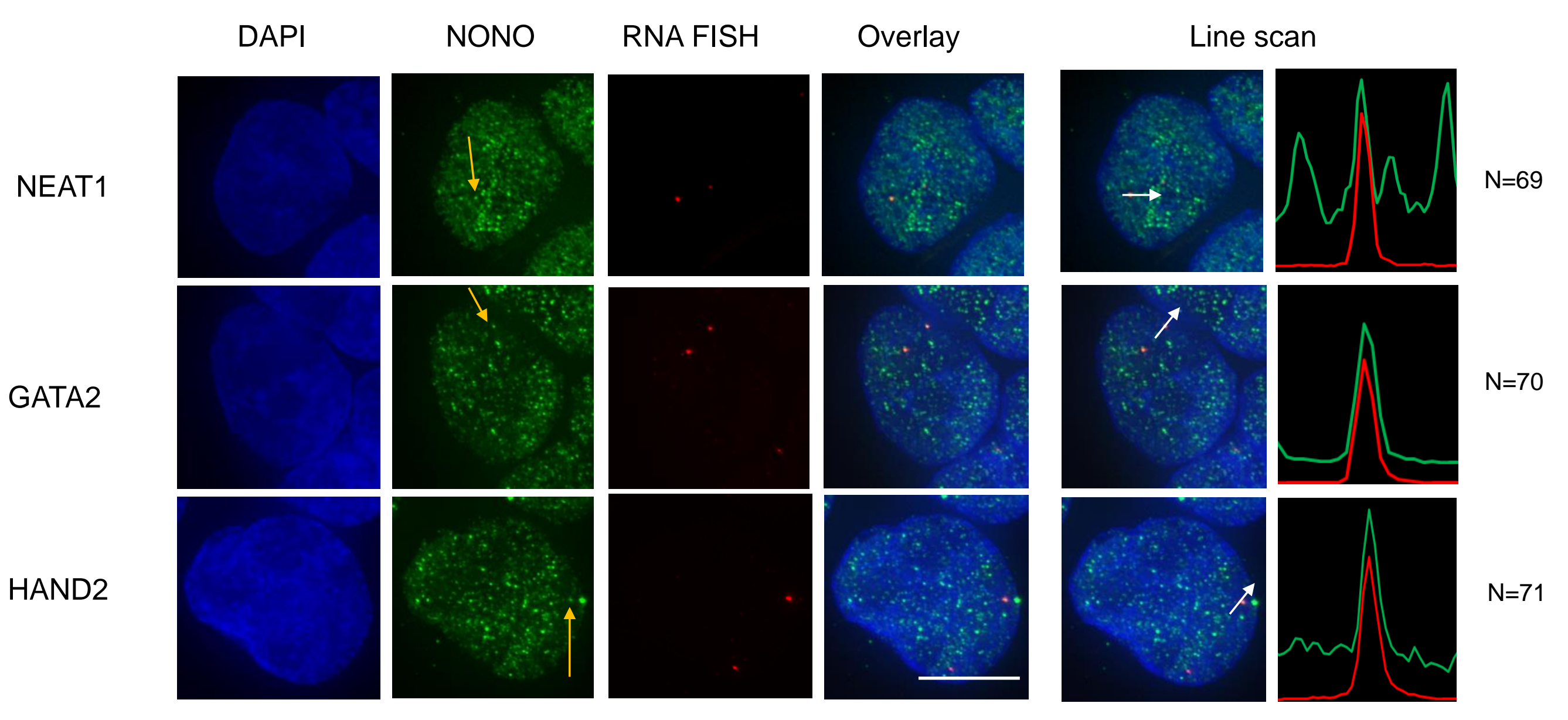

D

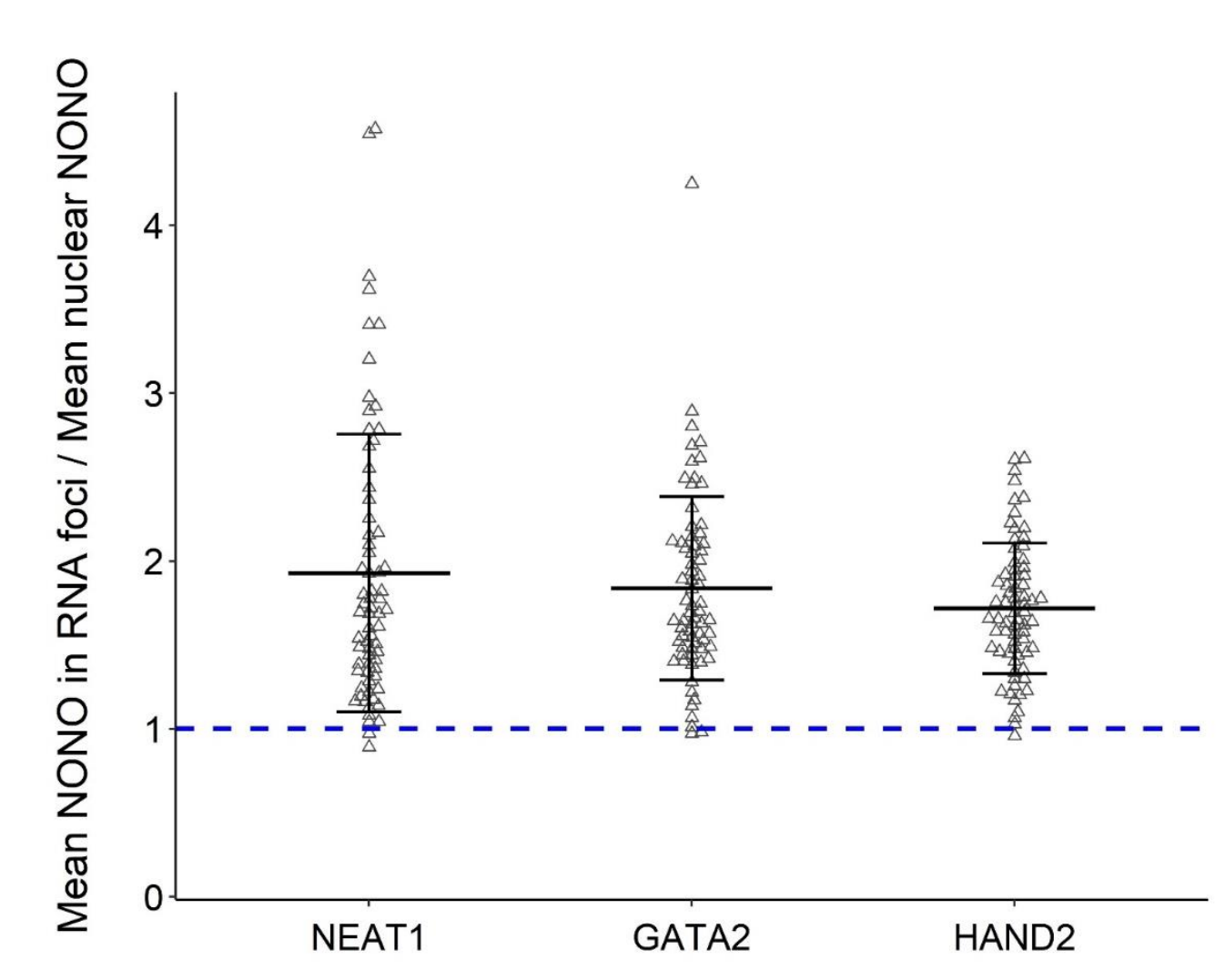


A

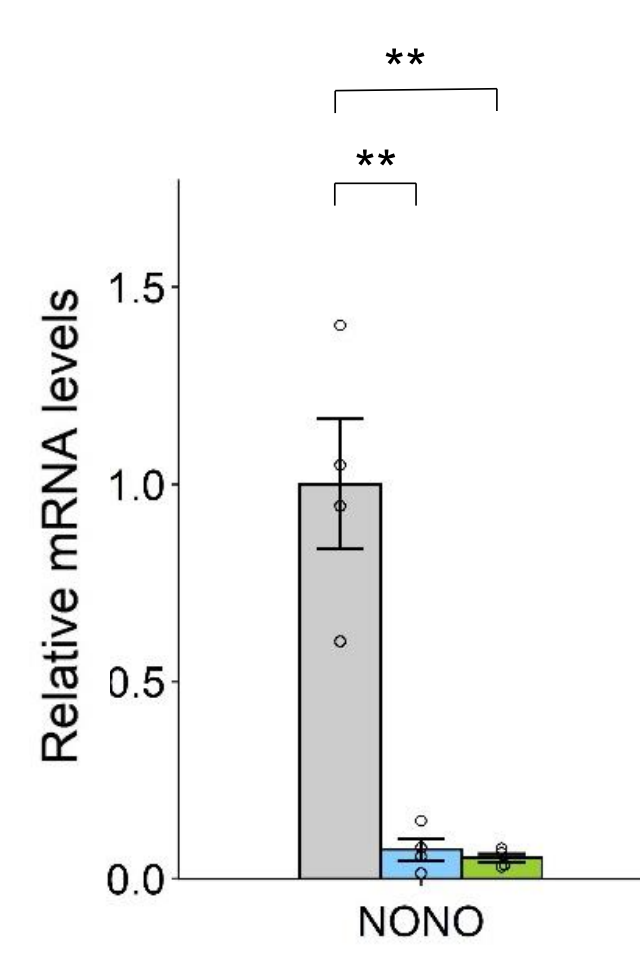

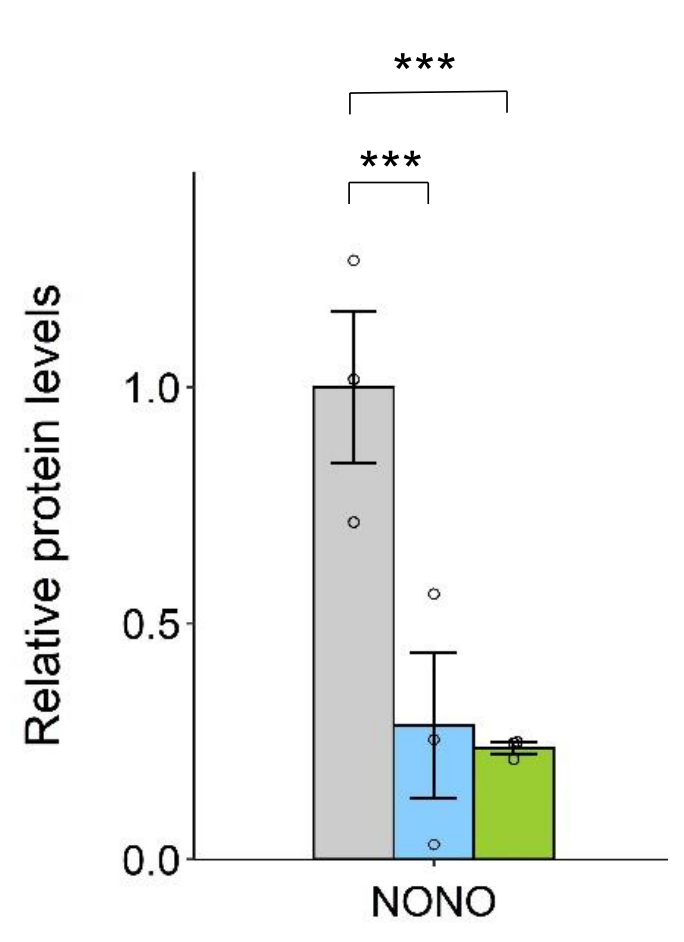

C

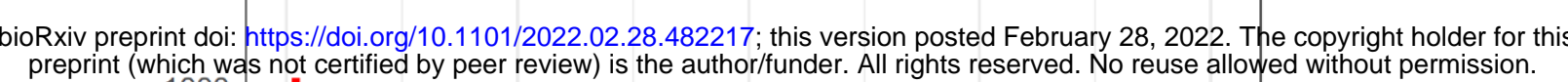
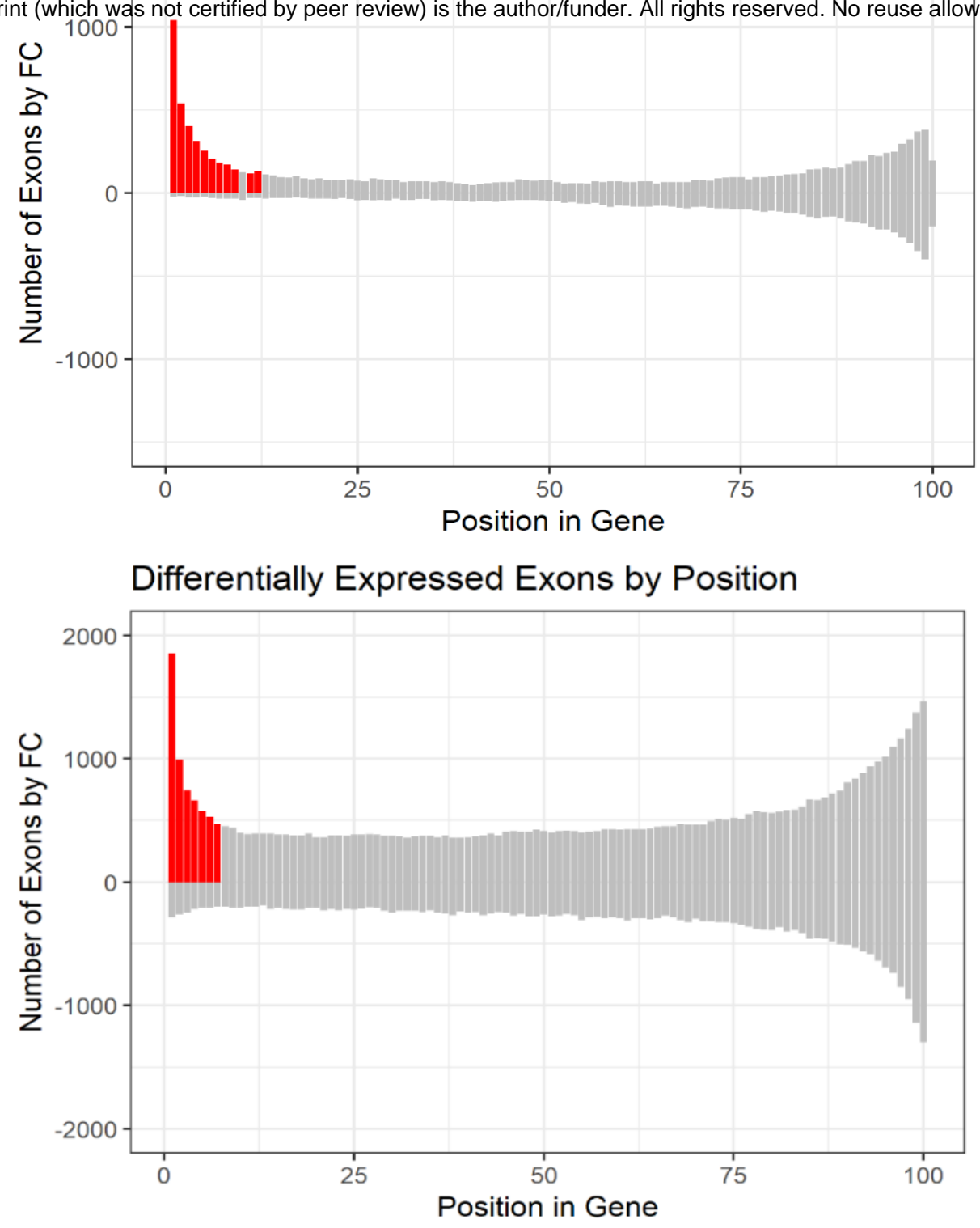

E

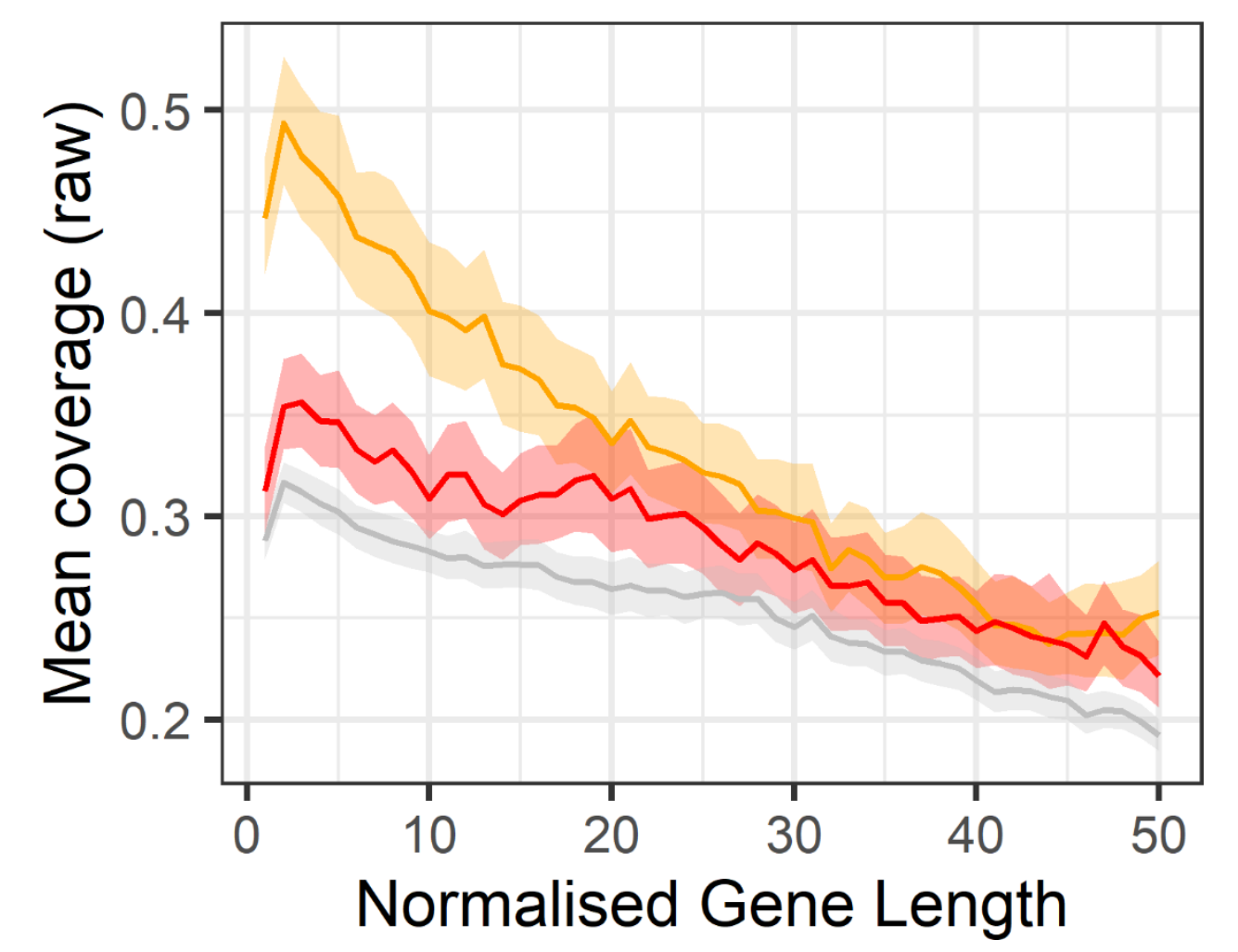

D

F
0 siRNA control

0 siRNA NONO_KD 1

0 siRNA NONO_KD 2
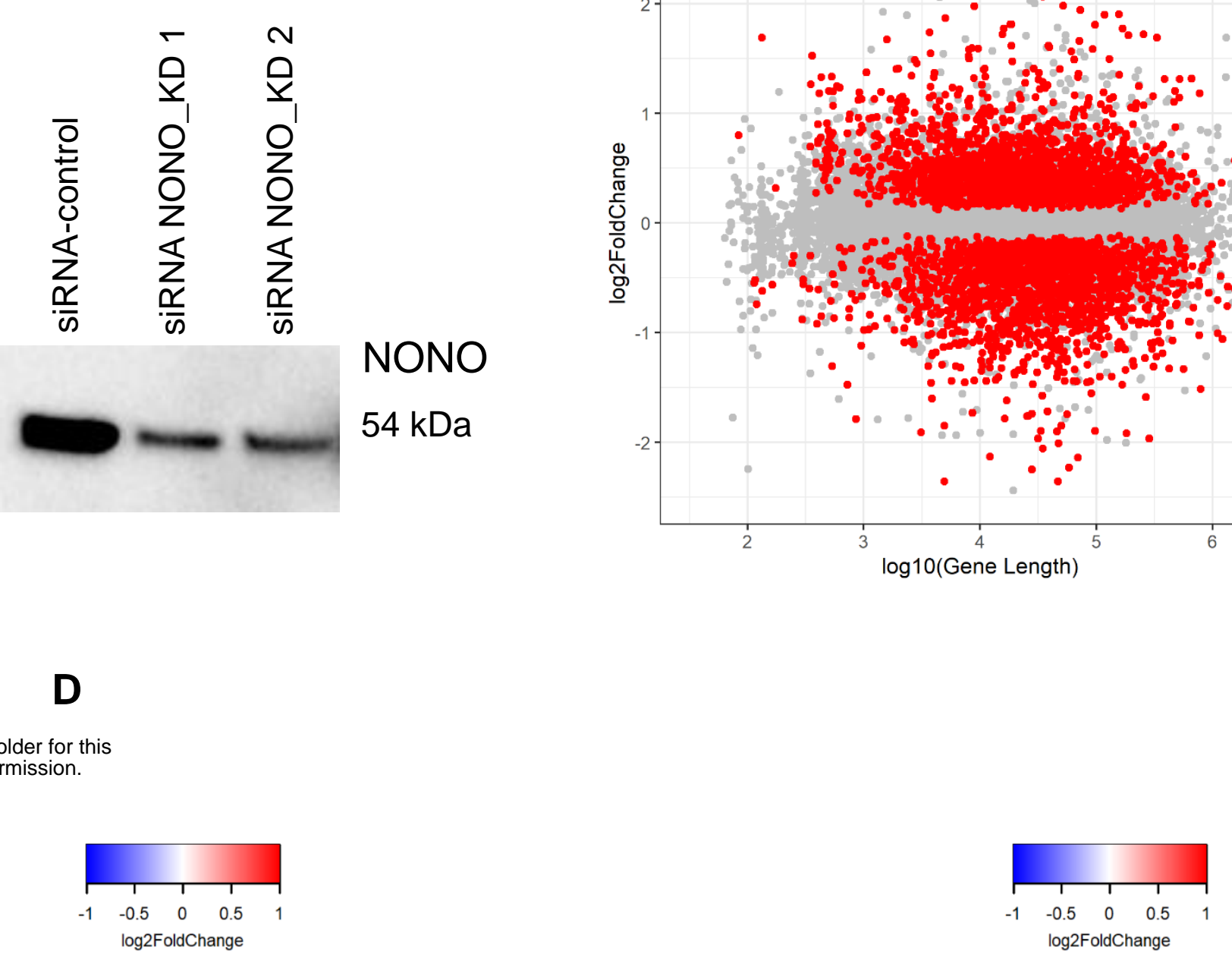

DEXSeq sig, n=2237

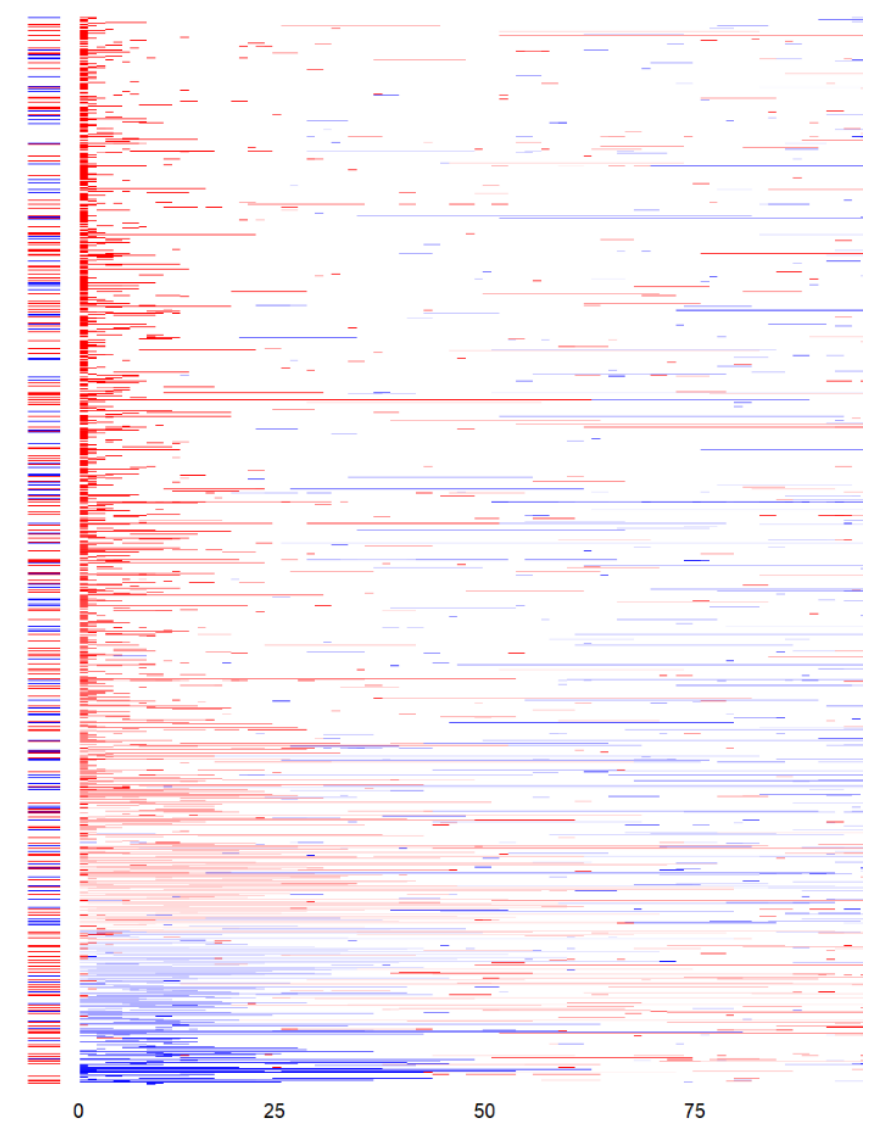

DESeq sig, n=2237
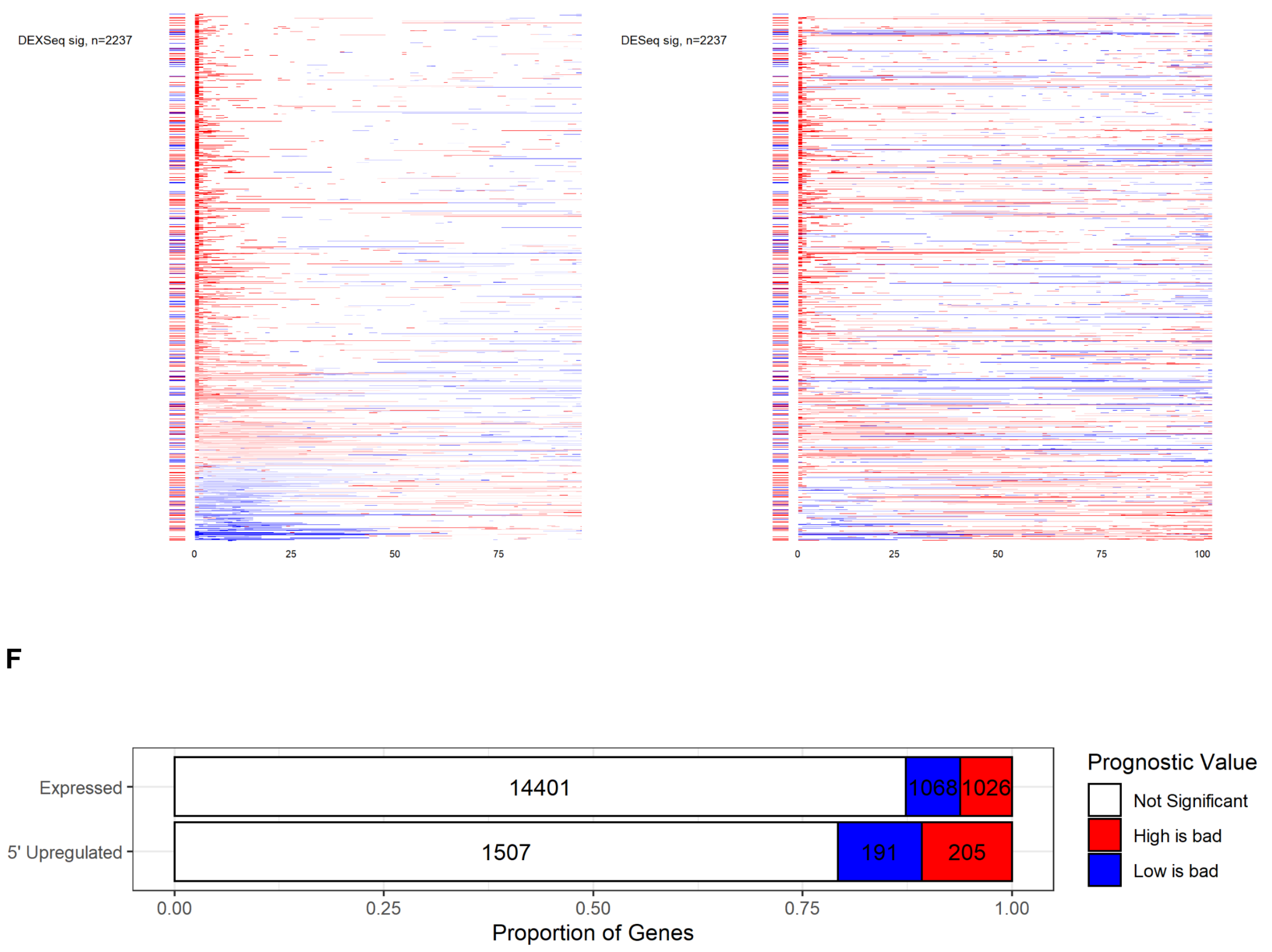

- NONO_5' Upregulated

NONO_Differentially Expressed

NONO_Expressed
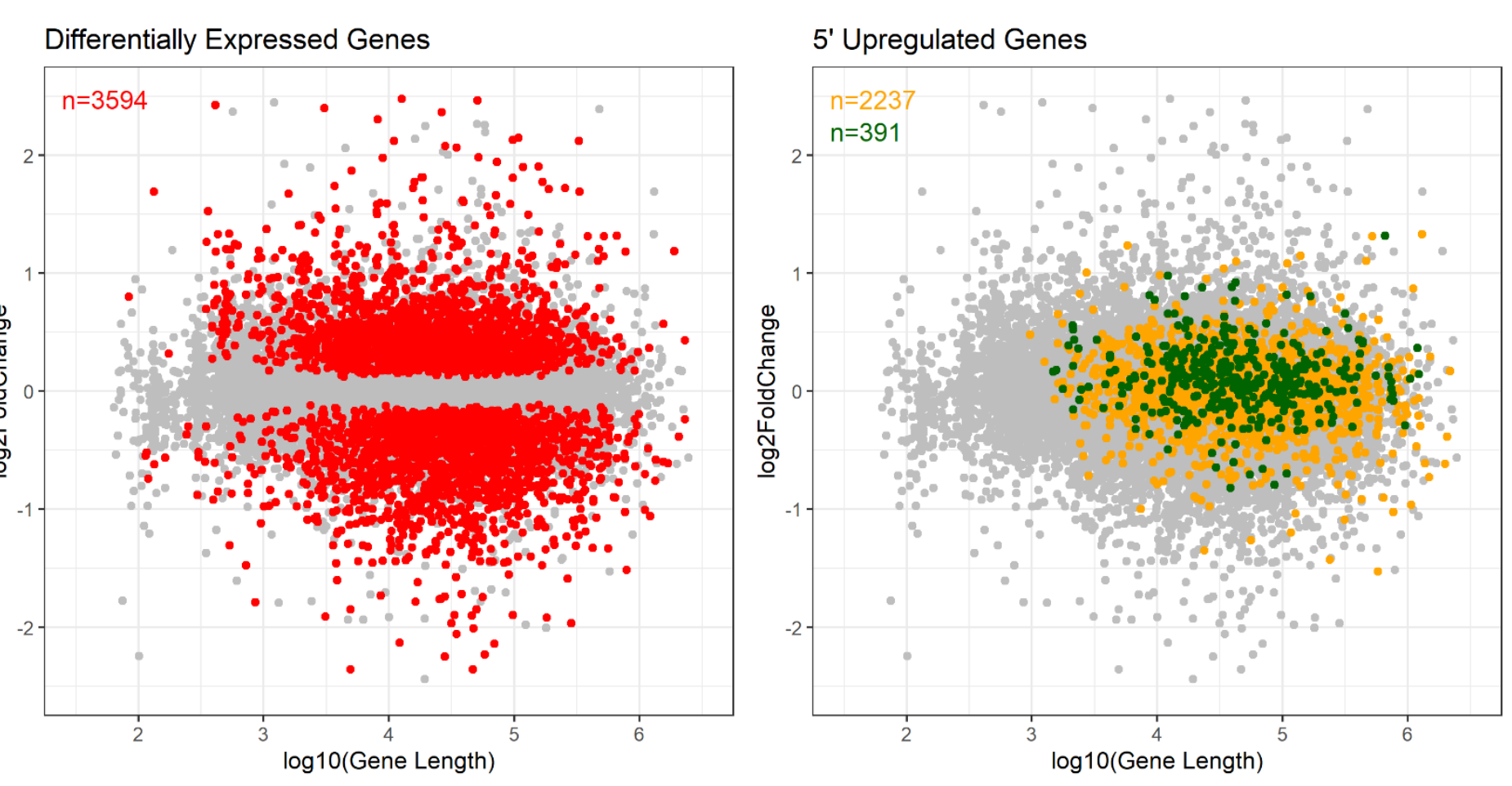
A

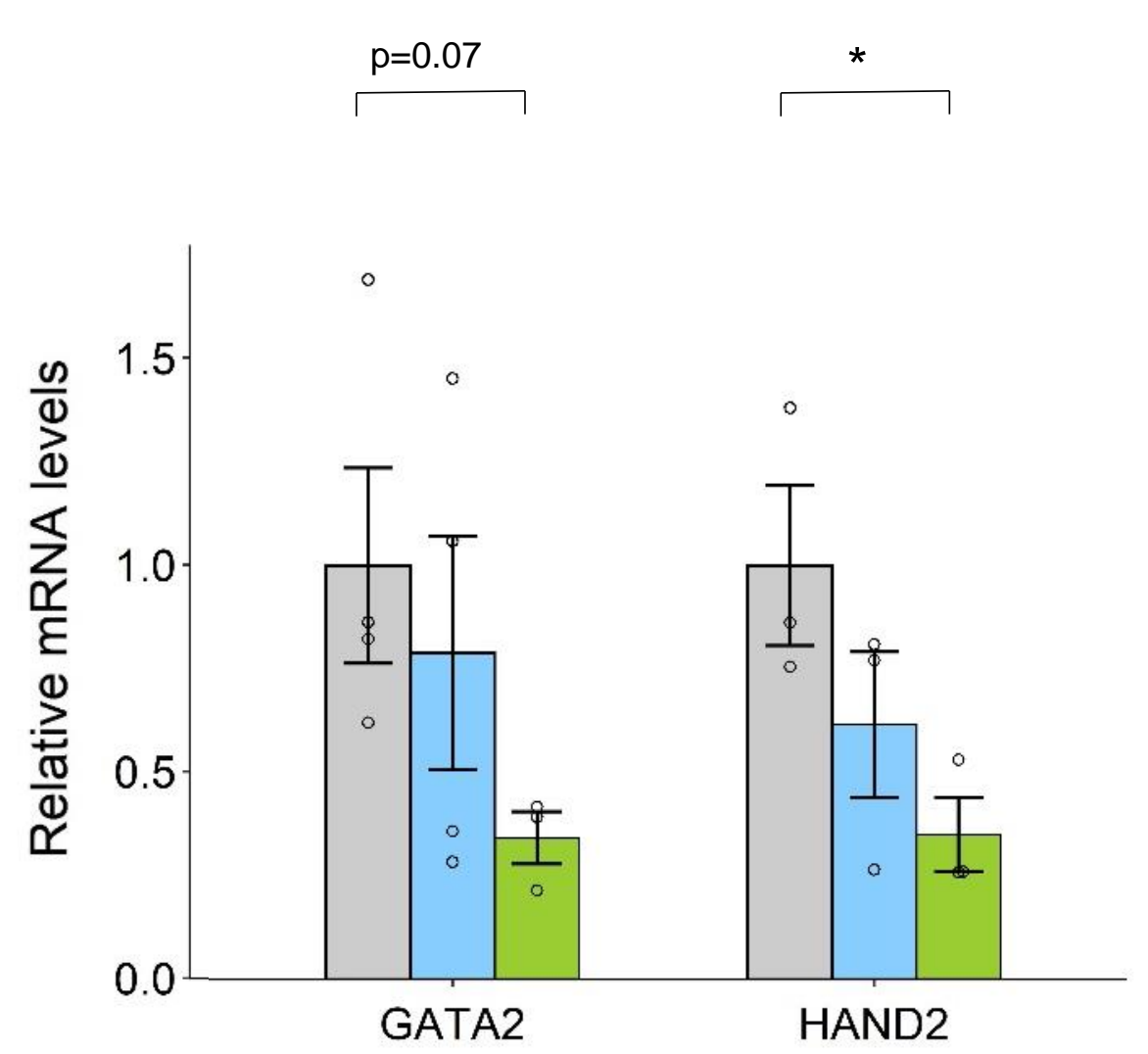

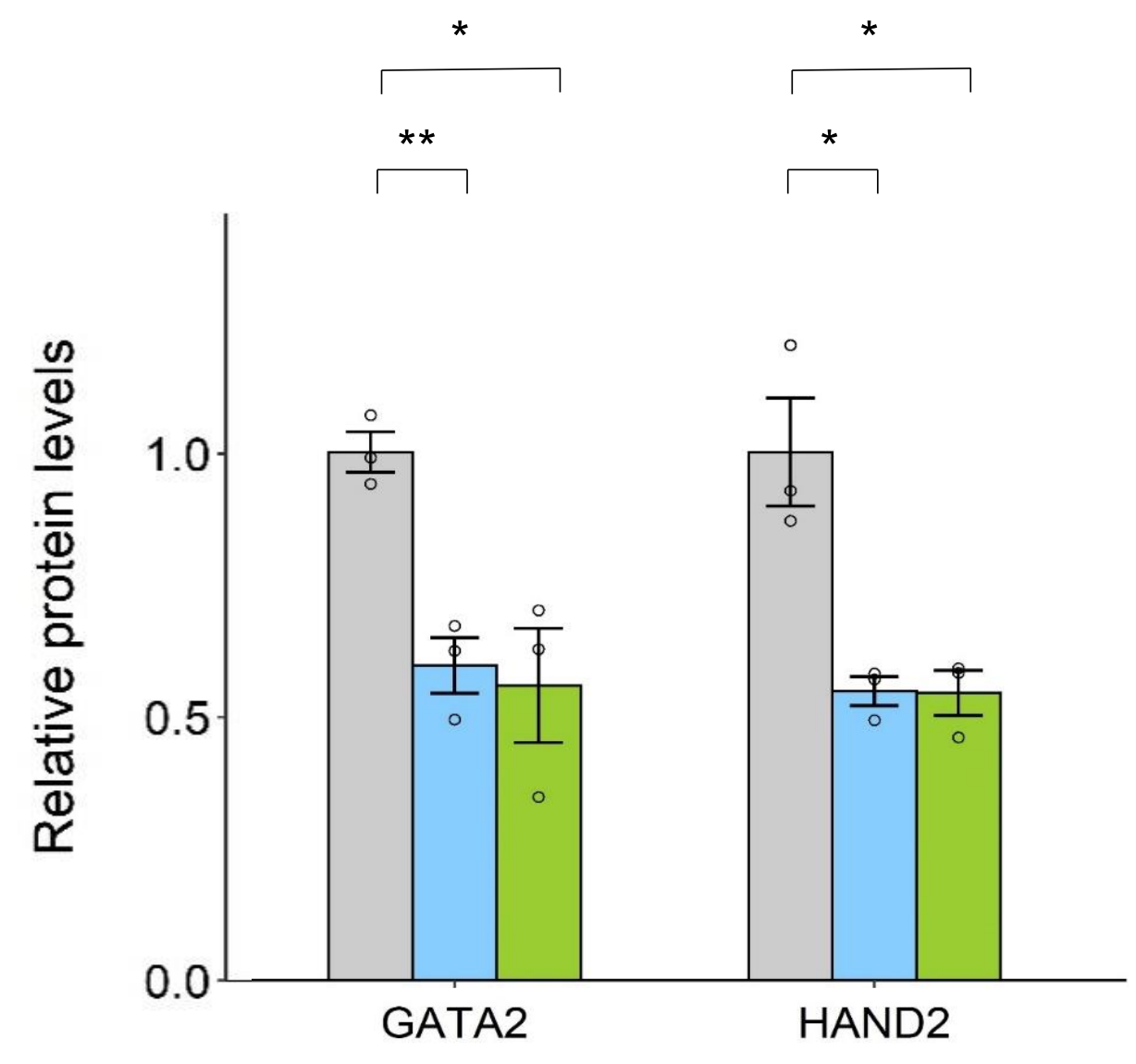

C

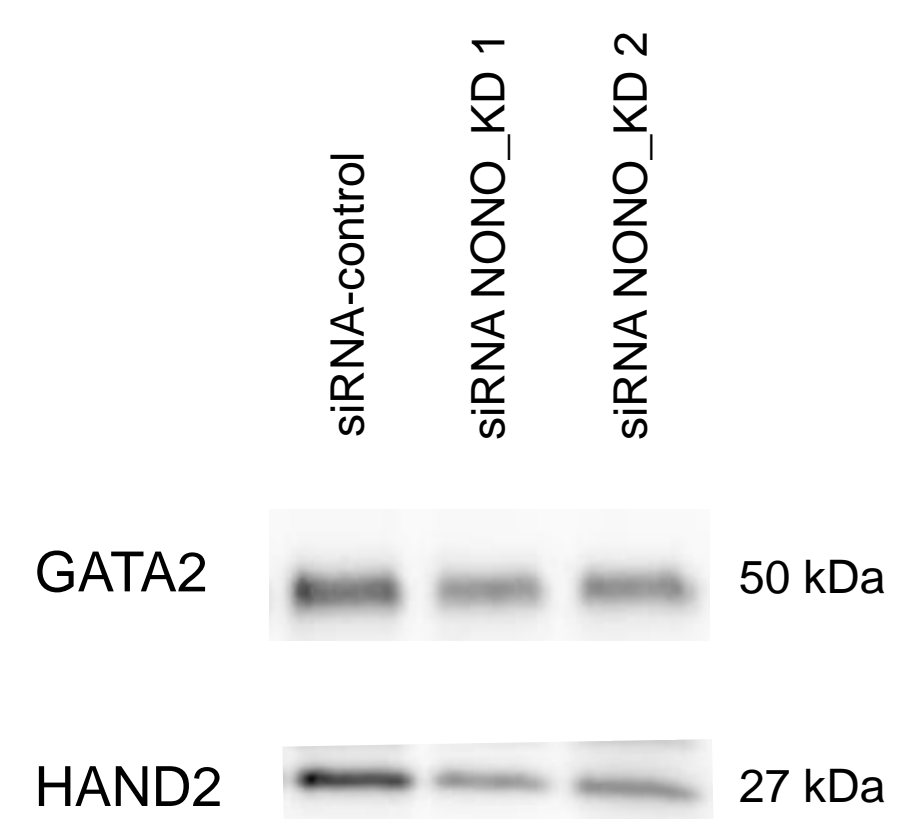

$\mathbf{F}$

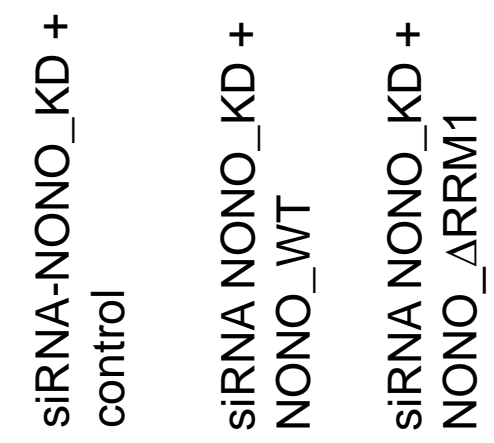

GATA2

HAND2

27 kDa

siRNA NONO KD + control siRNA NONO_KD + NONO_WT siRNA NONO_KD + NONO_ $\triangle R R M 1$ 
Supplementary figure 1
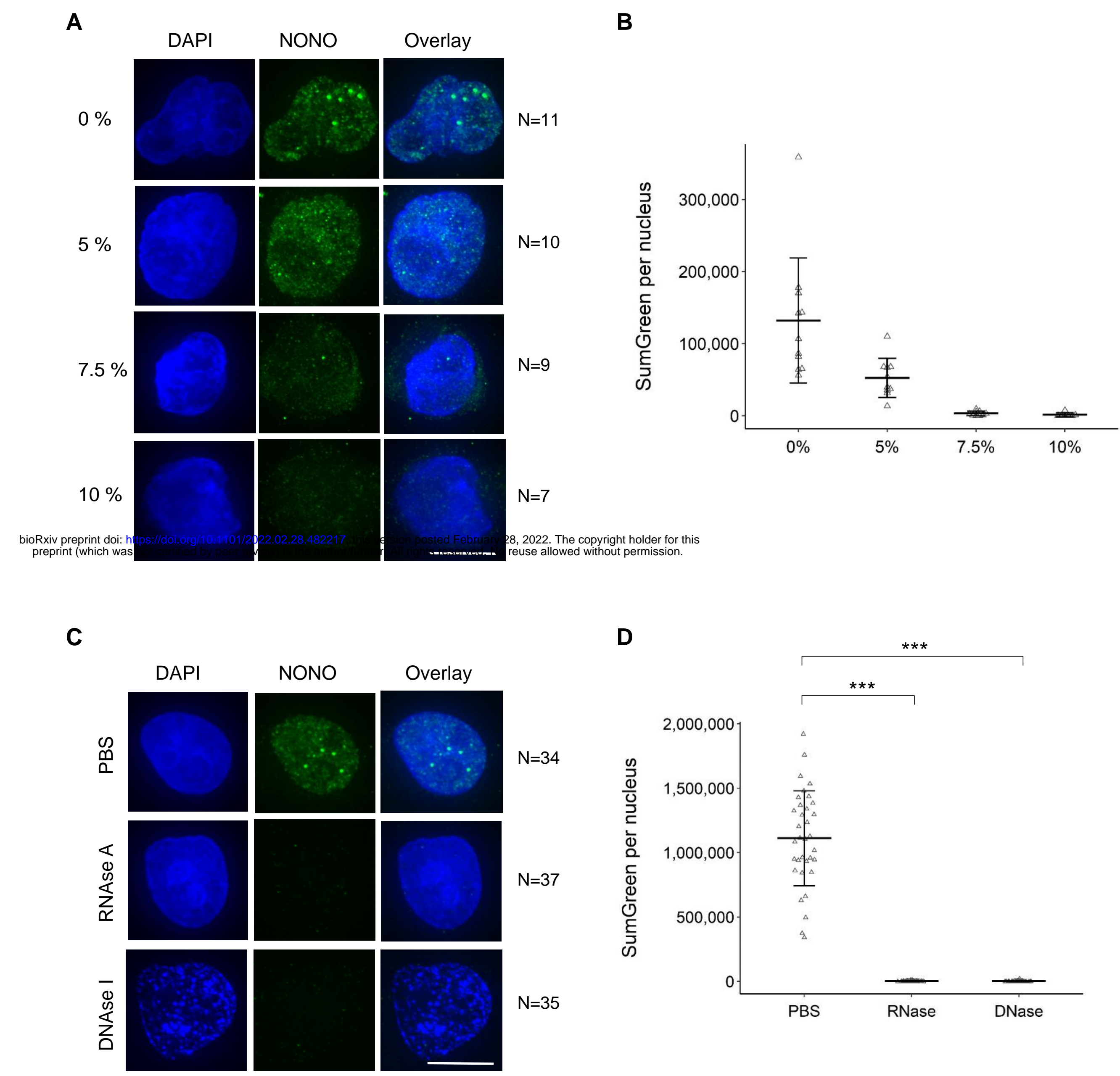


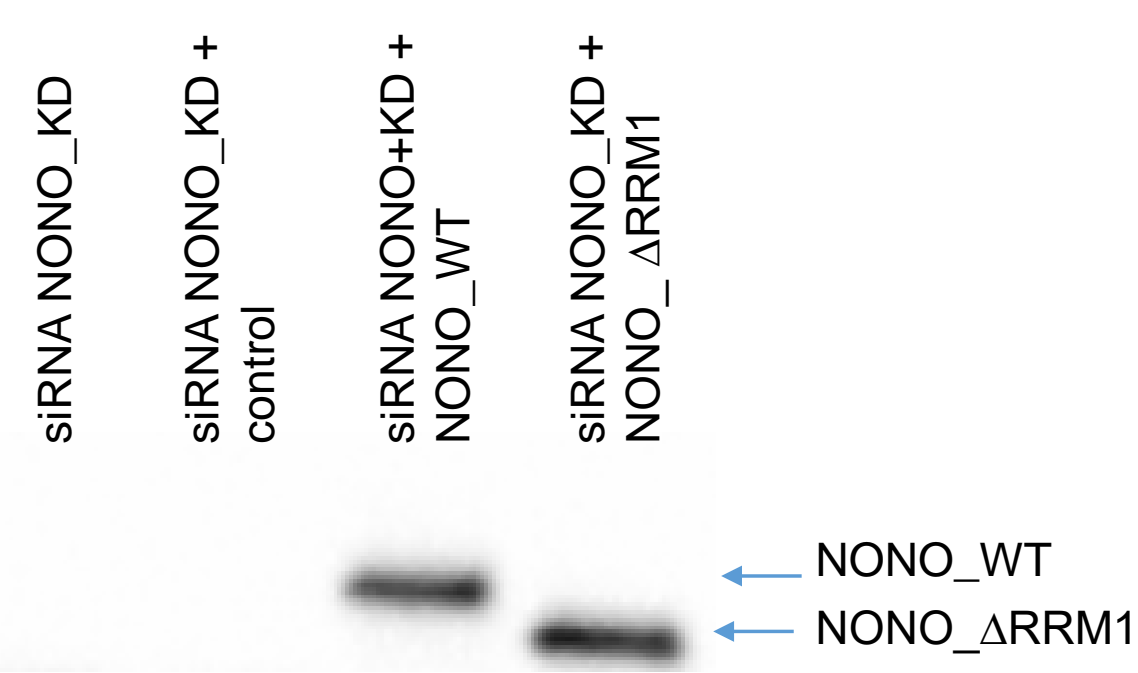

Fused YFPNONO proteins
NONO_R256I

NONO_F257I

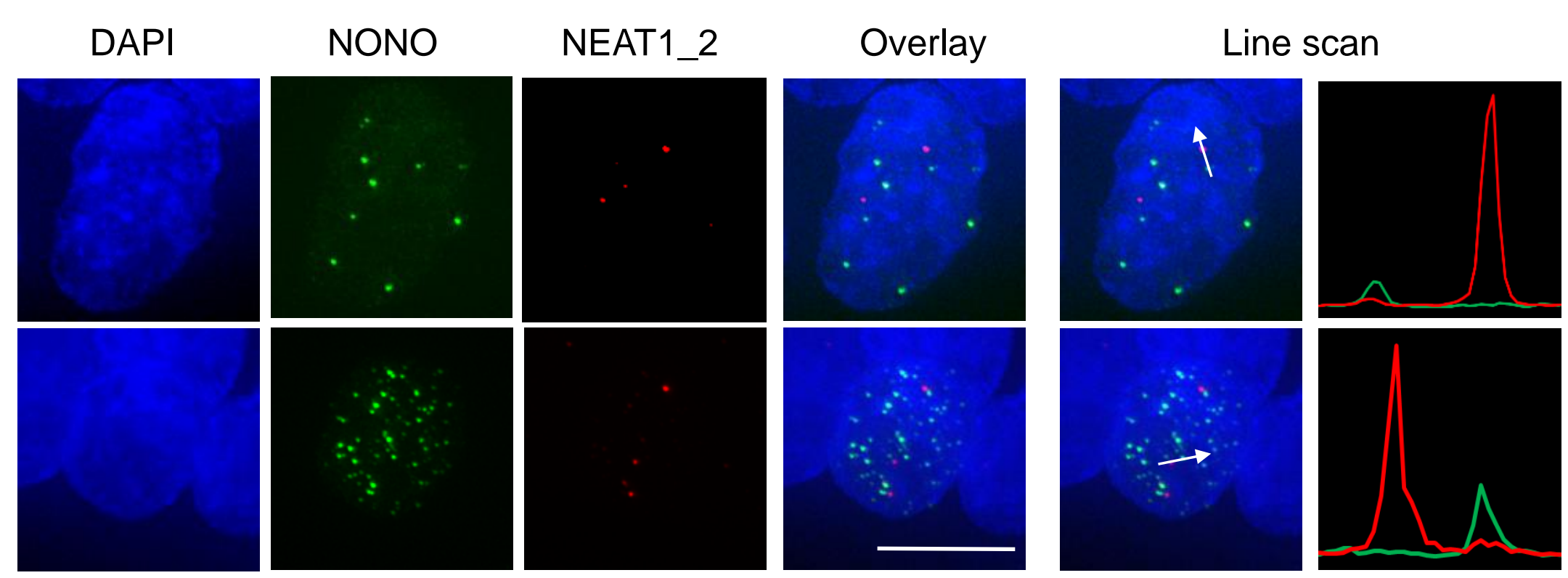

D

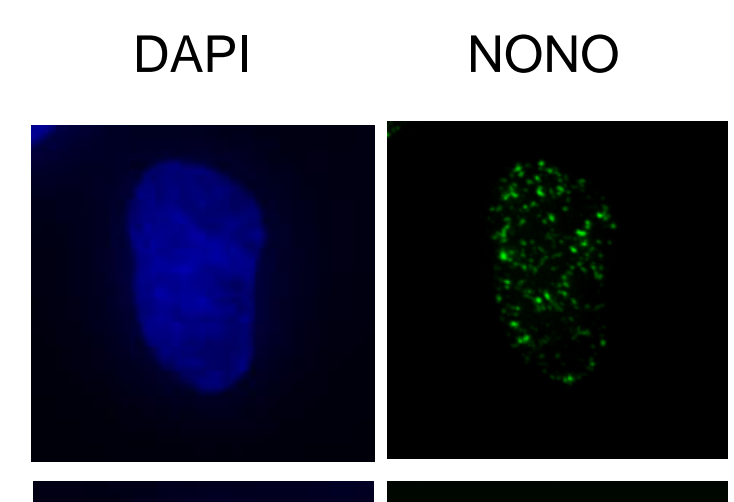

NEAT1_2
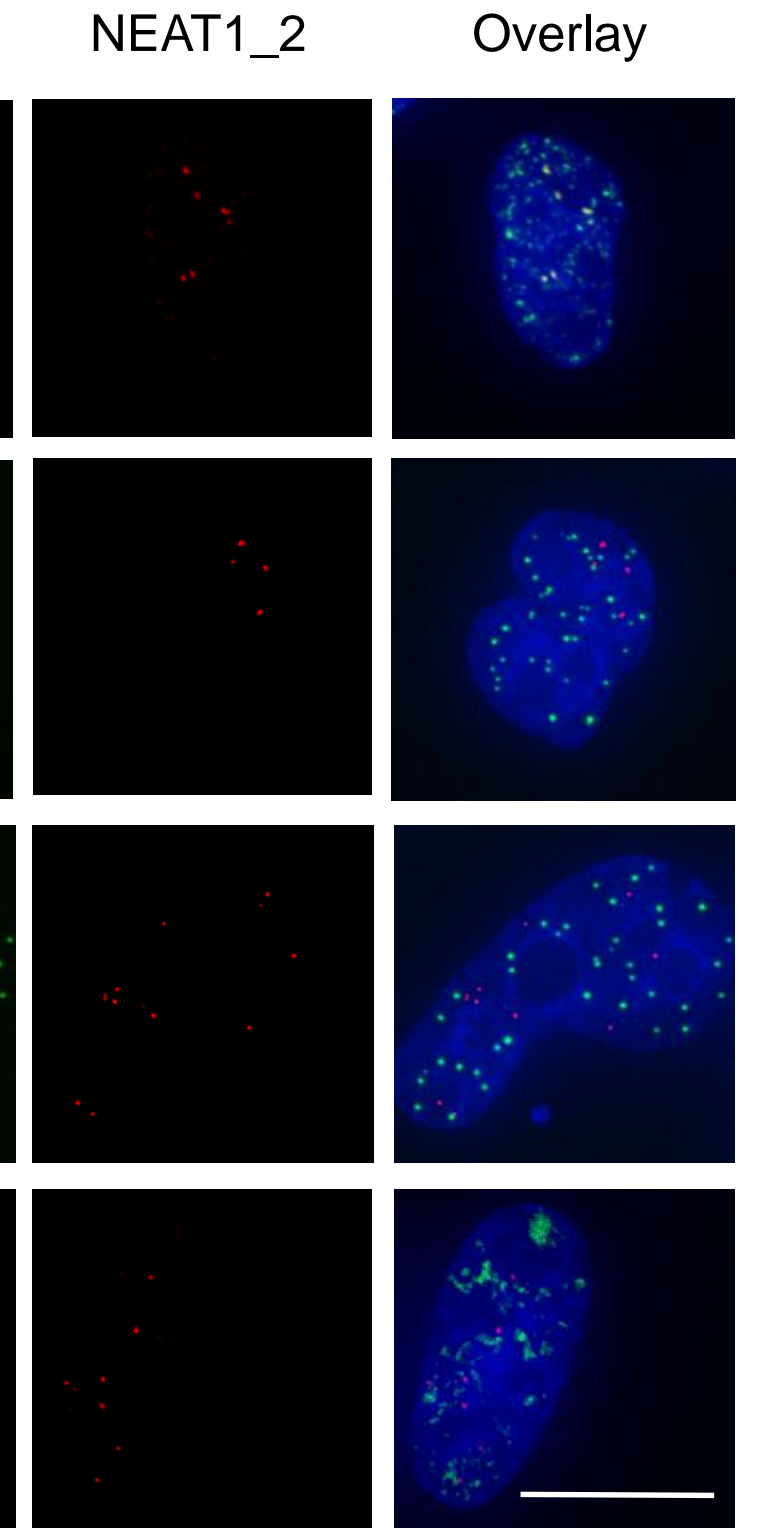

NONO_R256I

NONO_F257I
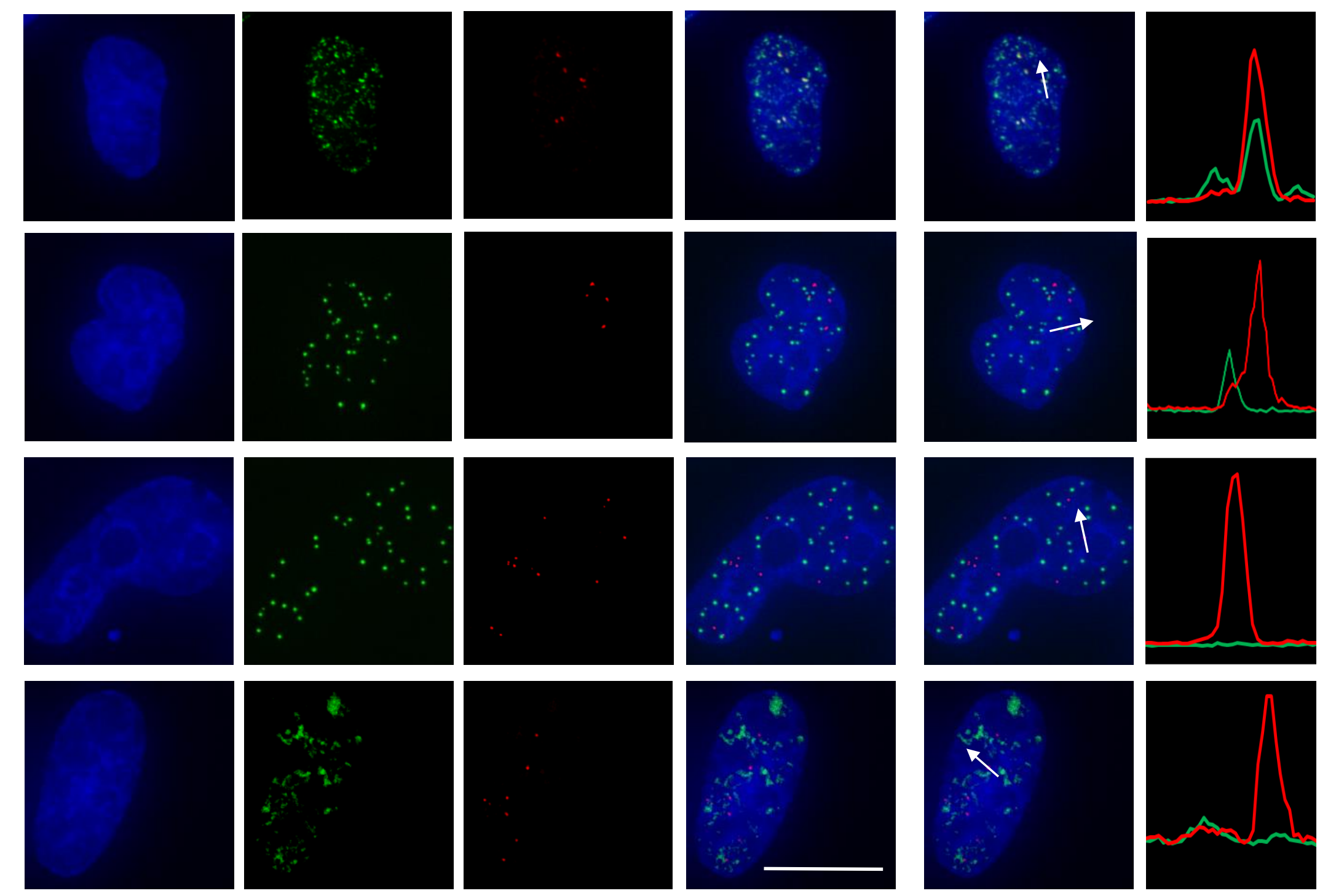

$\mathrm{N}=53$
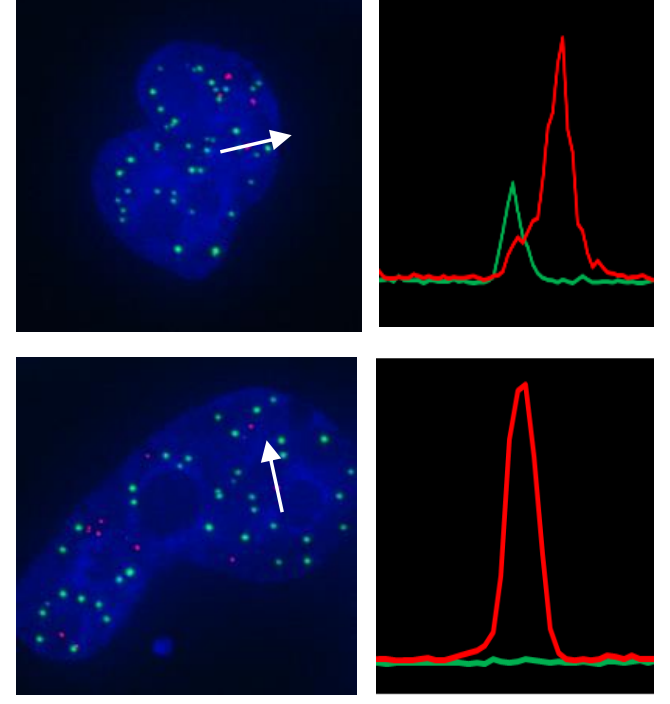

$N=68$

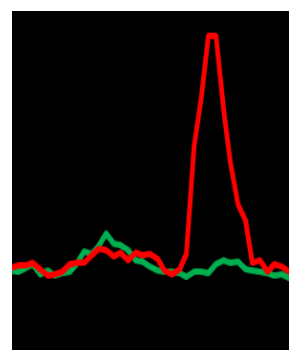

$\mathrm{N}=67$

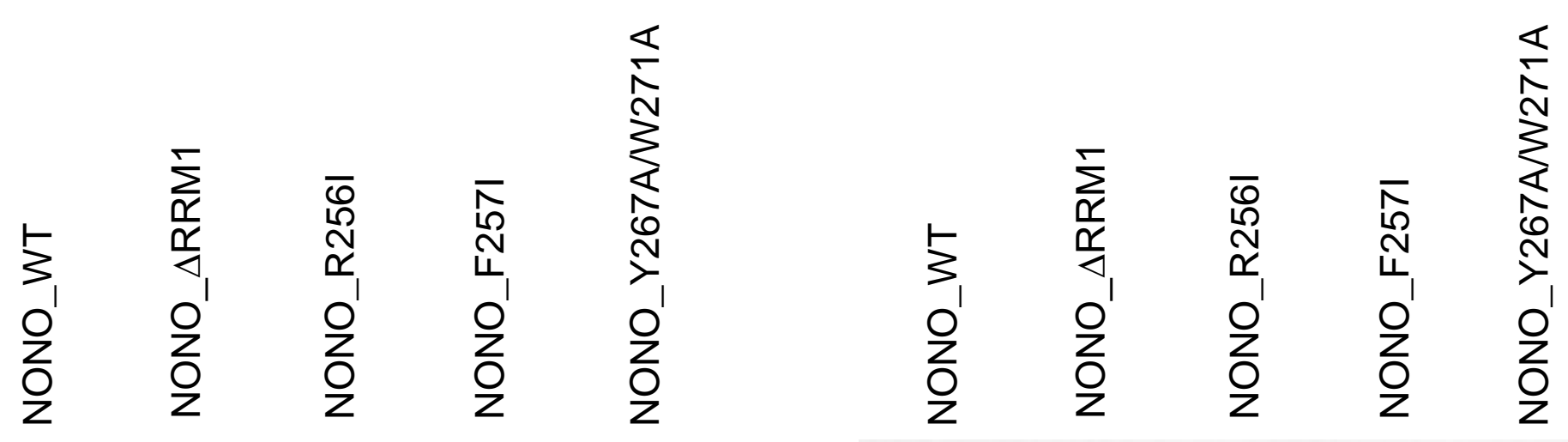

SFPQ

(KELLY)

$100 \mathrm{kDa}$

100 kDa 
A

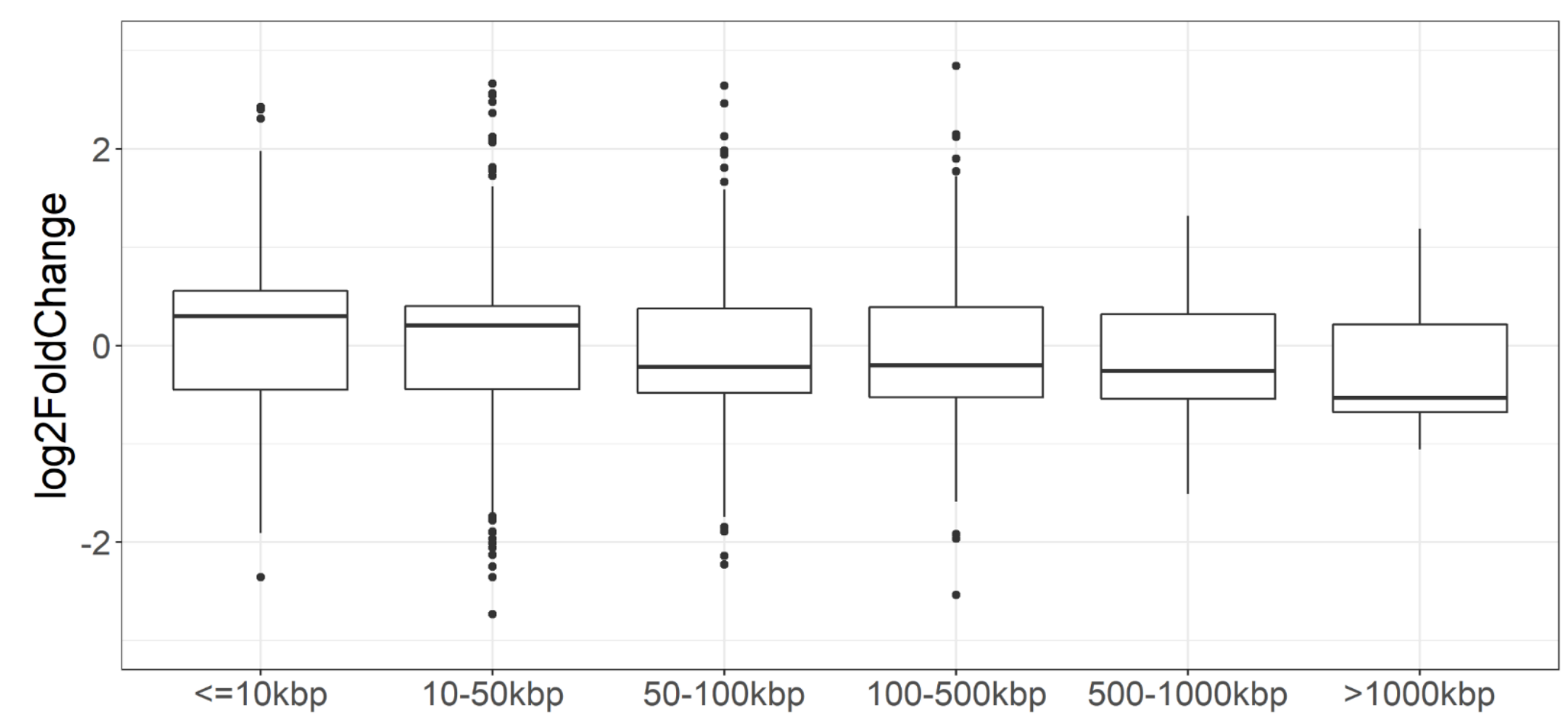

Gene length

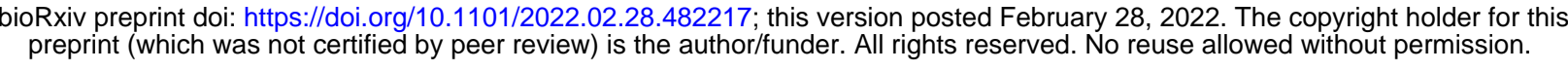

C

D
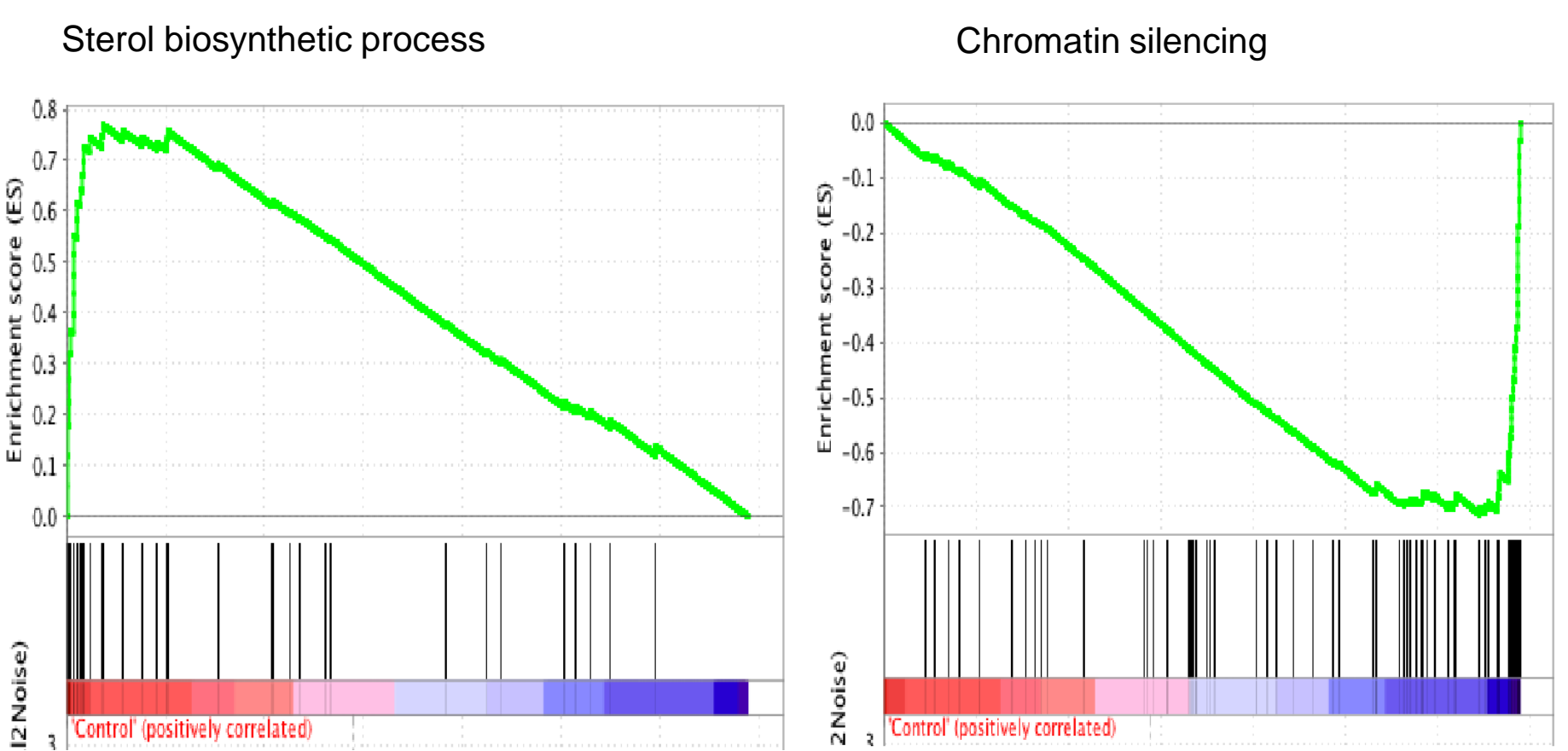

E

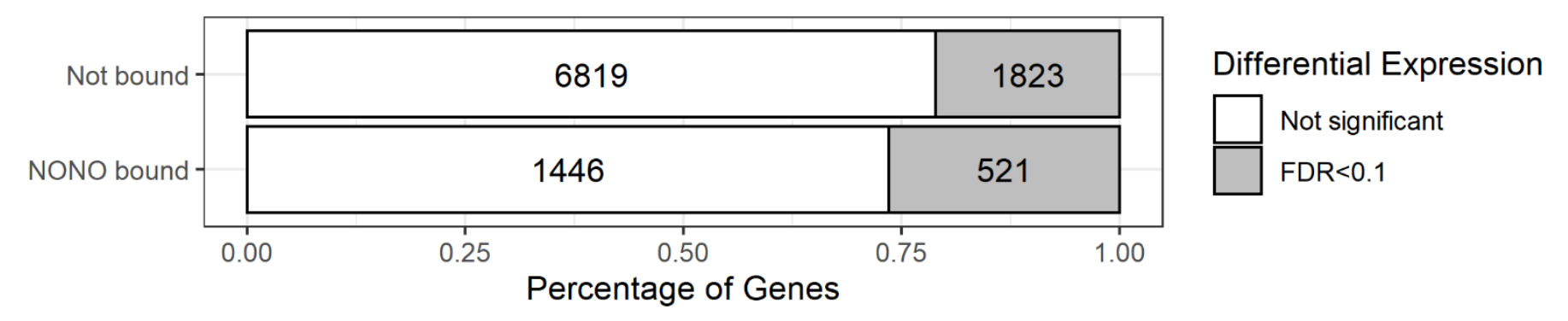

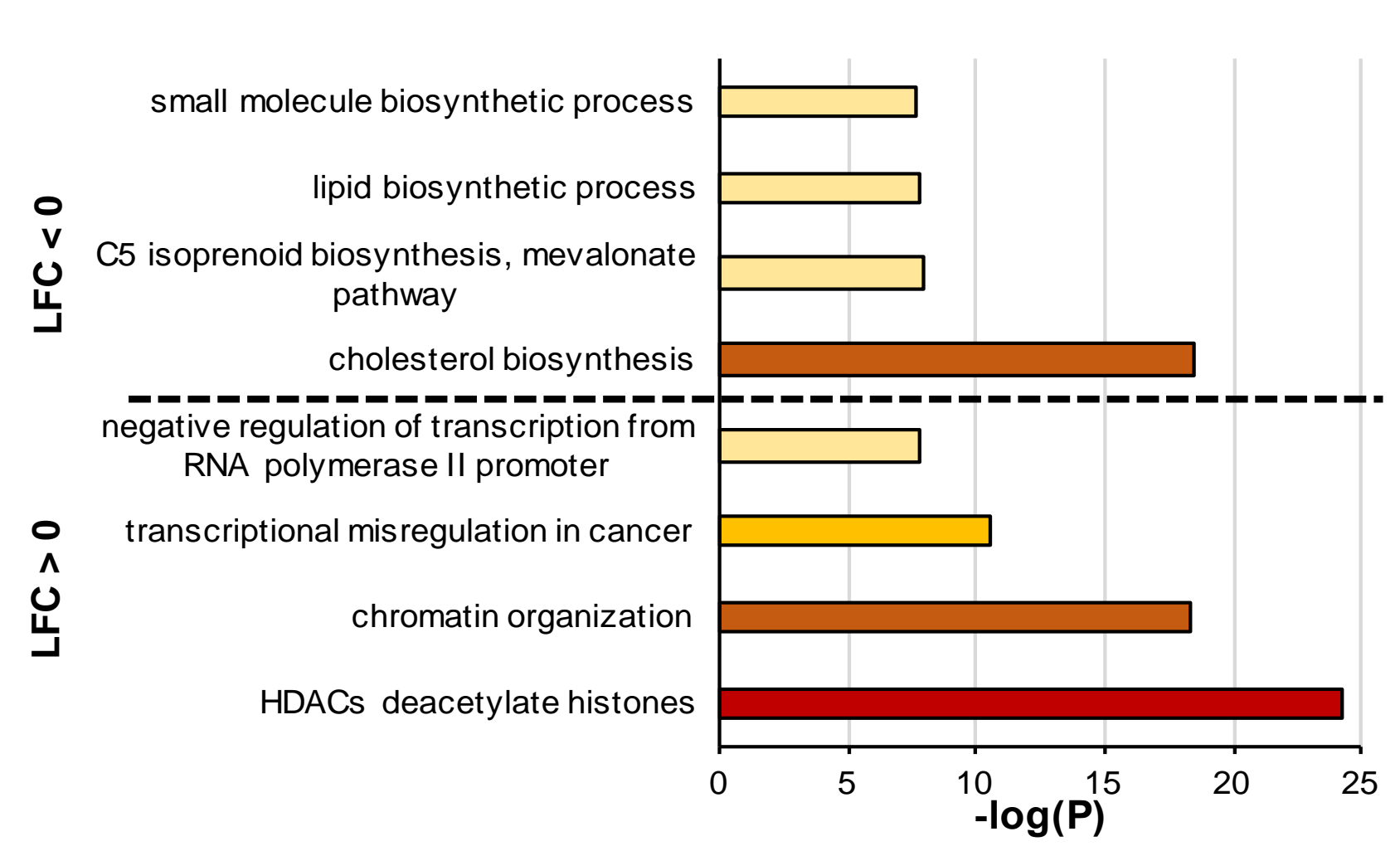

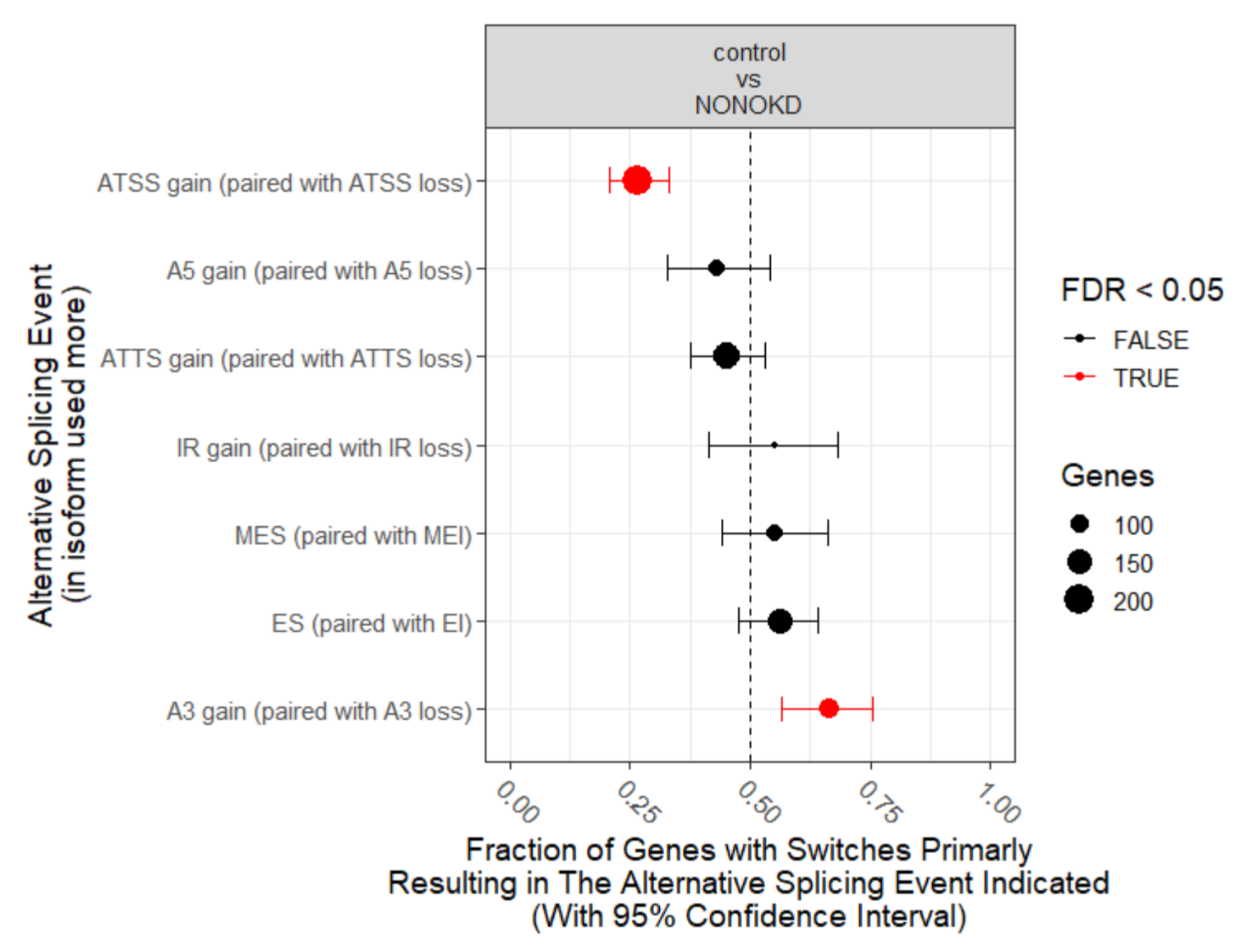


